Aus der Abteilung Unfallchirurgie, Plastische und Wiederherstellungschirurgie

(Prof. Dr. med. K. M. Stürmer)

im Zentrum Chirurgie

der Medizinischen Fakultät der Universität Göttingen

\title{
Einfluss der vertikalen Ganzkörpervibration unterschiedlicher Frequenz auf den osteoporotischen Lendenwirbelkörper der Ratte
}

\author{
INAUGURAL-DISSERTATION \\ zur Erlangung des Doktorgrades \\ der Medizinischen Fakultät \\ der Georg-August-Universität zu Göttingen
}

vorgelegt von

Carolin Juliane Döll

aus

Heidelberg

Göttingen 2010 
Dekan:

1. Berichterstatterin:

2. Berichterstatter:
Prof. Dr. med. C. Frömmel

PD Dr. med. E. Stürmer

Prof. Dr. med. Dr. med. dent. F.-J. Kramer

Tag der mündlichen Prüfung: ～19. April 2011 


\section{Inhaltsverzeichnis}

\section{Abkürzungsverzeichnis}

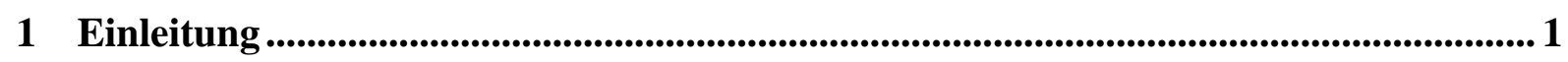

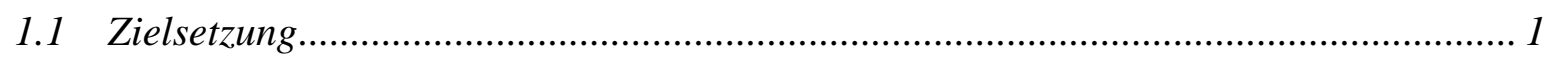

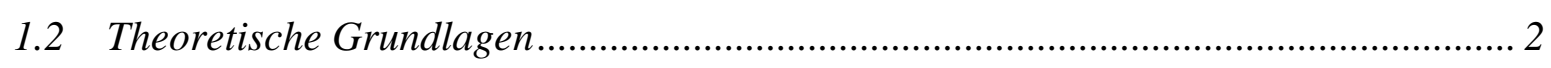

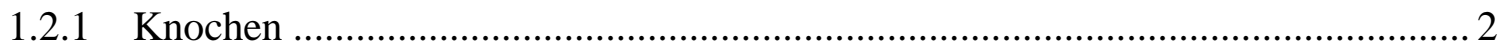

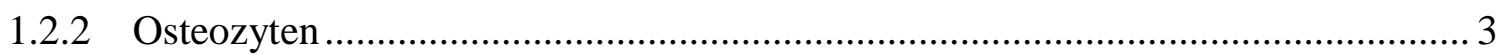

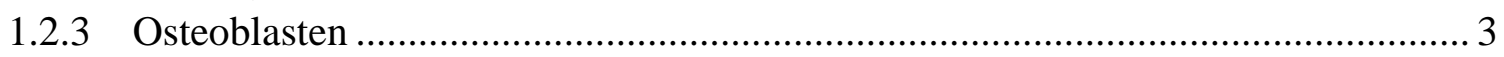

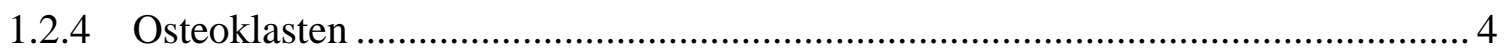

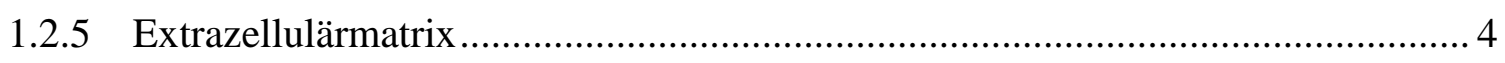

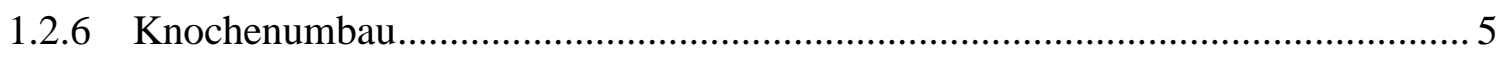

1.3 Osteoporose

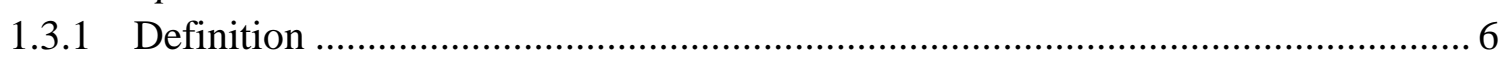

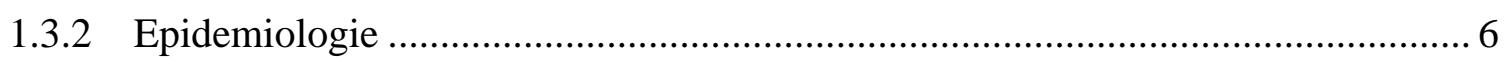

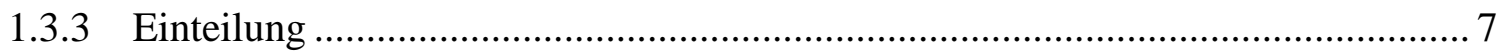

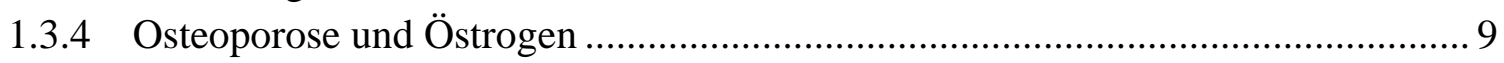

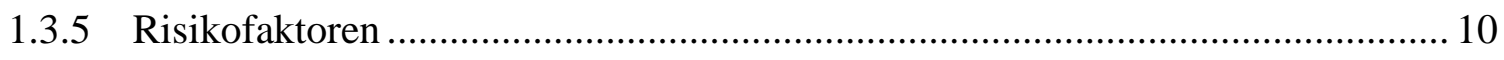

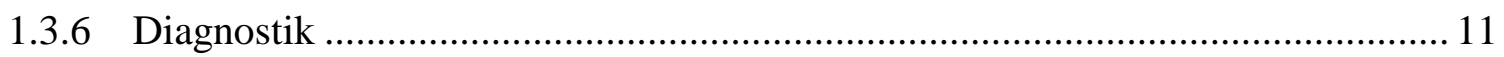

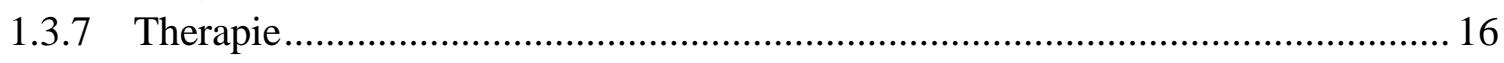

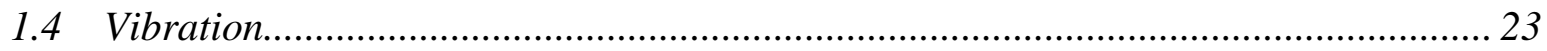

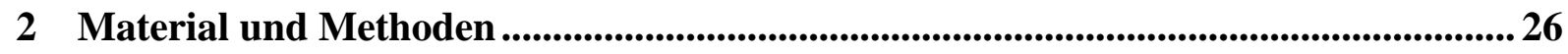

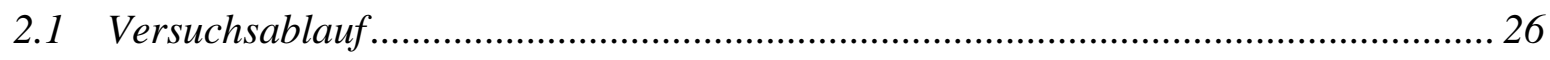

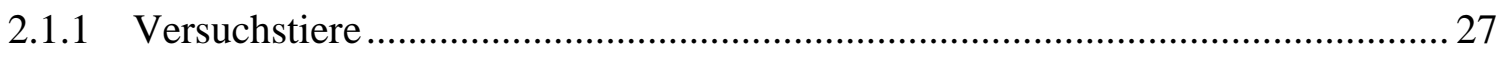

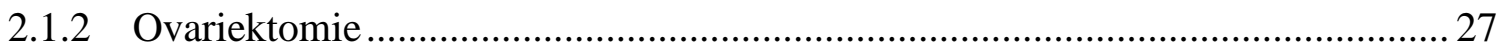

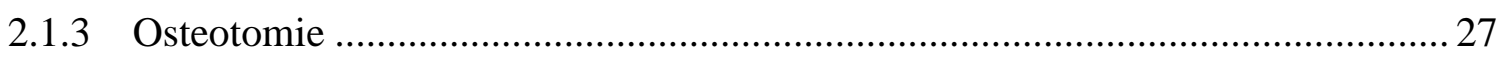

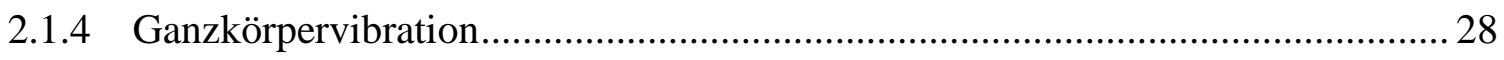

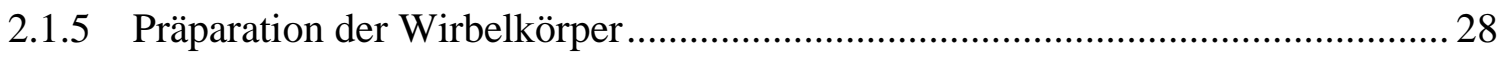

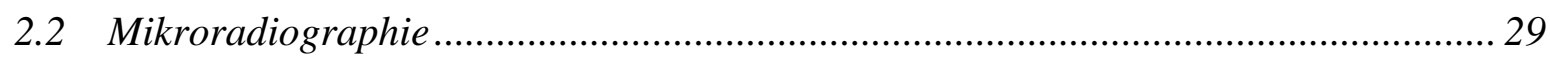

2.2.1 Histologische Aufarbeitung und Erstellen der Mikroradiographien .................... 29

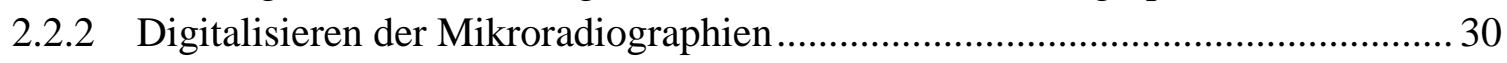

2.2.3 Histomorphometrische Auswertung der Mikroradiographien ............................. 30

2.2.4 Messparameter der Mikroradiographie .......................................................... 33

2.2.5 Validierung des Untersuchers der Mikroradiographien .................................... 34

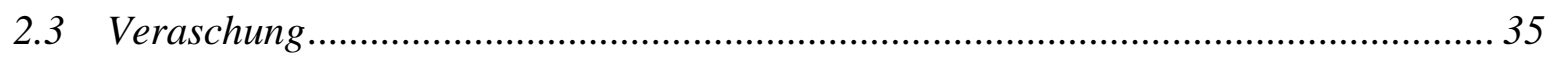

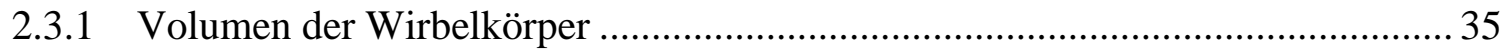

2.3.2 Bestimmung des Anteils organischer und anorganischer Knochensubstanz ....... 35

2.3.3 Bestimmung des Calcium- und Phosphatgehalts der Knochensubstanz .............. 35

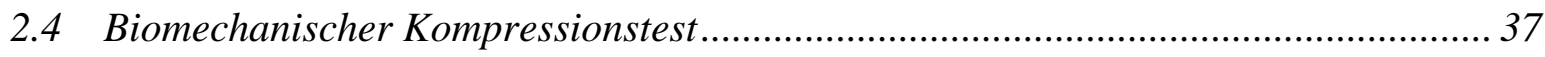

2.4.1 Durchführung des biomechanischen Kompressionstests .................................. 37 
2.4.2 Messparameter des biomechanischen Kompressionstests ................................ 38

2.4.3 Validierung des Untersuchers des biomechanischen Kompressionstests ............ 39

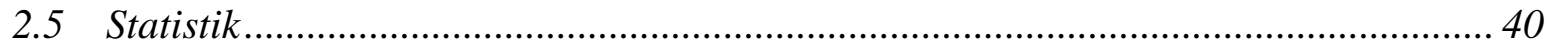

3 Ergebnisse

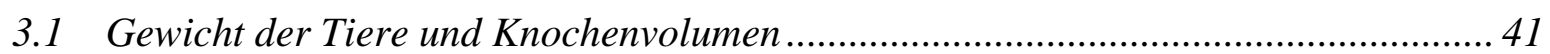

3.1.1 Gewicht und Futteraufnahme der Tiere im Verlauf ............................................. 41

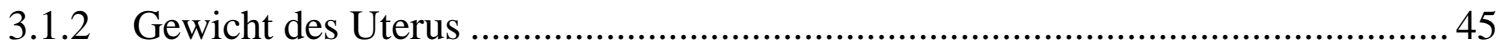

3.1.3 Volumen der Wirbelkörper ........................................................................ 45

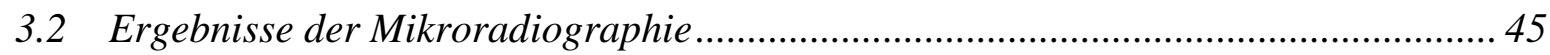

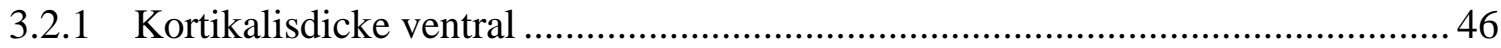

3.2.2 Kortikalisdicke dorsal ............................................................................. 48

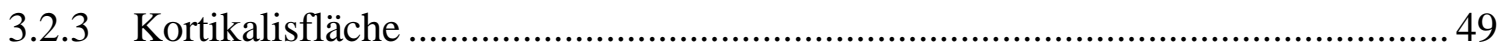

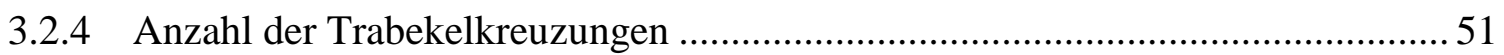

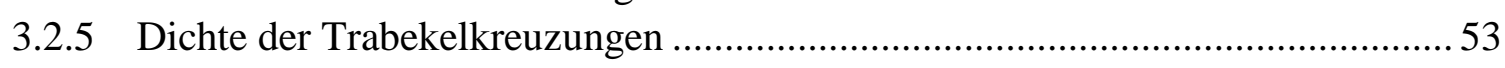

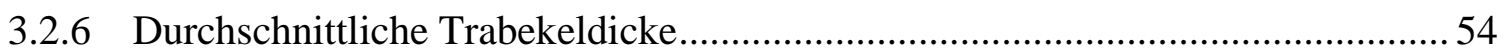

3.2.7 Zusammenfassung der Ergebnisse der Mikroradiographie ................................. 56

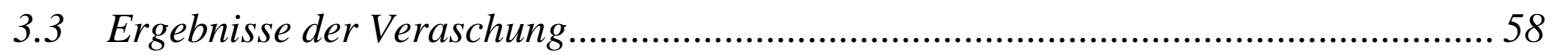

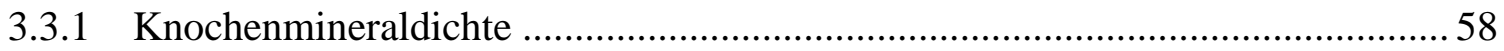

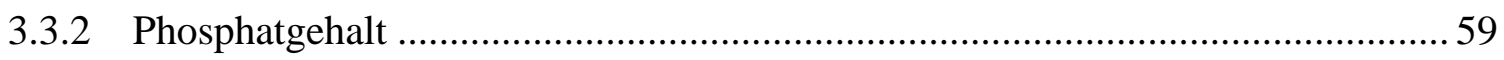

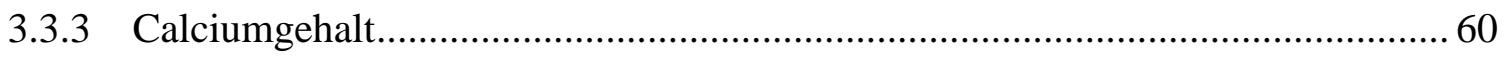

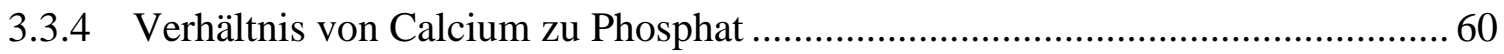

3.3.5 Zusammenfassung der Ergebnisse der Veraschung ......................................... 61

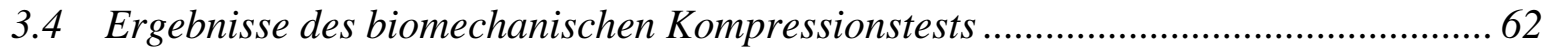

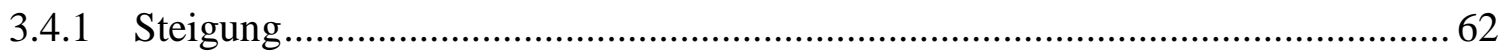

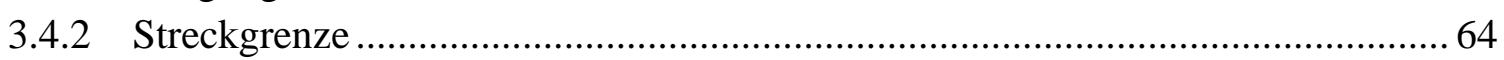

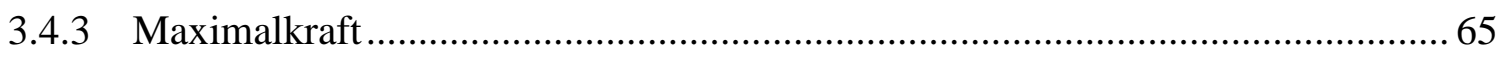

3.4.4 Zusammenfassung der Ergebnisse des biomechanischen Kompressionstests ..... 66

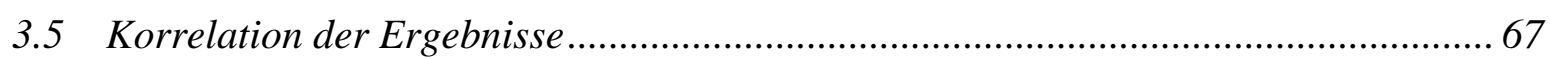

3.5.1 Korrelation der Ergebnisse des Kompressionsversuchs mit denen der

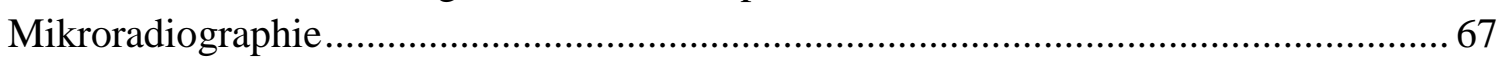

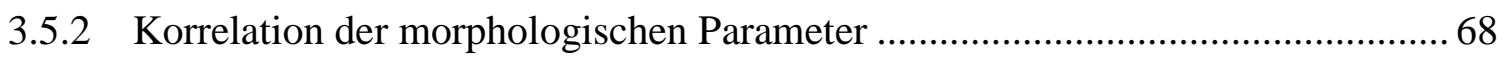

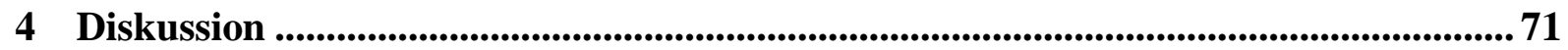

4.1 Die ovariektomierte Ratte als Osteoporosemodell..................................................... 71

4.2 Analyse der Ergebnisse der Mikroradiographie ..................................................... 72

4.3 Analyse der Ergebnisse der Veraschung ................................................................. 73

4.4 Analyse der Ergebnisse des biomechanischen Kompressionstests ........................... 76

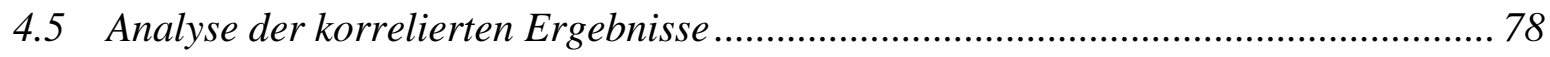

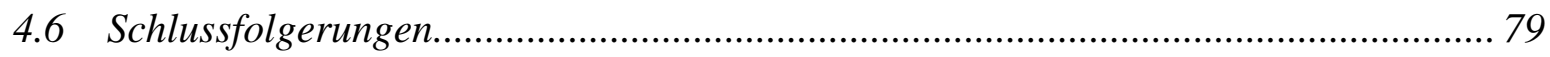




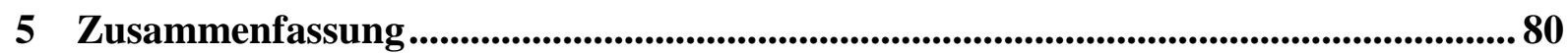

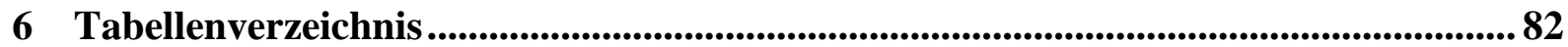

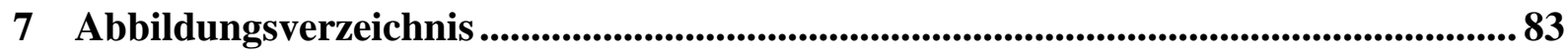

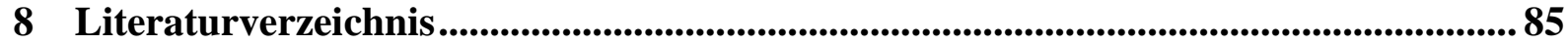




\section{Abkürzungsverzeichnis}

AAS Atomabsorptionsspektroskopie

AK Alizarin-Komplexon

ANOVA Analysis of Variance

BMD Bone Mineral Density

BSAP Bone Specific Alkaline Phosphatase

BUA Broadband Ultrasound Attenuation

BWK Brustwirbelkörper

CG Calcein-Grün

Ct. Kortikalis

Ct.Ar. Kortikalisfläche

Ct.Wi. d. Kortikalisdicke dorsal

Ct.Wi. v. Kortikalisdicke ventral

dB Dezibel

DVO Dachverband Osteologie

DXA Dual-Energy X-Ray Absorptiometry

$\mathrm{ER} \alpha \quad$ Estrogen Receptor Alpha

ER $\beta \quad$ Estrogen Receptor Beta

FIT Fracture Intervention Trial

FLEX Fracture intervention Trial Long-term Extension

FSH Follikel-stimulierendes Hormon

$\mathrm{GHz} \quad$ GigaHertz

HRT Hormone Replacement Therapy

$\mathrm{Hz} \quad$ Hertz

K Kelvin

KG Körpergewicht

$\mathrm{kV} \quad$ kiloVolt

LWK Lendenwirbelkörper

LWS Lendenwirbelsäule

$\mathrm{mA} \quad$ milliAmpere

$\mathrm{MHz} \quad$ MegaHertz

MORE Multiple Outcomes of Raloxifene Evaluation

Newton 


$\begin{array}{ll}\text { NaCl } & \text { Natriumchlorid } \\ \text { NO } & \text { Stickstoffmonoxid } \\ \text { PTH } & \text { Parathormon } \\ \text { QCT } & \text { quantitative Computertomographie } \\ \text { SERM } & \text { Selective Estrogen Receptor Modulator } \\ \text { SOS } & \text { Speed of Sound } \\ \text { SOTI } & \text { Spinal Osteoporosis Therapeutic Intervention } \\ \text { T3 } & \text { Trijodthyronin } \\ \text { T4 } & \text { Thyroxin } \\ \text { TC } & \text { Tetracyclin } \\ \text { Tr. } & \text { Trabekel } \\ \text { Tr.N. } & \text { Trabekelkreuzungen } \\ \text { Tr.N./mm } & \text { Dichte der Trabekelkreuzungen } \\ \text { Tr.Wi. } & \text { Trabekeldicke } \\ \text { TROPOS } & \text { Treatment of Peripheral Osteoporosis } \\ \text { TSH } & \text { Thyroidea-stimulierendes Hormon } \\ \text { VERT } & \text { Vertebral Efficacy with Risedronate Therapy } \\ \text { WBV } & \text { Whole-Body Vibration } \\ \text { WHI } & \text { Women's Healt Initiative } \\ \text { WHO } & \text { World Health Organisation } \\ \text { XO } & \text { Xylenol-Orange } \\ \text { ZTE } & \text { Zentrale Tierexperimentelle Einrichtung } \\ & \end{array}$




\section{$1 \quad$ Einleitung}

\subsection{Zielsetzung}

Die Osteoporose ist ein weltweites Gesundheitsproblem, welches aufgrund steigender Lebenserwartung stetig an Bedeutung gewinnt. Die Erkrankung geht für den Patienten mit Schmerzen, Immobilisation und einem wesentlichen Verlust von Lebensqualität einher. Im Jahre 2003 waren in der Bundesrepublik Deutschland fast acht Millionen Menschen von einer Osteoporose betroffen, die daraus resultierenden Kosten beliefen sich auf 5,4 Milliarden Euro pro Jahr (Häussler et al. 2007).

Die Anpassung des Knochengewebes an mechanische Druck- und Zugbelastung war erstmals von Julius Wolff beschrieben worden, er ging davon aus, dass der Knochen durch Modifikation der Trabekelstruktur mit möglichst geringer Knochenmasse eine möglichst hohe mechanische Stabilität zu erreichen sucht (Wolff 1892). Die Theorien Wolffs wurden stetig weiterentwickelt und resultierten letztlich in der Hypothese, die Knochenfestigkeit durch mechanische Stimulation verbessern zu können. Seitdem wurde eine Reihe von Studien durchgeführt, in denen verschiedene osteoporotische Versuchstiere durch mechanische Reize, meist in Form der Ganzkörpervibration, stimuliert und deren Knochen im Anschluss untersucht wurden. Aufgrund unterschiedlicher Methoden zur Analyse der Knochen und inkongruenter Applikation des Reizes (Dauer, Frequenz, Amplitude) mangelt es den bisher veröffentlichten Daten teilweise an Vergleichbarkeit. Die bisherige Datenlage lässt vermuten, dass die Ganzkörpervibration eine nicht-pharmakologische Therapieoption für die Osteoporose sein könnte (Rubin et al. 2006).

Ziel dieser Arbeit ist es, genauer zu differenzieren, welche Vibrationsfrequenzen bei vertikaler Vibrationsrichtung auf welche Weise die verschiedenen Anteile des osteoporotischen Knochens beeinflussen. Zu diesem Zweck werden die Wirbelkörper osteoporotischer Ratten nach Ganzkörpervibration mit den Frequenzen 35, 50, 70 und $90 \mathrm{~Hz}$ untersucht. Vorteil der Analyse von Lendenwirbelkörpern ist, dass hier gleichzeitig der Effekt sowohl auf trabekulären als auch auf kortikalen Knochen beobachtet werden kann. Da der Wirbelkörper als funktionelle Einheit betrachtet werden muss, wird seine biomechanische Stabilität gemessen, indem der Wirbelkörper in toto einem biomechanischen 
Kompressionstest unterzogen wird, nicht Stanzzylinder wie in den meisten bisherigen Studien. Weiter werden die Knochenmineraldichte sowie der prozentuale Gehalt von Calcium und Phosphat bestimmt, um den Einfluss der Vibration auf diese Parameter und deren Einfluss wiederum auf die mechanischen und morphologischen Eigenschaften des Knochens zu erfassen. Die mikroradiographische Untersuchung wird Aufschluss über die Morphologie von Kortikalis und trabekulärem Netzwerk geben.

\subsection{Theoretische Grundlagen}

\subsubsection{Knochen}

Das Knochengewebe setzt sich zusammen aus einer kalziumhaltigen Extrazellulärsubstanz, der Knochenmatrix, den Knochenzellen (Osteozyten, Osteoblasten und Osteoklasten) und Mineralien. Außerdem enthält der Knochen Bindegewebe, Knorpel, rotes und gelbes Knochenmark sowie als Versorgungsstrukturen Nerven und Gefäße. Die drei wesentlichen Aufgaben, welche das Knochengewebe erfüllen muss, sind hohe Belastbarkeit, hohe Elastizität und möglichst geringes Gewicht. Mit einer Dichte von 2-3 g/ml ist das Knochengewebe eines der schwersten Gewebe im menschlichen Körper, wobei der Knochen nicht allein aus massivem Gewebe aufgebaut ist, sondern nur direkt unter dem Periost aus der dichteren Substantia corticalis besteht. Diese umgibt die weniger dichte, leichtere Substantia spongiosa, die aus schwammartigen, nach Trajektionslinien ausgerichteten Knochenbälkchen aufgebaut ist. Diese Anordnung der Trabekel folgt den biomechanischen Einflüssen, denen der Knochen ausgesetzt ist. Laut dem vom Berliner Anatomen und Chirurgen Julius D. Wolff 1892 veröffentlichten Gesetz bewirkt diese Anpassung der Substantia spongiosa die maximale Stabilität des Knochens (Wolffsches Gesetz, (Wolff 1892)). Besonders in axialen und dementsprechend mechanisch stark beanspruchten Teilen des Skeletts wie dem proximalen Femur und der Wirbelsäule ist diese trajektorelle Bauweise ausgeprägt. Das Knochengewebe befindet sich ständig im Umbau, verantwortlich hierfür sind die Knochenzellen, wobei die Signaltransduktion dieser Zellen untereinander Gegenstand der Forschung ist. Alle inneren Oberflächen des Knochens sind mit Endost ausgekleidet, außen ist der Knochen, den Bereich der Gelenkflächen ausgeschlossen, von Periost überzogen (Bartl 2008; Benninghoff und Drenckhahn 2008; Junqueira und Carneiro 2004). 


\subsubsection{Osteozyten}

Die Osteozyten sind ehemalige Osteoblasten, welche von mineralisierter Knochenmatrix eingeschlossen sind. Sie liegen in linsenförmigen Lakunen und ihre Ausläufer erstrecken sich entlang zahlreicher Knochenkanälchen, den Canaliculi. Die Zellen und ihre Ausläufer füllen die sie umgebenden Hohlräume jedoch nicht völlig aus, so dass ein schmaler Bereich frei bleibt, der nur Kollagenfibrillen und interstitielle Flüssigkeit enthält, jedoch nicht mineralisiert ist. Somit sind alle Osteozyten via Diffusion erreichbar, außerdem verbinden gap junctions sie mit ihren direkten Nachbarn und mit den Zellen des Endosts.

Die Funktion der Osteozyten ist noch nicht abschließend erforscht. Sie scheinen jedoch für die Erhaltung des Knochens von Bedeutung zu sein, denn wo sie nicht mehr vital sind, bauen Osteoklasten die Knochenmatrix ab. Des Weiteren zeigen neuere Publikationen, dass die Osteozyten als mechanosensitive Zellen des Knochens die Signaltransduktion initiieren, welche die Reaktion des Knochens auf die externen Einflüsse zur Folge hat. Die Osteozyten sind elastisch mit der Knochenmatrix verbunden und erfahren somit den selben mechanischen Reiz wie der Knochen selbst (Turner et al. 2009). Da sie selbst nicht in der Lage sind, neue Knochensubstanz zu bilden, müssen sie Signale an Osteoblasten und Osteoklasten als Effektorzellen vermitteln, um die Knochenstruktur zu beeinflussen. Wichtige Botenstoffe scheinen dabei Stickstoffmonoxid (NO) und Prostaglandine $\mathrm{zu}$ sein, so führte die mechanische Stimulation von Zell- und Gewebekulturen in vitro zu einer vermehrten Produktion von verschiedenen Prostaglandinen und NO (Klein-Nulend et al. 1997; Pitsillides et al. 1995; Somjen et al. 1980). Umgekehrt hatte die Hemmung der Prostaglandin- und NOSynthese in vivo ein Ausbleiben der Reaktion von Knochengewebe auf mechanische Stimulation zur Folge (Forwood 1996; Fox et al. 1996; Turner und Pavalko 1998). Ein weiterer Mediator ist das Protein Sclerostin. Es wird von Osteozyten freigesetzt und hemmt die Neubildung von Knochensubstanz durch Osteoblasten. Dabei ist die Sekretion von Sclerostin proportional $\mathrm{zu}$ den auf den Knochen einwirkenden Kräften, im mechanisch beanspruchten Knochen wird die Expression des Proteins unterdrückt und somit die hemmende Wirkung auf die Osteoblasten aufgehoben (Turner et al. 2009).

\subsubsection{Osteoblasten}

Die Osteoblasten entstehen aus mesenchymalen Vorläuferzellen, den Osteoprogenitor-Zellen, aus deren Pool unter dem Einfluss von Wachstumsfaktoren und Hormonen zeitlebens neue 
Osteoblasten gebildet werden können. Aufgabe der Osteoblasten ist die Synthese und Sekretion von organischen Anteilen der Knochenmatrix, vor allem Typ-I-Kollagen, Proteoglykane und Glykoproteine. Das appositionelle Knochenwachstum geschieht durch Ablagerung neuer Knochenmatrix auf bereits vorhandener, mineralisierter Matrix. Die aktiven Osteoblasten liegen dementsprechend immer einer freien Oberfläche des Knochens an. Sie liegen einschichtig nebeneinander, nahe der mineralisierten Matrix, von dieser jedoch durch die noch nicht mineralisierte Osteoid-Schicht, welche sie selbst synthetisiert haben, getrennt. Wenn die Osteoid-Schicht durch Einlagerung von Kalziumphosphat in die stabile Knochenmatrix umgewandelt wird, wird ein Teil der Osteoblasten in der mineralisierten Matrix eingeschlossen und damit zu Osteozyten, die Zellen des anderen Teils gehen nach Beendigung der Synthese entweder durch Apoptose zugrunde oder sie reihen sich wieder als inaktive Zellen in das Endost ein (Lüllmann-Rauch 2003).

\subsubsection{Osteoklasten}

Progenitorzellen der Osteoklasten sind Vorläuferzellen des Monozytären Phagozytensytems im Knochenmark. Die mehrkernigen Osteoklasten entstehen durch Fusion von bis zu 100 einkernigen Vorläufern. Die aktiven Osteoklasten liegen direkt an der mineralisierten Matrix, sie demineralisieren das Knochengewebe und resorbieren die entstandenen Abbauprodukte. Dadurch sind sie von entscheidender Bedeutung bei Umbauvorgängen im Knochen und der Freisetzung bzw. Einlagerung von Kalzium. Die Rekrutierung, Differenzierung und Aktivierung dieser Zellen wird durch Hormone (Parathormon, Calcitonin, Östrogen, Leptin) und Wachstumsfaktoren beeinflusst (Lüllmann-Rauch 2003).

\subsubsection{Extrazellulärmatrix}

Die Extrazellulärmatrix ist die mineralisierte Substanz zwischen den Knochenzellen. Ihre Hauptbestandteile sind Kollagenfibrillen (überwiegend Typ-I-Kollagen), welche 95\% der organischen Masse ausmachen, und Hydroxylapatit-Kristalle. Letztere sind aus Calcium-, Phosphat- und Hydroxyl-Ionen aufgebaut und machen $45 \%$ des Feuchtgewichts im Knochengewebe aus. Des Weiteren finden sich im anorganischen Teil weitere Ionen wie Fluorid, Magnesium und Carbonat. Der organische Anteil enthält zusätzlich zu den Kollagenfibrillen Proteoglykane und verschiedene Glykoproteine wie Osteocalcin und Sialoprotein. 
Die Kollagenfibrillen bestimmen die Ausrichtung der Mineralkristalle, da diese sich an deren Oberfläche und in deren Innerem longitudinal anordnen. Diese besondere Zusammensetzung aus druckfesten Mineralkristallen und zugfesten Kollagenfibrillen verleiht dem Knochen seine Biegefestigkeit (Junqueira und Carneiro 2004; Lüllmann-Rauch 2003).

\subsubsection{Knochenumbau}

Während der Wachstumsphase wird der Knochen durch stetigen An- und Umbau von Knochensubstanz verändert, bis er seine endgültige Form hat. Auch im ausgewachsenen Skelett jedoch findet ein ständiger Umbau, das so genannte remodelling statt. Dabei werden jährlich $28 \%$ der Substantia spongiosa und $4 \%$ der Substantia corticalis erneuert. Zweck des Umbaus ist die Reparatur kleiner Defekte, die funktionelle Anpassung an mechanische Beanspruchungen und die Bereitstellung von Calcium.

Für eine ausgeglichene Bilanz zwischen der Arbeit der Knochen-abbauenden Osteoklasten und der aufbauenden Osteoblasten ist die mechanische Beanspruchung des Knochens der bedeutendste Faktor. Diese Art der Regulierung kann jedoch durch die Wirkung verschiedener Hormone überlagert sein, so hemmt zum Beispiel Östrogen die durch Osteoblasten induzierte Rekrutierung von Osteoklasten und damit den Knochenabbau. Das Schilddrüsenhormon Calcitonin hemmt direkt die Osteoklasten, sein Antagonist aus der Nebenschilddrüse, das Parathormon, mobilisiert Osteoblasten, welche wiederum die Entstehung von Osteoklasten fördern und wirkt damit einem sinkenden Calciumspiegel im Blut entgegen (Lüllmann-Rauch 2003).

Im menschlichen Körper nimmt die Knochenmasse bis zum 20.-30. Lebensjahr physiologischerweise $\mathrm{zu}$, und erreicht im Anschluss daran eine Plateauphase, in der Knochenbildung und Knochenabbau im Gleichgewicht stehen (peak bone mass). Die maximale Knochenmasse ist für die menschliche Wirbelsäule zwischen dem dreißigsten und vierzigsten Lebensjahr erreicht (Rodin et al. 1990), der erreichte Wert ist ein Prädiktor für das spätere Auftreten einer Osteoporose. Die peak bone mass wird durch Faktoren wie Geschlecht, genetisches Potential und Umwelteinflüsse (Bewegung, Kalziumzufuhr) beeinflusst. Mit Ende der Plateauphase wird die Bilanz der Knochenmasse negativ, der durchschnittliche Verlust beträgt unabhängig vom Geschlecht etwa $1 \%$ pro Jahr, dabei sind Wirbelkörper und proximales Femur etwas mehr betroffen als die übrigen Skelettareale. Aufgrund des Östrogenmangels kann der Verlust an Knochenmasse bei der postmenopausalen Frau auf bis zu 4\% steigen, das bedeutet, dass Frauen zwischen dem 40. und 70. Lebensjahr durchschnittlich ungefähr $40 \%$ ihrer Knochenmasse verlieren, Männer dagegen nur $12 \%$. 
Zusätzlich zum Substanzverlust verändern sich die statischen Eigenschaften des Knochens im Alter auch durch die verminderten Verknüpfungspunkte in der Trabekelstruktur (Bartl 2008).

\subsection{Osteoporose}

\subsubsection{Definition}

Die Definition der Osteoporose ist in der Vergangenheit mehrfach modifiziert worden. Im April 1993 definierte man auf der International Consensus Development Conference on Osteoporosis (Christiansen 1993) die Osteoporose wie folgt:

„Die Osteoporose ist eine systemische Skeletterkrankung, welche durch eine niedrige Knochenmasse und Verfall der Mikroarchitektur des Knochengewebes, einhergehend mit erhöhter Knochenbrüchigkeit und erhöhtem Frakturrisiko, charakterisiert ist.“

Dabei wird die Knochenmasse in Relation zur peak bone mass der Altersgruppe gesetzt. Früher wurde die Diagnose einer Osteoporose nur nach einem Frakturgeschehen gestellt, nach der neuen Definition kann eine Osteoporose auch präklinisch ohne Fraktur vorliegen. Als manifest wird die Osteoporose bezeichnet, wenn sie bereits zu einer oder mehreren Frakturen geführt hat.

Nach der Klassifikation der Weltgesundheitsorganisation (World Health Association, WHO) liegt eine Osteoporose per definitionem dann vor, wenn die Knochendichte 2,5 Standardabweichungen unter den Mittelwert der Knochendichte skelettgesunder Erwachsener zwischen dem zwanzigsten und vierzigsten Lebensjahr (T-Score) fällt. Liegt der Wert der Standardabweichung zwischen -1 und $-2,5$ spricht man von einer Osteopenie (Bonjour et al. 2004).

\subsubsection{Epidemiologie}

Mit über 200 Millionen betroffenen Menschen weltweit ist die Osteoporose eine der am weitesten verbreiteten skelettalen Erkrankungen (Gardner et al. 2006). Der größte Risikofaktor, eine Osteoporose $\mathrm{zu}$ entwickeln, ist ein hohes Lebensalter, entsprechend der 
demographischen Entwicklung gewinnt die Osteoporose zunehmend auch an wirtschaftlicher Bedeutung (Cummings und Melton 2002).

Im Jahr 2003 waren in der Bundesrepublik Deutschland 7,8 Millionen Menschen im Alter von über 50 Jahren an Osteoporose erkrankt, das entspricht einer Prävalenz von 26\%. Bei Frauen war die Prävalenz dabei mit 39\% deutlich höher als bei Männern mit 9,7\%, etwa 60\% der Frauen über 75 Jahre waren von einer Osteoporose betroffen. Innerhalb dieses Kollektivs hatten 4,3\% der Patienten eine osteoporotische Fraktur, die häufigsten Lokalisationen dabei waren die Hüfte, das Handgelenk und die Wirbelkörper (Häussler et al. 2007).

Obwohl neuere Studien aufzeigen, dass bis zu $60 \%$ aller Hüft- und Wirbelfrakturen bei Patienten über 45 Jahren im Zusammenhang mit einer Osteoporose stehen, wird diese Ursache meist nur dann erkannt, wenn die Fraktur typisch lokalisiert ist (Melton et al. 1997). Im Jahre 2003 beliefen sich die direkt durch Osteoporose entstandenen Kosten in der Bundesrepublik Deutschland auf rund 5,4 Milliarden Euro pro Jahr (Häussler et al. 2007).

\subsubsection{Einteilung}

Für die Einteilung der Osteoporose gibt es verschiedene Ansätze:

\subsubsection{Einteilung anhand der Ausdehnung}

Man unterscheidet je nach Befallsmuster am Skelett die lokalisierte Osteoporose von der typischeren generalisierten Osteoporose.

Die lokalisierte Osteoporose betrifft also nur einzelne Regionen des Skeletts. Ursächlich kann Inaktivität einer Extremität im Rahmen einer Immobilisation durch Schienung oder eine Parese sein. Des Weiteren können der lokalisierten Osteoporose verschiedene Krankheiten zugrunde liegen. $\mathrm{Zu}$ nennen ist hier Morbus Sudeck, die erstmalig bei Schwangeren beschriebene transiente Osteoporose und das Gorham-Syndrom.

Auch die klassische generalisierte Osteoporose befällt nicht homogen das gesamte Skelett, sondern die Prädilektionsstellen Wirbelsäule, Schenkelhals und distalen Radius. Dabei verhält sie sich jedoch immer symmetrisch. Die juvenile und die postmenopausale Form manifestieren sich besonders am Achsenskelett, die senile Form betrifft auch die Röhrenknochen (Bartl 2008).

\subsubsection{Einteilung anhand der Ätiologie}

Anhand der Krankheitsentstehung wird bei der Osteoporose eine primäre von einer sekundären Form unterschieden. Als primäre Osteoporose bezeichnet man die ätiologisch 
ungeklärte Form, welcher keine andere Erkrankung zugrunde liegt. $\mathrm{Zu}$ den primären Osteoporosen zählen die primär idiopathische Osteoporose sowie die Typ-I- und die Typ-IIOsteoporose. Wird die Osteoporose dagegen durch eine definierte Grunderkrankung ausgelöst, so spricht man von einer sekundären Osteoporose. Sekundäre Osteoporosen machen nur 5\% der Osteoporose-Fälle aus, sind jedoch Ursache von $20 \%$ der osteoporotischen Frakturen.

Die Einteilung nach der Ätiologie der Osteoporose ist besonders aus therapeutischer Sicht entscheidend, da je nach Grunderkrankung verschiedene Ansätze einer Therapie zur Verfügung stehen (Bartl 2008).

Die wichtigsten Ursachen der sekundären Osteoporose werden in Tabelle 1 zusammengefasst:

Tabelle 1: Ursachen der sekundären Osteoporose, modifiziert nach Classen et al. 2003

\begin{tabular}{|c|c|}
\hline endokrinologisch & $\begin{array}{ll}\text { - } & \text { Hypogonadismus } \\
\text { - } & \text { Hyperparathyreoidismus } \\
\text { - } & \text { Hyperthyreose } \\
\text { - } & \text { Cushing-Syndrom } \\
\text { - } & \text { Diabetes mellitus }\end{array}$ \\
\hline neoplastisch & $\begin{array}{l}\text { - } \text { Plasmozytom } \\
\text { - Mastozytose } \\
\text { - Non-Hodgkin-Lymphom } \\
\text { - Diffuse Knochenmarkskarzinose }\end{array}$ \\
\hline pharmakologisch & $\begin{array}{ll}\text { - } & \text { Glukokortikoide } \\
\text { - } & \text { Heparine } \\
\text { - } & \text { LHRH-Analoga }\end{array}$ \\
\hline gastrointestinal & $\begin{array}{l}\text { - } \text { Pankreasinsuffizienz } \\
\text { - Anorexia nervosa } \\
\text { - } \text { Morbus Crohn } \\
\text { - Biliäre Zirrhose } \\
\text { - Sprue }\end{array}$ \\
\hline hereditär & $\begin{array}{l}\text { - Osteogenesis imperfecta } \\
\text { - Marfan-Syndrom } \\
\text { - Ehlers-Danlos-Syndrom } \\
\text { - Homozystinurie }\end{array}$ \\
\hline rheumatologisch & - Chronische Polyarthritis \\
\hline
\end{tabular}




\subsubsection{Einteilung anhand des Patientenalters}

Die häufigste Form der primären Osteoporosen ist die Typ-I-Osteoporose. Diese beschränkt sich auf die Substantia spongiosa des Knochens, da diese schneller und häufiger umgebaut wird und als Folge dessen früher betroffen ist, als die Substantia corticalis. Somit findet man die Typ-I-Osteoporose in vorwiegend trabekulären Teilen des Skelettes wie der Wirbelsäule und dem proximalen Femur, sie betrifft besonders Frauen mit postmenopausalem Östrogenmangel.

Die fortgeschrittene Typ-II-Osteoporose (senile Osteoporose) ist nicht mehr auf das Achsenskelett beschränkt, sondern betrifft auch die Substantia corticalis und damit die Röhrenknochen der Extremitäten. Betroffen sind vor allem Patienten über 70 Jahre und das Verhältnis von Frauen zu Männern hat sich mit 2:1 angenähert, ein Hinweis darauf, dass ab einem gewissen Alter der Östrogenmangel nicht mehr die entscheidende Ursache zu sein scheint, sondern ein generell altersbedingter Substanzverlust. So sind alte Menschen weniger mobil, Vitamin-D- und Kalziumstoffwechsel sind gestört und die Anzahl der Osteoklasten steigt. Ungefähr 80\% der osteoporotischen Frakturen sind dem Altersabschnitt einer Typ-IIOsteoporose zuzuordnen.

Die Differenzierung zwischen Typ-I- und Typ-II-Osteoporose ist im klinischen Alltag kaum relevant (Bartl 2008).

\subsubsection{Einteilung anhand der Dynamik des Knochenabbaus}

Ungeachtet der Ätiologie kategorisiert diese Einteilung nach der Geschwindigkeit des Substanzverlusts. Im gesunden Knochengewebe stehen dessen Abbau und Bildung miteinander im Gleichgewicht. Bei mangelnder Knochenbildung oder überschießendem Knochenabbau resultiert langsam eine negative Bilanz („low turnover“). Treten beide Vorgänge parallel auf, so entsteht die Osteoporose schneller (,high turnover"). Je nach Kategorie wird ein antiresorptives oder ein die Knochenbildung stimulierendes Therapiekonzept verfolgt (Bartl 2008).

\subsubsection{Osteoporose und Östrogen}

Die drastisch erhöhte Prävalenz der Osteoporose bei postmenopausalen Frauen lässt vermuten, dass die verminderte Östrogensynthese in der Pathogenese von großer Bedeutung ist. Ein weiterer Hinweis auf den Zusammenhang von Östrogenspiegel und Osteoporose ist 
die Tatsache, dass adipöse Patientinnen mit ihrer erhöhten Östrogenproduktion im Vergleich zu untergewichtigen Frauen ein geringeres Risiko haben, an Osteoporose zu erkranken. Dabei ist jedoch zu beachten, dass adipöse Patienten durch ihr erhöhtes Körpergewicht zusätzlich den Knochen mechanisch stimulieren.

Die Zellen des Knochens, Osteoblasten, Osteozyten und Osteoklasten, tragen Östrogenrezeptoren. Von den beiden Östrogenrezeptoren ER $\alpha$ und ER $\beta$ scheint Ersterer im Knochenstoffwechsel entscheidend zu sein (Lee et al. 2003). Östrogen hemmt auf mehreren Wegen die Resorption von Knochensubstanz, indem es die Lebensdauer der Osteoklasten auf verschiedenen Signalwegen durch Hemmung von Zytokinen (Interleukin -1, -6, Tumornekrosefaktor 1,2) verkürzt (Pacifici 1998; Riggs 2000). Eine Untersuchung an 124 postmenopausalen Frauen konnte zeigen, dass eine frühe Menopause vor dem 45. Lebensjahr und ein Zeitraum von weniger als 30 Jahren zwischen Menarche und Menopause eine geringere Knochendichte zur Folge haben kann (Sioka et al. 2009).

\subsubsection{Risikofaktoren}

Häufig entwickelt sich die manifeste Osteoporose aus einer präklinischen primären Osteoporose, multiplen Risikofaktoren und möglicherweise zusätzlich einer sekundären Osteoporose als multifaktorielles Geschehen. Anthropometrische Risikofaktoren für eine osteoporotische Fraktur sind weibliches Geschlecht, Untergewicht, überdurchschnittliche Körpergröße und das Alter, wobei das relative Risiko pro 5 Jahre um 1,4 bis 2,0 zunimmt. Die familiäre und die individuelle Frakturanamnese sind weitere wichtige Faktoren für die Risikoabschätzung. So steigt das Risiko für eine osteoporotische Wirbelkörperfraktur mit jeder erlittenen Fraktur. Bei einer vorbestehenden Wirbelkörperfraktur liegt das relative Risiko, erneut eine solche Fraktur zu erleiden, bei 4, während es bei anamnestisch drei Frakturen auf 10 ansteigt. Dabei ist nicht relevant, ob die Frakturen symptomatisch waren oder klinisch stumm verlaufen sind.

Geringe körperliche Belastung erhöht das relative Risiko auf 2,4. Ebenfalls prädisponierend sind regelmäßiger Nikotinkonsum, Kalziummangel und geringe Exposition gegenüber Sonnenlicht. Im Alter von 70 Jahren findet sich bei $90 \%$ aller Patienten ein latenter oder manifester Vitamin-D-Mangel (Classen et al. 2004).

Knochenunabhängige Faktoren im höheren Lebensalter sind Mobilität und Koordinationsfähigkeit des Patienten. Motorische Einschränkungen, herabgesetzte Vigilanz, Sehstörungen und neurologische Defizite erhöhen die Sturzneigung und damit das Frakturrisiko. 
Ein entscheidender Risikofaktor für die Entstehung einer Osteoporose ist mangelnde körperliche Aktivität. Demzufolge können auch junge Patienten in wenigen Monaten bis zu $30 \%$ ihrer Knochenmasse verlieren, wenn sie zum Beispiel aufgrund eines Traumas mit Querschnittsymptomatik über einen längeren Zeitraum immobilisiert sind. Dagegen wirkt übermäßige körperliche Aktivität nicht protektiv. Auch Hochleistungssportlerinnen sind besonders gefährdet, eine Osteoporose zu entwickeln, da sie aufgrund strenger Diäten und hoher körperlicher Belastung einen sehr geringen Körperfettanteil und dementsprechend einen erniedrigten Östrogenspiegel haben (Bartl 2008).

\subsubsection{Diagnostik}

Die frühe Diagnosestellung ist neben der Vermeidung von Risikofaktoren entscheidend für die Behandlung der Osteoporose und die Verminderung des osteoporotischen Frakturrisikos. Dabei ist die alleinige Diagnose nicht ausreichend, es muss geklärt werden, wie viel Knochenmasse zum Zeitpunkt der Untersuchung vorhanden ist und mit welcher Geschwindigkeit sie abgebaut wird.

\subsubsection{Indikation zur Diagnostik}

Der Dachverband Osteologie (DVO) empfiehlt in seinen 2009 veröffentlichten Leitlinien die Durchführung einer Basisdiagnostik für Patienten, deren klinisches Risikoprofil ein erhöhtes Frakturrisiko erwarten lässt (Pfeilschifter 2009). Das heißt, wenn trotz der allgemeinen Prophylaxemaßnahmen ein Risiko von mindestens $20 \%$ besteht, dass der Patient innerhalb der nächsten zehn Jahre eine Fraktur der Wirbelkörper und/oder des proximalen Femurs erleiden wird. Auch bei einem Frakturrisiko unter 20\% kann eine Basisdiagnostik empfehlenswert sein, nämlich dann, wenn operativ sanierbare Ursachen (primärer Hyperparathyreoidismus) dem nur mäßig erhöhten Risiko zugrunde liegen. Die Ergebnisse der Diagnostik können Indikationen für den chirurgischen Eingriff darstellen, gleichzeitig kann die Eliminierung dieser Ursache zu einer nachhaltigen Reduktion des Risikos führen.

Ein Zehn-Jahres-Frakturrisiko ist bei Frauen über 70 und Männern über 80 Jahren aufgrund des dominanten Risikofaktors Lebensalter prinzipiell so hoch, dass eine Basisdiagnostik empfohlen wird, sofern die Ergebnisse der Untersuchungen für den Patienten eine therapeutische Konsequenz haben. Bei Frauen zwischen 60 und 70 Jahren bzw. Männern zwischen 70 und 80 Jahren ist der Schwellenwert überschritten, wenn zusätzlich ein weiterer begünstigender Faktor vorliegt, als Beispiele sind vorangegangene Frakturen, positive Familienanamnese für proximale Femurfrakturen, Nikotinkonsum, Immobilität, 
Untergewicht, Sturzneigung und Hyperkortisolismus zu nennen. Bei Frauen unter 50 und Männern unter 60 Jahren steigt das Zehn-Jahres-Frakturrisikos selbst bei Vorliegen eines Risikofaktors selten über $20 \%$, bzw. es ergeben sich selten therapeutische Konsequenzen, welche über die Durchführung der allgemeinen Prophylaxemaßnahmen hinausgehen. Ausnahme ist die vorangegangene Fraktur eines oder mehrerer Wirbelkörper, Hyperkortisolismus oder Hyperparathyreoidismus.

\subsubsection{Anamnese und körperliche Untersuchung}

$\mathrm{Zu}$ Beginn sollte ein ausführliches Anamnesegespräch mit Fokus auf Risikofaktoren und Krankheiten, welche eine sekundäre Osteoporose bedingen können, erfolgen. Die anschließende körperliche Untersuchung prüft die Körpergröße des Patienten und seine Haltung. Die Sinterung der Wirbelkörper kann zu einer Größenabnahme von mehr als $4 \mathrm{~cm}$ führen, wobei die Höhenminderung ausschließlich in der Wirbelsäule stattfindet und die Beinlänge konstant bleibt. Physiologischerweise entspricht die Armspannweite eines Menschen seiner Körpergröße, dem Scheitel-Sohlen-Abstand. Da dieser bei der Osteoporose abnimmt, ist Armspannweite relativ zu groß. Durch die Verkürzung des Rumpfes kann es zu schmerzhaftem Kontakt zwischen dem unteren Rippenbogen und dem Beckenkamm oder den Dornfortsätzen kommen. Vom Rücken zu den Flanken bilden sich typische Hautfalten („Tannenbaumphänomen“).

Die keilförmigen Einbrüche in der Brustwirbelsäule führen zum charakteristischen Rundrücken, zur Quantifizierung des Ausmaßes eignet sich die Messung der Distanz zwischen Hinterkopf und Wand, wenn der Patient sich aufrecht mit dem Rücken zur Wand stellt (Bartl 2008).

\subsubsection{Labordiagnostik}

Typische Veränderungen von Laborparametern fehlen bei der primären Osteoporose, allenfalls frische Frakturen können einen vorübergehenden Anstieg der alkalischen Phosphatase auslösen. Die Bedeutung der Labordiagnostik liegt hier in der differentialdiagnostischen Abklärung sekundärer Osteoporosen (siehe 1.3.3.3) und anderer Stoffwechselerkrankungen des Knochens.

Sie umfasst routinemäßig im ersten Schritt ein kleines Blutbild, Blutkörperchensenkungsgeschwindigkeit, alkalische Phosphatase, Kalium, Kalzium, Phosphat, Kreatinin, Transaminasen und $\gamma$-GT. 
Zum Ausschluss hormoneller Ursachen werden nur bei klinischem Verdacht zusätzlich Schilddrüsenhormone (T3, T4, TSH), Geschlechtshormone (FSH, Östrogen, Testosteron) und Vitamin-D-Metabolite (Calcitriol, 25-Hydroxy-Vitamin-D) sowie Parathormon untersucht.

Die Bestimmung von Knochenumsatzparametern kann bei der Differenzierung zwischen „slow“- und „fast-loser“-Osteporosen helfen (siehe 1.3.3.4) und ermöglicht somit eine spezifischere medikamentöse Therapie. Sie werden unterschieden in Parameter des Knochenanbaus und Parameter des Knochenabbaus. Erstere werden typischerweise von Osteoblasten produziert, als Beispiele sind die knochenspezifische alkalische Phosphatase (bone specific alkaline phosphatase, BSAP), das Osteocalcin und das Osteonectin zu nennen. Wegen ihrer Gewebespezifität sind die BSAP und das Osteocalcin bisher die am besten geeigneten Marker (Fassbender et al. 2002; Gomez et al. 1995), wobei das Osteocalcin einer zirkadianen Rhythmik unterliegt.

Als Marker für die Knochenresorption dienen vor allem Abbauprodukte des Knochengewebes wie Kollagenbausteine, welche in die Blutbahn freigesetzt und renal ausgeschieden werden. Verwendung finden Desoxypyridinolin und Cross-link-Telopeptide des Kollagen Typ I. Sie sind spezifisch für das Knochengewebe und werden nicht metabolisiert. Da auch ihr Spiegel im Blut in Abhängigkeit von der Tageszeit schwankt, sollten die Blutentnahmen vormittags beim nüchternen Patienten stattfinden. Sie eignen sich zur Messung des Therapieerfolgs bei Hormonsubstitution oder Einnahme von Bisphosphonaten, von einem Therapieerfolg spricht man bei einer Reduktion der Marker des Knochenabbaus um mindestens 30\% gegenüber dem Ausgangswert.

Eine Erhöhung der Knochenumsatzparameter in Blut oder Urin hat sich als unabhängiger Risikofaktor für das Auftreten osteoporotischer Frakturen gezeigt. Dennoch werden sie im klinischen Alltag noch nicht in der Routinediagnostik verwendet, da noch keine ausreichenden Informationen über das Zusammenspiel mit anderen Risikofaktoren vorliegen (Bartl 2008).

\subsubsection{Projektionsradiographie}

Konventionelle Röntgenaufnahmen des Skeletts lassen Verluste von Knochensubstanz erst nach einer Demineralisierung von 30-40\% erkennen und sind daher für die Frühdiagnose ungeeignet. Dennoch sind sie wesentlicher Bestandteil der Osteoporose-Diagnostik, da sie für das Erkennen von Frakturen essentiell sind. Typische Zeichen osteoporotischer Frakturen der Wirbelsäule sind Grund- und Deckplatteneinbrüche, Sinterungsfrakturen sowie Fisch- und Keilwirbel mit einer Höhenminderung von mehr als 20\%. Der Verlust an trabekulärer 
Knochenmasse bei erhaltener Substantia corticalis zeigt sich im konventionellen Röntgen durch eine auffällige Rahmenstruktur des Wirbelkörpers.

Das Ausmaß der Deformierung der Wirbelsäule lässt sich mit dem „Spine Deformity Index“ objektivieren. Dabei wird die Höhe eines Wirbelkörpers, bzw. dessen Mitte, Vorder- und Hinterkante, mit der benachbarter Wirbelkörper verglichen. Der selten frakturierte BWK IV dient als individuelle Norm (Classen et al. 2004).

Unverzichtbar sind die konventionellen Röntgenaufnahmen zur Abklärung sekundärer Osteoporosen und bei unklaren Rückenschmerzen, um andere Differentialdiagnosen wie entzündlich-degenerative Erkrankungen, Osteomalazie und tumoröse Läsionen auszuschließen (Bartl 2008).

\subsubsection{Messung der Knochendichte}

Die Messung der Knochendichte ist die einzige Möglichkeit, eine Osteoporose zu diagnostizieren, bevor Frakturen auftreten. Sie ermöglicht die Risikoaussage für spätere Frakturen, dabei ist das Frakturrisiko bei einer Verminderung der Knochenmasse von 10\% im Bereich der Wirbelsäule verdoppelt, im Bereich des proximalen Femurs verdreifacht. Wenn bereits eine Fraktur vorliegt, wird die Messung der Knochendichte verwendet, um die Diagnose einer Osteoporose zu bestätigen und deren Schweregrad zu bestimmen.

Das Prinzip der Knochendichtemessung beruht auf der Minderung der Intensität von Photonen- oder Röntgenstrahlen beim Durchtritt durch das Knochengewebe, wodurch indirekt der Rückschluss auf die Knochendichte möglich ist. Hauptverantwortlich für diesen Effekt ist das Hydroxylapatit des Knochens, entsprechend dessen Masse die ionisierenden Strahlen abgeschwächt werden. Je nach Methode wird der Knochenmineralgehalt in Gramm oder die Knochenmineraldichte in $\mathrm{g}$ Calciumhydroxylapatit $/ \mathrm{cm}^{2}$ bzw. $\mathrm{g} / \mathrm{cm}^{3}$ gemessen.

Die Messmethoden sind wesentlicher Bestandteil der Osteoporosediagnostik. Ihre Bedeutung für die Bestimmung des Frakturrisikos ist jedoch nicht ausreichend. So ergaben verschiedene Studien, dass eine verringerte Knochendichte nicht zwingend mit einem erhöhten Frakturrisiko einhergehen muss. Insgesamt konnten weniger als $20 \%$ der aufgetretenen osteoporotischen Frakturen allein auf eine verringerte Knochendichte zurückgeführt werden, die gleichzeitige Beachtung der Risikofaktoren ist von wesentlicher Bedeutung (Cummings und Melton 2002; Sarkar et al. 2002; Watts et al. 2004).

\subsection{DXA}

Die duale Röntgenabsorptiometrie (Dual Energy X-ray Absorptiometry) ist derzeit die geläufigste Methode zur Messung der Knochendichte und die von WHO und dem 
Dachverband Osteologie (DVO) anerkannte Standardmethode zur Diagnose der Osteoporose (Christiansen 1993; Pfeilschifter 2009). Bei der Messung strahlen zwei Energiequellen unterschiedlicher Intensität durch das Knochengewebe, anhand der Strahlenabsorption kann der Mineralgehalt des durchstrahlten Gewebes als Absolutwert $(\mathrm{g} / \mathrm{cm})$ oder als Dichte bezogen auf die Fläche $\left(\mathrm{g} / \mathrm{cm}^{2}\right)$ errechnet werden. Es ist anzumerken, dass der als Knochenmineraldichte bezeichnete Wert nicht dem der physikalischen Dichte entspricht, welche als Masse pro Volumen $\left(\mathrm{g} / \mathrm{cm}^{3}\right)$ definiert ist.

Gemessen werden mit der DXA meist das proximale Femur und die Lendenwirbelkörper L1 bis L4, wobei nicht nur die Wirbelkörper, sondern auch Wirbelbögen und Dornfortsätze erfasst werden, welche zu einem erheblichen Anteil aus Substantia corticalis bestehen.

Die Methode ist nicht invasiv, schnell und preiswert. Bei einer geringen Strahlenbelastung, welche nur 1-10\% einer konventionellen Röntgenaufnahme entspricht, misst sie sehr präzise und ist daher auch für Verlaufskontrollen geeignet.

\subsection{QCT}

Die quantitative Computertomographie kann an jedem Computertomographen erfolgen, sofern dieser zuvor mit einem genormten Hydroxylapatit-Phantom kalibriert worden ist (Link und Majumdar 2003). Diese Volumenmessmethode ist das beste Verfahren, den für die Osteoporose typischen Verlust von trabekulärem Knochen an der Wirbelsäule früh zu detektieren, da sie die Differenzierung zwischen trabekulären und kortikalen Knochenanteilen erlaubt. Die ermittelten Werte werden als Masse Hydroxylapatit pro Volumen angegeben, die Knochendichtemessung erfolgt also dreidimensional, ein Vorteil im Vergleich zur DXA. Die Strahlenbelastung ist gegenüber der DXA jedoch etwa hundertfach erhöht, wodurch die QCT für regelmäßige Kontrolluntersuchungen ungeeignet ist.

\subsection{QUS}

Die quantitative Ultraschallmessung (quantitative Ultrasound) ist ein weiterer Ansatz in der Knochendichtemessung, sie ist ebenso wie die DXA eine schnelle und preisgünstige, nichtinvasive Methode, welche dabei aber ohne jede Strahlenbelastung auskommt.

Hier wird nicht nur die Absorption gemessen, sondern das Verhalten der Schallwellen, deren Geschwindigkeit und Reflexion bestimmt. Das unterschiedliche Schallverhalten in verschiedenen Geweben und Oberflächen gibt Aufschluss über Knochenstruktur und -architektur. Dabei sind zwei Parameter ausschlaggebend, erstens die Schallgeschwindigkeit (Speed of Sound, SOS, $\mathrm{m} / \mathrm{s}$ ) und zweitens die Schallwellenschwächung (Broadband ultrasound attenuation, BUA, dB/MHz). 
Für die Messung müssen kombinierte Schallsender und -empfänger an gegenüberliegenden Seiten des Knochens lokalisiert sein, daher ist die Methode geeignet für Knochen mit wenig umgebendem Weichteilgewebe wie Phalangen, Calcaneus, Tibia und Radius. Die besonders frakturgefährdeten Areale Wirbelsäule und proximales Femur können jedoch nicht untersucht werden, die Ergebnisse von QUS-Messungen im Bereich der Wirbelsäule korrelieren nur unzureichend mit denen valider Messungen der Knochendichte (Tuna et al. 2008). Eine normale Knochendichte in den messbaren peripheren Knochen kann eine Osteoporose der Wirbelsäule nicht ausschließen, bei pathologischen Werten in den Phalangen ist jedoch von einer schweren generalisierten Osteoporose auszugehen. Zur Therapieplanung ist die QUS dementsprechend nicht geeignet.

\subsubsection{6 $\mu \mathrm{CT}$}

Die Knochendichtemessung allein lässt nur teilweise Rückschlüsse auf die Festigkeit des Knochens und damit einhergehend das Frakturrisiko zu, da sie nur die Makrostruktur des Knochens erfasst. Dagegen ermöglichen neue, hochauflösende Techniken wie die MikroComputertomographie die Bestimmung der Zahl der Trabekel sowie ihrer Verbindungen untereinander und erlauben somit eine genauere Beschreibung der dreidimensionalen Mikrostruktur des Knochens. Die $\mu \mathrm{CT}$ erreicht unter Verwendung einer im Vergleich zur konventionellen Computertomographie deutlich höheren Strahlendosis eine Auflösung von 10-100 $\mu \mathrm{m}$, so dass die einzelnen Trabekel klar voneinander abgegrenzt werden können. Bisher kann die $\mu \mathrm{CT}$ nur in der Bildgebung kleiner Knochen eingesetzt werden, so dass sie in der Untersuchung der Knochen kleiner Tiere und von Knochenstanzbiospien zum Einsatz kommt (Kalpakcioglu et al. 2008). Dabei konnten vergleichende Studien eine signifikante Korrelation $(\mathrm{p}<0,0001)$ zwischen den Ergebnissen der histologischen Untersuchung und der $\mu \mathrm{CT}$ von Knochenbiopsien des menschlichen Beckenkamms belegen (Muller et al. 1998).

\subsubsection{Therapie}

Die Therapie der Osteoporose beinhaltet mehrere Ziele. Zum einen die Verbesserung der Biomechanik des Knochens und die Senkung des Frakturrisikos, zum anderen die Verbesserung der Lebensqualität durch Linderung von Beschwerden wie Schmerzen oder Bewegungseinschränkungen. Dabei sind allgemeine Basis- und Prophylaxemaßnahmen von spezifischen medikamentösen Therapieansätzen abzugrenzen. 
Der Dachverband Osteologie veröffentlicht diesbezüglich Empfehlungen in seinen Leitlinien, welche alle drei Jahre aktualisiert werden. Die folgenden Abschnitte beziehen sich auf die aktuellen Leitlinien von 2009 (Pfeilschifter 2009).

\subsubsection{Allgemeine Basis- und Prophylaxemaßnahmen}

Unabhängig von diagnostischen Ergebnissen und einer gezielten medikamentösen Therapie werden für alle Risikopatienten Maßnahmen zur Prophylaxe von osteoporotischen Frakturen empfohlen.

Dazu gehört die konsequente körperliche Aktivität, welche bei älteren Patienten zu einer Senkung des Risikos für proximale Femurfrakturen führt. Patienten, welche aus Angst vor Sturzereignissen oder Frakturen in ihrer Mobilität eingeschränkt sind, können Hilfe in ausgewiesenen Selbsthilfegruppen oder durch psychosoziale Betreuung finden. Generell sollten die in 1.3.5 aufgeführten Risikofaktoren eruiert und, sofern möglich, beseitigt werden. Bei Patienten mit erhöhtem Sturzrisiko besteht die Möglichkeit, erstens im Rahmen einer Begehung der Wohnräume „Stolperfallen“ zu entfernen und zweitens durch Hüftprotektoren und andere Hilfsmittel das Risiko für Frakturen als Folge eines Sturzereignisses zu minimieren. Eine jährliche Sturzanamnese wir ab einem Alter von 70 Jahren empfohlen. Die Therapie mit Medikamenten, welche das Sturzrisiko erhöhen (Antidepressiva, orthostatisch wirkende Medikamente) oder die Entstehung einer Osteoporose begünstigen können (Kortikoide, Glitazone) bedarf der kritischen Hinterfragung.

Bei der Ernährung ist auf die ausreichende Zufuhr von Milchprodukten zu achten, um den täglichen Kalziumbedarf von $1000 \mathrm{mg}$ zu decken. Kann die Ernährung dies nicht gewährleisten, sollte Kalzium supplementiert werden, dabei sollte die Gesamtmenge des zugeführten Kalziums 1500 mg jedoch nicht überschreiten. Gleiches gilt für Vitamin D bei einer Konzentration unter 20 ng 25-Hydroxy-Vitamin D pro ml Serum. Bei den meisten Patienten wird diese Grenze durch die langfristige Gabe von 1000 IE Vitamin D pro Tag überschritten, die Messungen unterliegen jedoch enormen Schwankungen und sind aufgrund der mangelnden Standardisierung derzeit nicht generell zu empfehlen. Bei einem Body Mass Index unter $20 \mathrm{~kg} / \mathrm{cm}^{2}$ sollte die Ursache des Untergewichts abgeklärt und eine ausreichend kalorische Ernährung empfohlen werden.

Wegen des erhöhten Risikoprofils älterer Patienten und postmenopausaler Frauen sollte bei diesen besonderes Augenmerk auf die Präventionsmaßnahmen gelegt werden. 


\subsubsection{Indikationen für die medikamentöse Therapie}

Liegt das aufgrund vorliegender epidemiologischer Daten zu erwartende 10-Jahresrisiko für Wirbelkörper- und proximale Femurfrakturen über 30\% und sind die T-Werte der DXA an mindestens einer dieser Lokalisationen vermindert, so wird unabhängig von Geschlecht und Lebensalter eine medikamentöse Therapie empfohlen. Dasselbe gilt für die Einnahme oraler Glukokortikoide, wie die tägliche Applikation von mehr als 7,5 mg Prednisolonäquivalent für mehr als drei Monate in Kombination mit einem DXA T-Wert kleiner gleich -1,5.

Der positive Effekt einer spezifischen medikamentösen Therapie, nämlich die Reduktion des Frakturrisikos um 30-40\%, ist für DXA T-Werte $<-2$ belegt. Das entspricht einer ,number needed to treat" von 15, das heißt zur Verhütung einer osteoporotischen Fraktur müssen 15 Patienten behandelt werden. Die Messung der Knochendichte mittels DXA gibt somit nicht nur Auskunft über das Ausmaß der Osteoporose, sondern auch über die Erfolgssaussichten einer medikamentösen Therapie.

In Abhängigkeit von Alter und Geschlecht ist die verminderte Knochendichte auch ohne das Vorliegen anderer Risikofaktoren oder stattgehabter Frakturen bei Unterschreiten bestimmter T-Werte eine Therapieindikation (siehe Tabelle 2).

Tabelle 2: T-Werte als Therapieindikation in Abhängigkeit von Alter und Geschlecht, modifiziert nach Pfeilschifter 2009

\begin{tabular}{|cc|c|}
\hline \multicolumn{2}{|c|}{ Lebensalter in Jahren } & T-Wert (DXA) LWS oder proximales Femur \\
\hline$\varnothing$ & 0 & $-4,0$ \\
\hline$<50$ & $<60$ & $-4,0$ \\
\hline $50-60$ & $60-70$ & $-3,5$ \\
\hline $60-65$ & $70-75$ & $-3,0$ \\
\hline $65-70$ & $75-80$ & $-2,5$ \\
\hline $70-75$ & $80-85$ & $-2,0$ \\
\hline$>75$ & $>85$ & \\
\hline
\end{tabular}

Bei Vorliegen zusätzlicher Risikofaktoren wie anamnestisch einer peripheren Fraktur nach Bagatelltrauma oder positiver Familienanamnese für proximale Femurfrakturen, Nikotinkonsum, Gangunsicherheit sowie Immobilität ist die Indikation zur Therapie früher zu stellen.

\subsubsection{Medikamentöse Osteoporosetherapie}

Die antiosteoporotischen Substanzen lassen sich anhand ihrer Wirkweise in zwei Gruppen unterteilen. Die antiresorptiven Substanzen reduzieren bei insgesamt positiver Knochenbilanz 
den Knochenumbau und die Knochenresorption im Rahmen des remodelling. Obwohl die positive Knochenbilanz überwiegt, hemmen die antiresorptiven Substanzen indirekt auch den Knochenanbau. Die signifikante Reduktion des Frakturrisikos ist selten höher als 50-60\% im Vergleich zur Kontrollgruppe. $\mathrm{Zu}$ ihnen gehören unter anderem die Bisphosphonate, das Raloxifen, Kalzitonin, Kalzium, Vitamin D, und Östrogen. Die osteoanabolen Substanzen stimulieren den Knochenumbau, indem sie Osteoblasten und Stromazellen aktivieren, wobei letztere wiederum über Zytokine die Osteoblasten stimulieren. Durch die starke Aktivierung der Osteoblasten nimmt die Knochenmasse konsequent zu, was mit einer Reduktion des Frakturrisikos bei zunehmender Knochenfestigkeit verbunden ist. Als Beispiele sind Parathormon, Fluoride und Strontium zu nennen, wobei Fluoride nur zu einer Zunahme der Knochenmasse führen, der neu gebildete Knochen ist jedoch nicht ausreichend stabil gegenüber mechanischer Belastung (Bartl 2008). In neueren Forschungsprojekten wurde auch für Östrogen eine osteoanabole Wirkung beobachtet, so verglichen Stürmer et al. die Frakturheilung in der osteoporotischen Tibia der Ratte mit der bei gesunden Versuchstieren. Dabei wurde beobachtet, dass der Heilungsprozess im osteoporotischen Knochen unter dem Einfluss von Östrogen nahezu auf das Niveau des gesunden Knochens verbessert werden konnte (Stuermer et al. 2010).

\subsection{Hormonersatztherapie}

Der postmenopausale Östrogenmangel ist der entscheidende Faktor für die Entstehung einer Osteoporose bei Frauen. Schon einige Jahre vor der Menopause verursacht das Absinken des Östrogenspiegels einen kontinuierlichen Verlust an Knochenmasse. Ohne Hormonersatztherapie (hormone replacement therapy, HRT) verlieren Frauen nach der Menopause jährlich bis zu 4\% ihrer Knochenmasse.

Nachdem der Zusammenhang zwischen Sexualhormonen und der Synthese von Zytokinen und Wachstumsfaktoren im Knochengewebe bekannt wurde, konzipierte man die Studien der „Women's Health Initiative“ (WHI) (Rossouw et al. 2002) und die britische „Million Women Study“ (Beral 2003).

Zwischen 1993 und 1998 untersuchte die WHI randomisiert die Wirkung von Östrogen, der Kombination von Östrogen und Progesteron sowie von Placebos an 161.809 postmenopausalen Frauen mit intaktem Uterus. Die 2002 publizierten Ergebnisse zeigten, dass beide HRT-Kollektive signifikant weniger Frakturen erlitten hatten. Gleichzeitig war das relative Risiko des Östrogen-Progesteron-Kollektivs für Mammakarzinome, Lungenembolie, Apoplex und koronare Herzkrankheit so drastisch erhöht, dass dies zu einem vorzeitigen Abbruch der Studie nach 5,2 Jahren (anstelle von geplanten 8,5 Jahren) führte (Rossouw et al. 
2002). Die Applikation von Östrogen ohne Progesteron erhöhte in diesem Kollektiv das Risiko für das Auftreten eines Apoplex, so dass auch hier die Studie nach 6,8 Jahren vorzeitig abgebrochen wurde (Anderson et al. 2004).

Im August 2003 erschienen die ersten Ergebnisse der „Million Women Study“, im Rahmen derer 1.084.110 Frauen zwischen 50 und 64 Jahren in den Jahren 1996 bis 2001 zur HRT befragt worden waren. Von den befragten Frauen nahmen ungefähr die Hälfte zum Zeitpunkt der Befragung oder zuvor Hormone ein. Analog zu den Ergebnissen der WHI fand auch die „Million Women Study“ ein erhöhtes relatives Risiko an einem Mammakarzinom zu erkranken oder zu versterben für Frauen, die zum Zeitpunkt der Befragung Hormone einnahmen, wobei das Risiko bei der Kombination von Östrogen und Progesteron am höchsten war (Beral 2003).

Aufgrund dieser Erkenntnisse wird die Östrogentherapie nur noch in Ausnahmefällen zur Behandlung klimakterischer Beschwerden und der Osteoporose postmenopausaler Frauen empfohlen. Die Entscheidung für eine HRT sollte gegebenenfalls im Dialog mit dem Gynäkologen getroffen werden.

\subsubsection{2 Östrogen-Rezeptor-Agonisten/Antagonisten}

Die Östrogen-Rezeptor-Agonisten/Antagonisten (Selective Estrogen Receptor Modulators, SERMs) sind selbst keine Steroidhormone, können aber an die Östrogenrezeptoren ER $\alpha$ und ER $\beta$ binden und in verschiedenen Geweben analog zum Östrogen wirken. Für das Knochengewebe ist Raloxifen das am ausführlichsten untersuchte SERM, es wirkt als Östrogenagonist am Knochen, hat aber keinen Effekt auf Mamma und Uterus. Eine randomisierte, Placebo-kontrollierte Phase-III-Studie mit 7705 postmenopausalen Osteoporosepatientinnen (Multiple Outcomes of Raloxifene Evaluation, MORE) konnte den positiven Effekt von Raloxifen nachweisen. Dabei wurde den Probandinnen täglich $60 \mathrm{mg}$ Raloxifen verabreicht, was zu einer erhöhten Knochendichte in proximalem Femur und Wirbelsäule und einem fast um die Hälfte verminderten Frakturrisiko für Wirbelkörper im Vergleich zur Placebo-Gruppe führte. Extravertebrale Frakturen wurden nicht signifikant beeinflusst, jedoch sank gleichzeitig das Risiko, an einem Mammakarzinom zu erkranken, um 54-74\% (Ettinger et al. 1999).

\subsection{Bisphosphonate}

Mit der Entdeckung der Bisphosphonate und deren Wirkung auf den Knochen wurde vor 30 Jahren die Behandlung von Knochenkrankheiten revolutioniert. Die Bisphosphonate werden auf der Knochenoberfläche angereichert und hemmen die Osteoklasten, während inaktive 
Osteoblasten reaktiviert werden. Demzufolge wird der Knochenabbau gehemmt und die Knochenbilanz wird positiv. Sie gehören somit zur Gruppe der antiresorptiven Substanzen.

Die Bisphosphonate werden in stickstoffhaltige und nicht-stickstoffhaltige Substanzen eingeteilt, wobei erstere die potenteren zur Behandlung aller Formen der Osteoporose sind.

Die Wirksamkeit des Aminobisphosphonats Alendronat wurde in verschiedenen klinischen Studien an über 17.000 Patienten belegt, eine davon ist die „Fracture Intervention Trial“Studie (FIT) bzw. die „Fracture Intervention Trial Long-term Extension“ (FLEX). Hier wurde einem Kollektiv von 6459 postmenopausalen Frauen zwischen 55 und 81 Jahren entweder Alendronat oder ein Placebo verabreicht. Dabei konnte gezeigt werden, dass die Osteoporosepatientinnen, welche im Rahmen der Studie über drei bis vier Jahre täglich Alendronat eingenommen hatten, ein geringeres relatives Risiko hatten, eine Fraktur der Wirbelsäule, der Hüfte oder des Handgelenks zu erleiden (Black et al. 2000).

Bei den Studienteilnehmerinnen, die nach fünf Jahren die Einnahme von Alendronat beendeten, fand sich zwar eine leicht verminderte BMD (Bone Mineral Density, Knochendichte), jedoch kein erhöhtes Frakturrisiko im Vergleich zu dem Kollektiv, welches die Alendronateinnahme für weiter fünf Jahre fortsetzte (Black et al. 2006). Die Verträglichkeit von Alendronat ist sehr gut, das Auftreten von unerwünschten Arzneimittelwirkungen unterschied sich von der Placebogruppe nicht.

Risedronat ist ein weiteres Bisphosphonat, dessen Wirksamkeit in großen internationalen Studien getestet worden ist. So untersuchte die VERT-Gruppe (Vertebral Efficacy with Risedronate Therapy) die Wirkung von Risedronat in einer randomisierten, doppelblinden, placebo-kontrollierten Studie an 2458 postmenopausalen Patientinnen unter 85 Jahren. Die tägliche Einnahme von $5 \mathrm{mg}$ Risedronat in den drei Jahren der Studie senkte dabei das Auftreten neuer Wirbelfrakturen um 41\% (Harris et al. 1999). Eine weitere Studie zeigte, dass Risedronat schon innerhalb von sechs Monaten das Risiko für Wirbelfrakturen bei postmenopausalen Frauen signifikant senken kann (Roux et al. 2004).

\subsection{Strontium-Ranelat}

Das Strontium-Ranelat ist eine vergleichsweise neue Substanz zur Therapie der postmenopausalen Osteoporose. Es handelt sich dabei um ein knochenaffines Element aus der Gruppe der Erdalkalimetalle, das sich chemisch ähnlich verhält wie Kalzium. Seit 2004 ist es auf dem deutschen Markt als osteoanabole und gleichzeitig antiresorptive Substanz zugelassen. Das Strontium-Ranelat steigert die Differenzierung von Präosteoblasten und die Kollagensynthese in Osteoblasten, während es gleichzeitig durch Hemmung von Osteoklasten und deren Vorläuferzellen antiresorptiv wirkt (Reginster et al. 2005). 
Die SOTI-Studie (Spinal Osteoporosis Therpeutic Intervention) untersuchte die Effekte von Strontium-Ranelat an 1649 postmenopausalen Osteoporosepatientinnen, die über einen Zeitraum von drei Jahren täglich entweder ein Placebo oder $2 \mathrm{~g}$ Strontium-Ranelat einnahmen. In der Placebo-Gruppe traten im Verlauf der Studie deutlich mehr Wirbelkörperfrakturen auf, außerdem stieg die Knochendichte nach Einnahmen von Strontium-Ranelat innerhalb der drei Jahre um 8,3\% am Schenkelhals und um 14,4\% an der LWS (Meunier et al. 2004).

Im Rahmen der TROPOS-Studie (Treatment of Peripheral Osteoporosis) wurden 5091 postmenopausale Osteoporosepatientinnen untersucht, welche über einen Zeitraum von 5 Jahren randomisiert täglich entweder $2 \mathrm{~g}$ Strontium-Ranelat oder ein Placebo erhielten. Bei den 2714 Patientinnen, welche die Studie nicht vorzeitig abbrachen, war in der StrontiumRanelat-Gruppe das Risiko für nicht-vertebrale Frakturen im Vergleich zur Placebo-Gruppe um $15 \%$ reduziert (Reginster et al. 2008).

\subsection{Parathormon}

Parathormon (PTH) wird in der Nebenschilddrüse synthetisiert und bei Absinken des extrazellulären Kalziums in das Blut freigesetzt, um dort die Konzentration von Kalzium zu erhöhen und die von Phosphat zu senken. Dies geschieht, indem vermehrt Kalzium aus dem Knochen freigesetzt und in der Niere rückresorbiert wird, bei gleichzeitig vermehrter Synthese von Calcitriol. Nur bei pulsatiler Applikation einmal täglich wirkt PTH osteoanabol, wird es kontinuierlich verabreicht, führt es zur Osteolyse (Canalis et al. 2007; Gao et al. 2008).

Eine Studie mit 1637 postmenopausalen Osteoporosepatientinnen konnte die Reduktion der Frakturrate unter pulsatiler Applikation des rekombinanten humanen Parathormonfragments 1-34 (Teriparatid, rhPTH 1-34) zeigen. Dabei wurden die Patientinnen randomisiert in eine Placebo-Gruppe und zwei Gruppen eingeteilt, welche jeweils entweder 20 oder $40 \mu \mathrm{g}$ rhPTH1-34 täglich sub cutem erhielten. Die Zahl neuer Wirbelkörperfrakturen sank unter der Therapie in 21 Monaten um 65\%, die Knochendichte stieg um 9\% an der LWS und um 3\% am Schenkelhals (Neer et al. 2001). Bei vergleichsweise geringer Zunahme der Knochendichte nehmen unter PTH auch die periostale Knochenneubildung, das kortikale Volumen und die Querschnittsfläche der langen Röhrenknochen zu. Somit steigt die biomechanische Stabilität des Knochens (Bartl 2008). 


\subsection{Vibration}

Eine entscheidende Ursache für die Entstehung der Osteoporose ist die Immobilisation, das Risiko für das Auftreten einer osteoporotischen Fraktur wird dabei von drei Faktoren beeinflusst: mechanische Stabilität des Knochens, Sturzneigung und die Effektivität der neuromuskulären Reaktion, welche den Knochen schützt. Körperliche Aktivität kann das Frakturrisiko senken, indem sie nicht nur dem Verlust von Knochenmasse entgegenwirkt, sondern durch besseren Gleichgewichtssinn und verbessertes Reaktionsvermögen auch die Sturzneigung, und im Falle eines Sturzes die Konsequenzen dessen für den Knochen, vermindert (Smith und Gilligan 1991).

Julius Wolff beschrieb erstmals die Anpassung des Knochengewebes an mechanischen Stress durch strukturellen Umbau (Wolff 1892). Der US-amerikanische Orthopäde und Chirurg Harold Frost entwickelte Wolffs Theorien weiter und verfasste 1960 die Utah Paradigm of Skeletal Physiology. Darin beschreibt er einen Regelkreis der stetigen Anpassung des Knochens an die auf ihn wirkenden Kräfte, genannt Mechanostat. Die maximale elastische Verformbarkeit des Knochens und die auf ihn einwirkenden Maximalkräfte stellen darin die ursächlichen Reize für Knochenwachstum und -umbau dar. Der Knochen adaptiert konsequent an die an ihn gestellten biomechanischen Ansprüche, um eine maximale Festigkeit zu erreichen (Frost 2000).

Das Maß für die Verformung des Knochens ist Strain, $1000 \mu$ Strain entsprechen einer Längenänderung von $0,1 \%$. Die auf den Knochen einwirkenden Kräfte werden dabei in vier Intensitäten eingeteilt ${ }^{1}$ :

- Disuse: < $800 \mu$ Strain, Remodeling, negative Knochenbilanz

- Adapted State: 800 bis $1500 \mu$ Strain, Remodeling, konstante Knochenbilanz

- Overload: > $1500 \mu$ Strain, Modeling, positive Knochenbilanz

- Fracture: > $15000 \mu$ Strain, Belastungsgrenze, Knochen bricht.

Demnach hat der Knochen einen Sicherheitsabstand zwischen typischerweise einwirkenden Maximalkräften und den Belastungen, denen er nicht mehr standhalten kann und die zur Fraktur führen (Frost 1960).

Da den meisten der Patienten mit Osteoporose ausreichende körperliche Aktivität nicht möglich ist, wurde als Weiterführung dieser Erkenntnis das Konzept der mechanischen Stimulation entwickelt. Das Vibrationstraining (Whole-Body Vibration, WBV) war

\footnotetext{
${ }^{1}$ Die angegebenen Grenzwerte beziehen sich hier auf das Beispiel der Tibia, verschiedene Knochen können entsprechend verschiedene Schwellenwerte aufweisen
} 
ursprünglich für die Behandlung von Muskelatrophie und Verlust von Knochenmasse bei russischen Kosmonauten entworfen worden. Der Patient steht dabei auf einer Plattform, welche mit unterschiedlichen Frequenzen vibriert. Die Vibration löst in der Muskulatur monosynaptisch propriozeptive Eigenreflexe aus, welche über anulospirale Dehnungsrezeptoren in der Muskelspindel vermittelt werden. Die Dehnung des Muskels aktiviert diese Rezeptoren, über Ia-Fasern werden Impulse zu den Alphamotoneuronen geleitet und die reflektorische Verkürzung des Muskels bewirkt (Delank und Gehlen 2006). Bei geeigneter Anwendung kann die WBV einem Verlust von Knochenmasse entgegenwirken, indem die einwirkenden Kräfte zu einer leichten elastischen Verformung des Knochens führen und Remodeling und Knochenwachstum induzieren (Armbrecht et al. 2009; Rittweger et al. 2009). Die stärkste auf den Knochen einwirkende Kraft ist nicht die des Körpergewichts, sondern die der Muskulatur (Burr 1997).

Eine randomisierte Studie an 70 postmenopausalen Frauen zwischen 58 und 74 Jahren konnte zeigen, dass das Vibrationstraining mit 35-40 Hertz im Gegensatz zur Kontrollgruppe zu einer signifikanten Zunahme der Knochendichte im Bereich des proximalen Femurs führte (Verschueren et al. 2004). Xie et al. untersuchten die Effekte auf die Knochenbildung im wachsenden Skelett. Zu diesem Zweck wurden acht Wochen alte Mäuse für drei Wochen täglich 15 Minuten mit 45 Hertz vibriert. Die anschließenden Untersuchungen des Knochengewebes ergaben eine um über $30 \%$ reduzierte Aktivität von Osteoklasten im Vergleich zur Kontrollgruppe bei gleichzeitig um 30\% erhöhter Knochenbildungsrate (Xie et al. 2006). Weiter untersuchten Xie et al. die Auswirkungen auf das muskuloskelettale System, indem sie ausgewachsene Mäuse über einen Zeitraum von sechs Wochen täglich 15 Minuten mit einer Frequenz von 45 Hertz vibrierten. Nach Ablauf des Versuches war die strukturelle Knochenqualität der WBV-Tiere im Vergleich zur Kontrollgruppe signifikant verbessert und das trabekuläre Knochenvolumen der Tibiae um 14\% höher (Xie et al. 2008).

Die Empfänglichkeit des Knochens gegenüber der mechanischen Stimulation scheint durch Östrogen beeinflusst. Eine Untersuchung mittels peripherer quantitativer Computertomographie von ovariektomierten Ratten im Vergleich mit einer nicht ovarektomierten Kontrollgruppe kam zu dem Ergebnis, dass die WBV bei der Kontrollgruppe keinen Effekt zeigte, während sie bei den ovariektomierten Tieren signifikant osteoanabol wirkte. Dabei verstärkte sich dieser Effekt mit steigender Vibrationsamplitude. Die Tiere waren über einen Zeitraum von acht Wochen jeweils fünf Tage pro Woche für 20 Minuten der WBV unterzogen worden (Rubinacci et al. 2008). 
In einer weiteren Studie, welche ebenfalls den Einfluss von mechanischer Stimulation auf den Knochen gesunder und ovariektomierter Ratten untersuchte, erhöhte die vertikale WBV mit einer Frequenz von $90 \mathrm{~Hz}$ über einen Zeitraum von 35 Tagen in allen Gruppen die Knochendichte. Dabei zeigten die ovariektomierten WBV-Ratten am Ende ähnliche Werte für die Knochendichte, wie die nicht mechanisch stimulierte und nicht ovariektomierte Kontrollgruppe (Sehmisch et al. 2009a). In einem weiteren Tierversuch an den osteotomierten Tibiae von Schafen bildete sich durch die mechanische Stimulation mit einer Frequenz von 30 $\mathrm{Hz}$ bei einer Amplitude von $25 \mu \mathrm{m}, 17$ Minuten an fünf Tagen der Woche, nach Ablauf der zehnwöchigen Studie 29\% mehr und stabilerer Callus im Vergleich zur nicht stimulierten Kontrollgruppe, gleichzeitig erhöhte sich der Mineralgehalt des Knochens um 52\% (Goodship et al. 2009).

Die veröffentlichten Daten legen nahe, dass die mechanische Stimulation durch WBV eine nicht-pharmakologische und nicht-invasive Therapieoption bei Osteoporose sein könnte. Dabei ist noch nicht ausreichend erforscht, welche Frequenzen, Stimulationszeiträume, Vibratiosrichtung und Amplituden optimale Ergebnisse herbeiführen, durch welche Faktoren sie beeinflusst werden und wie sich diese an verschiedenen Körperregionen möglicherweise unterscheiden (Judex et al. 2009).

Neben den Effekten des Vibrationstrainings auf den Knochen wurde auch solche auf die Muskelkraft und -stärke beobachtet, welche unter anderem als Therapieoption bei Inkontinenz in Betracht gezogen werden (Lauper et al. 2009). 


\section{$2 \quad$ Material und Methoden}

\subsection{Versuchsablauf}

$\mathrm{Zu}$ Beginn des Versuches wurden 90 Ratten in sechs Gruppen eingeteilt, von denen eine Gruppe SHAM-operiert und die fünf anderen ovariektomiert wurden, um anschließend eine Osteoporose zu entwickeln (siehe Tabelle 3: Aufteilung der Tiere und Käfige). Bei diesem Eingriff starben zwei der Tiere, so dass ab diesem Zeitpunkt das Gesamtkollektiv nur noch aus 88 Ratten bestand. Acht Wochen später folgte, für eine andere Untersuchung, mit der Osteotomie und Osteosynthese der metyphysären Tibiae die zweite Operation. 65 Tage nach SHAM- oder OVX-OP wurde mit der mechanischen Stimulation durch WBV begonnen, wobei die Tiere täglich 15 Minuten mit der ihrer Gruppe zugeordneten Frequenz vibriert wurden. Um nach Abschluss des Versuches Rückschlüsse auf den Knochenumbau beziehungsweise die Aktivität der Knochenzellen während der WBV ziehen zu können, wurde in Anlehnung an Rahn eine polychrome Sequenzmarkierung durchgeführt (Rahn 1976). Die Tiere erhielten am 8. Tag nach Beginn der WBV 90 mg/kg KG Xylenol-Orange (XO), am 13. Tag 10 mg/kgKG Calcein-Grün (CG), am 19. sowie am 21. Tag 30 mg/kg KG Alizarin-Komplexon (AK) und am 30. Tag 30 mg/kg KG Tetracyclin (TC). Nach 30 Tagen WBV wurden die Tiere durch Dekapitation getötet.

Tabelle 3: Aufteilung der Tiere und Käfige

\begin{tabular}{|c|c|c|}
\hline Tiernummer & Käfige & Behandlung \\
\hline $1-15$ & $1-3$ & SHAM \\
\hline $16-30$ & $4-6$ & OVX \\
\hline $31-45$ & $7-9$ & OVX + WBV 35 Hz \\
\hline $46-59$ & $10-12$ & OVX + WBV 50 Hz \\
\hline $60-73$ & $13-15$ & OVX + WBV 70 Hz \\
\hline $74-88$ & $16-18$ & OVX + WBV 90 Hz \\
\hline
\end{tabular}




\subsubsection{Versuchstiere}

Für den Versuch wurden 88 weibliche Sprague Dawley Ratten der Firma Harlan Laboratories, Indianapolis, verwendet. Die Ratten wurden über den gesamten Versuchszeitraum in der Zentralen Tierexperimentellen Einrichtung (ZTE) der Universitätsmedizin Göttingen in Käfigen vom Typ Makrolon® IV gehalten, wobei sich in einem Käfig jeweils vier bis fünf Tiere befanden. Jeden dritten Tag erfolgte ein Austausch mit desinfizierten Käfigen durch die dort beschäftigten Tierpfleger. Haltungsfutter (ssniff SM R/M, 10mm-Pellets, ssniff Spezialdiäten $\mathrm{GmbH}$, Soest) und Wasser wurden ad libitum bereitgestellt. Die Umgebungstemperatur betrug konstant $20^{\circ} \mathrm{C}$ bei einer relativen Luftfeuchtigkeit von $55 \%$, es wurde eine Hell-Dunkel-Periodik von jeweils 12 Stunden eingehalten. Ovariektomie und Haltung der Tiere erfolgte unter der Aufsicht von Dr. Schunck (Tierarzt ZTE) und PD Dr. E. Stürmer.

Die im Rahmen dieses Forschungsprojektes durchgeführten Tierversuche wurden von der Bezirksregierung Braunschweig genehmigt (AZ 33.9.42502-04/011/07).

\subsubsection{Ovariektomie}

Am Tag der Ovariektomie betrug das Durchschnittsgewicht der Tiere 239 g (215 - $280 \mathrm{~g})$ (siehe Ergebnisse 3.1). Zur Anästhesie wurden die Ratten mit $\mathrm{CO}_{2}$ narkotisiert, anschließend wurde ein 5:3 Gemisch aus Ketamin (90 mg/kg KG, Hostaket ${ }^{\circledR}$, Firma Hoechst, Bad Soden) und Xylazin (7,5 mg/kg KG, Rompun ${ }^{\circledR}$, Firma Bayer, Leverkusen) in einer Dosierung von $0,01 \mathrm{ml} / \mathrm{g} \mathrm{KG}$ intraperitoneal appliziert. Es erfolgte zunächst die Rasur und Desinfektion der lateralen Hautpartien zwischen Rippenbogen und Hinterläufen. Nach Inzision der Haut wurde vorsichtig bis zum Peritoneum präpariert und anschließend die Bauchhöhle eröffnet. Nach Darstellung der Adnexen wurden die Tubae uterinae ligiert und die Ovarien abgesetzt. Der Wundverschluss erfolgte durch Naht der Muskulatur mit Vicryl und Klammern der Haut. Um einen potentiellen Flüssigkeitsverlust zu vermeiden wurde den Tieren postoperativ ein Depot von $3 \mathrm{ml} \mathrm{NaCl}$ 0,9\% sub cutem verabreicht, sie wurden bis zum Ende der Narkose beaufsichtigt.

\subsubsection{Osteotomie}

Um den Einfluss der WBV auch auf die Frakturheilung zu untersuchen erfolgte acht Wochen nach der Ovariektomie die Osteotomie und Plattenosteosynthese der Tibiae der Versuchstiere. Die Resultate dieses Versuchs wurden im Rahmen einer anderen Studie ausgewertet. 


\subsubsection{Ganzkörpervibration}

Nachdem 88 Ratten innerhalb von 65 Tagen eine Osteoporose entwickelt hatten wurde mit der vertikalen WBV begonnen, das heißt die Tiere wurden über einen Zeitraum von 30 Tagen täglich jeweils zur selben Zeit 15 Minuten vibriert. Um die potentiell unterschiedlichen Effekte verschiedener Frequenzen $\mathrm{zu}$ erfassen, wurden die $\mathrm{zu}$ vibrierenden Tiere in vier Gruppen eingeteilt, welche bei einer Amplitude von 0,5 mm mit 35, 50, 70 oder 90 Hertz vibriert wurden (siehe 2.1 Tabelle 3 ).

Für die WBV wurden jeweils sieben bis acht Ratten in einen seitlich gepolsterten Käfig gesetzt, welcher auf einem Vibrationstisch fixiert war (Vibriertisch VTG, DrehstromVibrationsmotor Typ HVL/HVE, Vibra Schultheis, Offenbach). Während der WBV konnten sich die Ratten innerhalb des Käfigs frei bewegen, wobei jedoch darauf geachtet wurde, dass die Tiere sich nicht aufeinander legen und Fuß-Boden-Kontakt halten, so dass der Effekt der Vibration nicht abgeschwächt wird.

\subsubsection{Präparation der Wirbelkörper}

Die Ratten wurden 14 Wochen nach Beginn des Forschungsprojektes durch Dekapitation in $\mathrm{CO}_{2}$-Narkose getötet. Im Durchschnitt lag das Körpergewicht zu diesem Zeitpunkt bei $314 \mathrm{~g}$ (272 - 370 g) (siehe Ergebnisse 3.1). Das gewonnen Blut wurde für die laborchemische Bestimmung von alkalischer Phosphatase, Kreatinkinase und Osteocalcin aufbewahrt. Zur Präparation der Wirbelsäule wurde die Haut entlang der Processus spinosi eröffnet und paraspinale Muskulatur sowie Sehnenansätze entfernt. Das kraniale und kaudale Ende der Lendenwirbelsäule ließ sich durch digitales Aufsuchen der Rippen und des Os sacrum gut darstellen. Im Bereich dieser begrenzenden Strukturen wurde die Wirbelsäule beziehungsweise das Becken mithilfe einer Zange scharf durchtrennt und zur Präparation der einzelnen Wirbelkörper entnommen (siehe Abbildung 1, die roten Markierungen umfassen die Lendenwirbelsäule). Nachdem Muskulatur und Sehnenreste mit einem scharfen Löffel vorsichtig entfernt worden waren, konnten die Grund- und Deckplatten der Wirbel mit dem Skalpell von den dazwischen liegenden Disci intervertebrales getrennt werden. Bis zur weiteren Verwendung wurden die Wirbelkörper bei $-20^{\circ} \mathrm{C}$ aufbewahrt. Neben den LWK wurden den Tieren auch Tibiae, Femora, Muskulatur und Uterus für weitere Untersuchungen entnommen. 


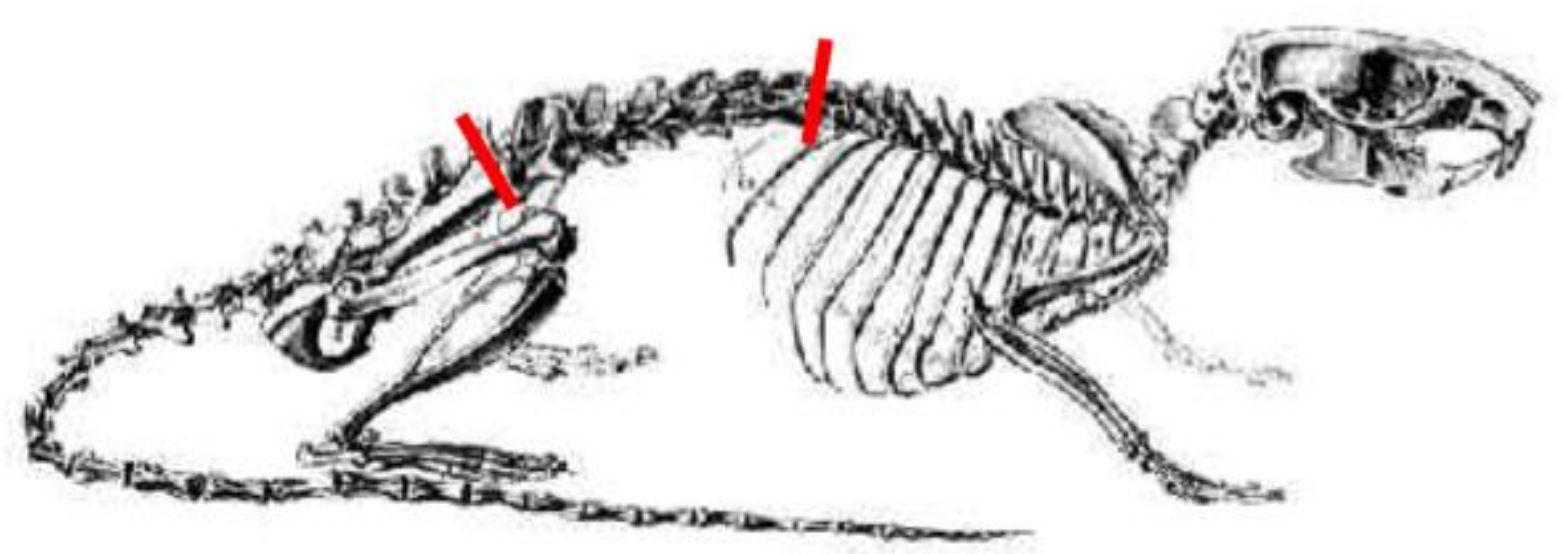

Abbildung 1: Anatomie der Ratte, modifiziert nach Hebel und Stromberg 1986, S. 10

\subsection{Mikroradiographie}

\subsubsection{Histologische Aufarbeitung und Erstellen der Mikroradiographien}

Die LWK I der Versuchstiere wurden nach der Präparation zunächst in einer aufsteigenden Alkoholreihe entwässert und entfettet, das heißt sie lagerten zweimal drei Tage in 40prozentigem, zweimal fünf bis sechs Tage in 70prozentigem, fünf bis sechs Tage in 80prozentigem und zwei Tage in 96prozentigem Ethanol. Es folgten weitere zwei Tagen in einem 1:1 Gemisch aus 96prozentigem Ethanol und Methylmethacrylat und zwei Tage in reinem Methylmethacrylat. Danach wurden sie einzeln in einem Gemisch aus insgesamt 1000 ml Methylmethacrylat, $200 \mathrm{ml}$ Dibutylphtalat und $29 \mathrm{~g}$ Benzoylperoxid eingebettet, bis die Kunststoffblöcke nach etwa 21 Tagen ausgehärtet waren.

Mit einer speziellen Innenlochsäge (Leica SP 1600 Diamantsäge, Leica Instruments GmbH, Nussloch) wurden im Anschluss pro Wirbelkörper neun bis zehn $100 \mu \mathrm{m}$ (+/- $20 \mu \mathrm{m})$ dünne Sagittalschnitte angefertigt. Diese wurden im Faxitron Röntgengerät (Hewlett Packard, San Diego, USA, Model-Nummer 43855A) auf langsamem Industriefilm (Kodak SR Typ 45) geröntgt. Die Röhrenspannung betrug bei einer Belichtungszeit von sechs Minuten $40 \mathrm{kV}$, die Stromstärke 0,3 mA. Nach Fixierung der Filme wurden diese getrocknet, beschriftet und archiviert. 


\subsubsection{Digitalisieren der Mikroradiographien}

Von den angefertigten Sägeschnitten wurden jeweils die drei zentralen unter dem Makroskop (Leica Stereomakroskop MZ 7-5) analysiert. Durch vorangegangene Versuche konnten die verschiedenen Belichtungsoptionen der Lichtquelle des Makroskopes (Kaltlichtquelle Leica KL 1500 LCD) für die vorliegenden Mikroradiographien optimal gewählt werden. So wurde für die mechanische Blende konstant die Schalterposition „B“ gewählt, das entsprach einer mäßigen Helligkeit (A: geringste Helligkeit, E: maximale Helligkeit). Da jedoch die Schnittdicke aus technischen Gründen zwischen 80 und $120 \mu \mathrm{m}$ schwankte, variierte folglich trotz identischer Einstellung auch die Helligkeit bei Betrachtung der Bilder. Dem konnte durch Modifikation der Temperatur der Halogenlampe entgegengewirkt werden, wobei die Temperatur jedoch immer zwischen 2800 und $3000 \mathrm{~K}$ lag.

Die Bilder wurden einzeln unter dem Makroskop positioniert, so dass die dorsalen Anteile des LWK unten, die ventralen oben, die kranialen links und die kaudalen rechts abgebildet wurden. Im Anschluss wurden sie über eine mit dem Computer (Intel Pentium 4, 2,6 GHz) verbundene Kamera (Leica DC 300F) eingelesen. Dabei wurde aus Gründen der Standardisierung stets das 1,0er Objektiv verwendet, welches die importierten Bilder in optimaler Größe auf dem Monitor abbildete, und die Belichtungszeit konstant auf $766 \mathrm{~ms}$ eingestellt. Der digitalisierte Sagittalschnitt konnte dann mit der dazugehörigen Software (Leica Quantimet QWin 2003) bearbeitet und nach einem standardisierten Algorithmus ausgewertet werden (Sehmisch et al. 2009b).

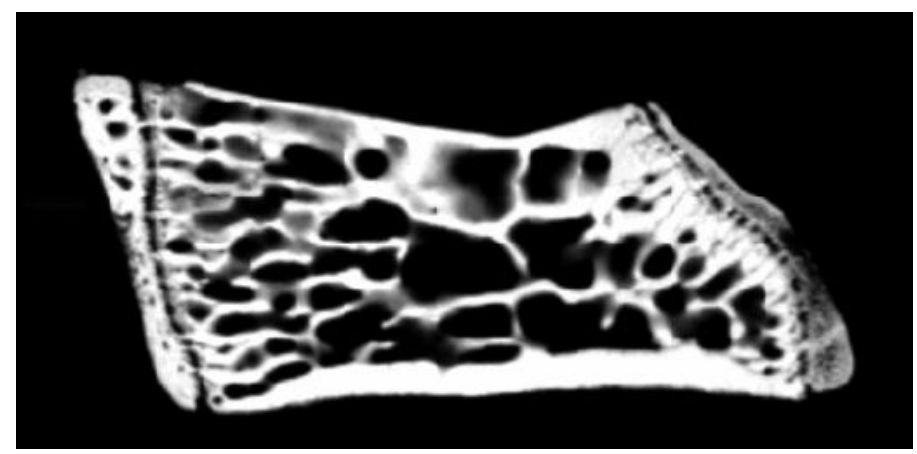

Abbildung 2: Digitalisierte Mikroradiographie

\subsubsection{Histomorphometrische Auswertung der Mikroradiographien}

Um eine standardisierte sowie benutzerunabhängige digitale Auswertung zu gewährleisten, wurde ein Programm spezifisch für die Sagittalschnitte der Wirbelkörper der Ratte konzipiert. Die Analyse wurde als Blind-Versuch durchgeführt, das heißt der Untersucher hatte keine 
Kenntnis davon, zu welcher Gruppe der zu untersuchende Wirbelkörperschnitt gehörte. Die folgenden Untersuchungsschritte wurden für die drei zentralen Sagittalschnitte eines jeden Wirbelkörpers in stets dieser Reihenfolge und stets durch denselben Untersucher durchgeführt: 1. Graudetektion, 2. Messung der Gesamtfläche des Wirbelkörpers, 3. Messung der Trabekelfläche, 4. Messung der ventralen und dorsalen Kortikalisdicke.

\subsubsection{Graudetektion}

Die verwendete Software färbte alle von ihr automatisch als Knochen erkannten Bereiche der Mikroradiographie blau an, da dabei jedoch nicht alle Anteile des Knochens als solcher erfasst wurden, war eine manuelle Korrektur durch den Untersucher notwendig. Diese erfolgte so lange, bis alle sichtbaren weißen bis grauen Bereiche (= Knochen) erfasst worden waren, im Zweifel wurde konsequent eher eine Überdetektion toleriert. Damit war der Software im zweiten Untersuchungsschritt die Unterscheidung von knöcherner zu nichtknöcherner Oberfläche möglich.

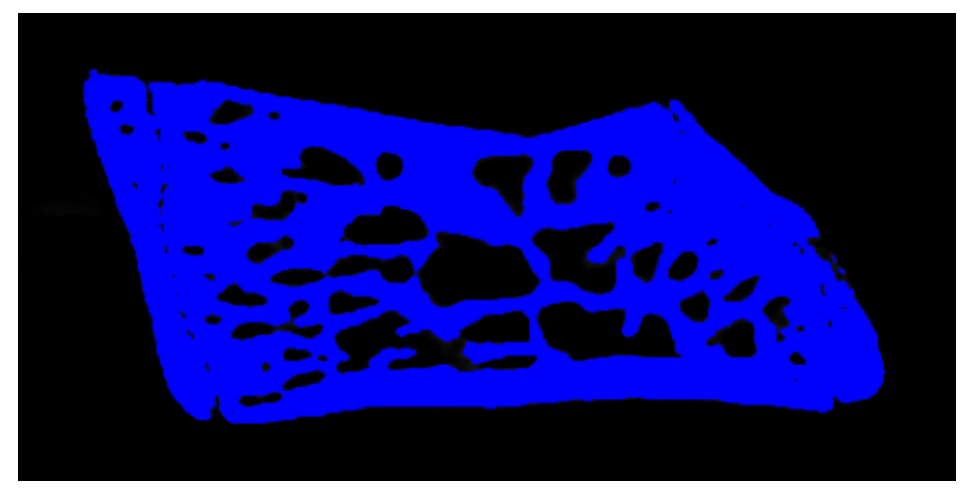

Abbildung 3: Graudetektion

\subsubsection{Messung der Gesamtfläche des Wirbelkörpers}

Im nächsten Schritt wurde die Gesamtfläche des Wirbelkörpers bestimmt, ohne anhängende Strukturen wie zum Beispiel die Dornfortsätze zu berücksichtigen. Um die Fläche des Wirbelkörpers zu erfassen, wurde entlang des äußeren Randes der Kortikalis manuell eine Linie gezogen, wobei ein Pixel einer Länge von 6,73 $\mu \mathrm{m}$ entsprach. Die Epiphysen an den kaudalen und kranialen Enden wurden nicht in die Gesamtfläche der LWK mit einbezogen. Innerhalb dieser Linie konnte die Software sowohl die Gesamtfläche des Wirbelkörpers, als auch die reine Knochenfläche berechnen. 


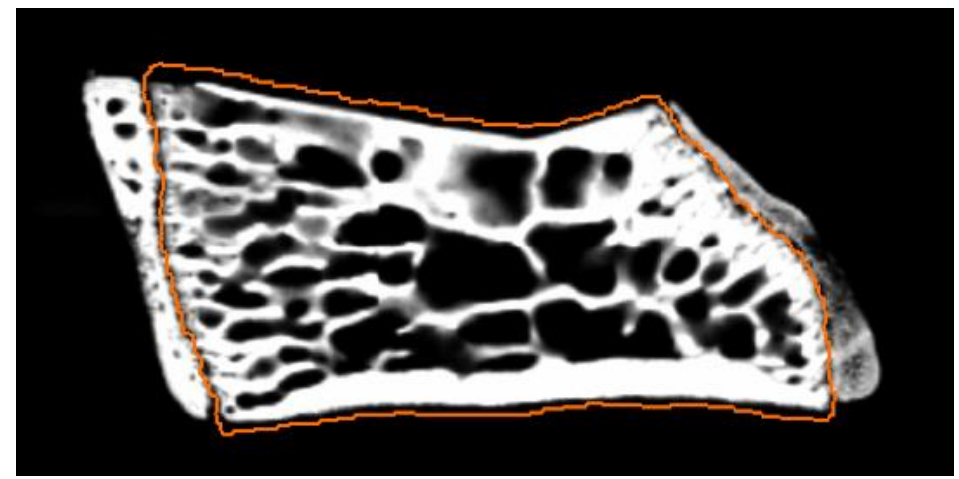

Abbildung 4: Gesamtfläche

\subsubsection{Messung der endostalen Gesamtfläche}

Für die Differenzierung zwischen trabekulärer und kortikaler Gesamtfläche wurde manuell eine weitere Linie gezogen, dieses Mal entlang des Endosts an der inneren Kortikalis. Als kraniale und kaudale Begrenzung dienten die Epiphysenfugen, die innerhalb des Endosts liegenden Bereiche wurden der trabekulären Fläche zugerechnet, der Bereich zwischen den beiden eingezeichneten Linien wurde als Kortikalis bestimmt.

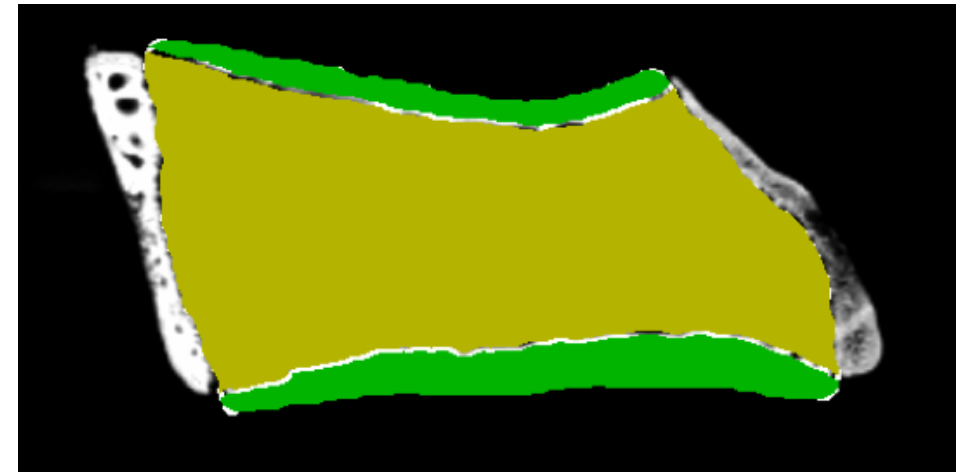

Abbildung 5: Endostale Gesamtfläche

\subsubsection{Messung der ventralen und dorsalen Kortikalisdicke}

Um die Dicke der Kortikalis zu bestimmen wurden ventral und dorsal jeweils zehn Vektoren manuell über der Kortikalis platziert. Die Vektoren waren möglichst senkrecht zur Kortikalis und überragten diese mit beiden Enden. Basierend auf den im vorangegangen Arbeitsschritt gewonnenen Informationen über die Gesamtfläche der Kortikalis war die Software in der Lage, die überragenden Vektorenden so zu beschneiden, dass sie exakt mit der Grenze der Kortikalis, dem Periost außen und dem Endost innen, endeten. Dies konnte im Anschluss durch den Untersucher visuell überprüft und gegebenenfalls korrigiert werden. Die mittlere 
Kortikalisdicke ventral und dorsal ergab sich jeweils aus dem arithmetischen Mittel der Länge der zehn gekürzten Vektoren.

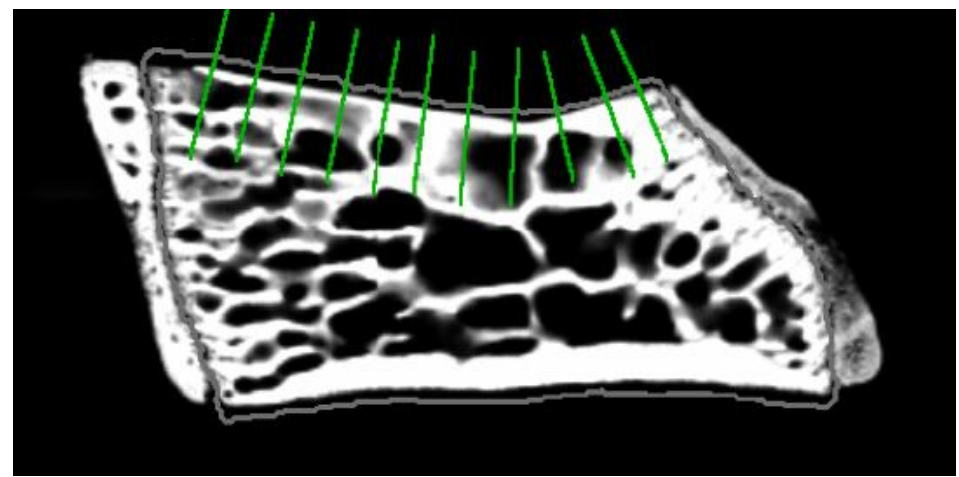

Abbildung 6: Ventrale Kortikalisdicke

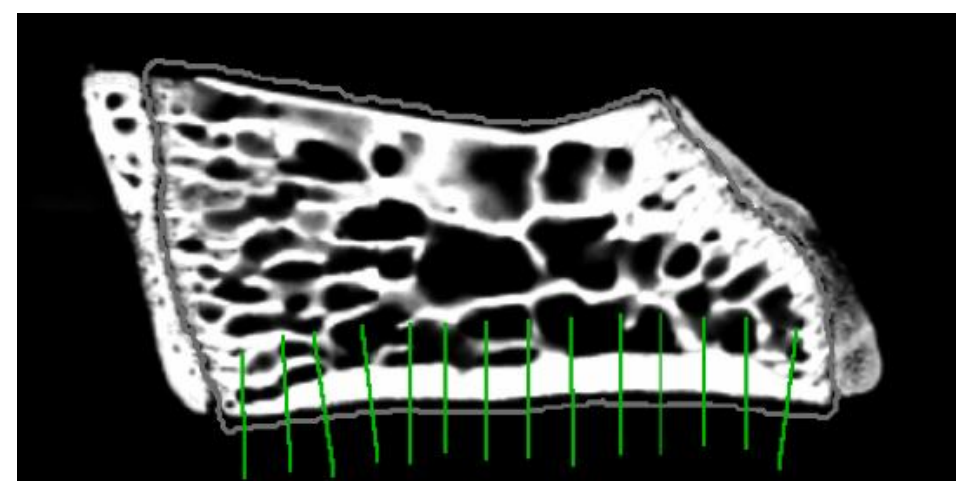

Abbildung 7: Dorsale Kortikalisdicke

\subsubsection{Messparameter der Mikroradiographie}

Die mittels der Mikroradiographie erfassten Kenngrößen werden in der folgenden Auflistung zusammenfassend erläutert:

Gesamtfläche Wirbelkörper

Gesamtfläche des Wirbelkörpers, bestehend aus kortikaler und trabekulärer Fläche sowie nichtknöchernen Anteilen ohne Processus spinosus, $\left(\mathrm{mm}^{2}\right)$

Knöcherne Gesamtfläche

kalzifizierte, knöcherne Gesamtfläche des Wirbelkörpers, $\left(\mathrm{mm}^{2}\right)$ 
Endostale Gesamtfläche

Trabekuläre Knochenfläche

Kortikale Knochenfläche

Ventrale Kortikalisdicke

Dorsale Kortikalisdicke

Dichte Trabekelkreuzungen

Trabekelkreuzungen absolut

Durchschnittliche Trabekeldicke
Gesamtfläche innerhalb des Endosts, beinhaltet knöcherne sowie nicht-knöcherne Anteile, $\left(\mathrm{mm}^{2}\right)$

Endostale Gesamtfläche abzüglich der nichtknöchernen Anteile, $\left(\mathrm{mm}^{2}\right)$

Knöcherne Gesamtfläche der Kortikalis, $\left(\mathrm{mm}^{2}\right)$ arithmetisches Mittel der zehn Vektoren durch die ventrale Kortikalis ist die durchschnittliche Dicke der ventralen Kortikalis, (mm)

arithmetisches Mittel der zehn Vektoren durch die dorsale Kortikalis ist die durchschnittliche Dicke der dorsalen Kortikalis, (mm)

mittlere Anzahl der Trabekelkreuzungen pro $\mathrm{mm}^{2}$, gemessen innerhalb der trabekulären Knochenfläche, (pro $\mathrm{mm}^{2}$ )

Anzahl der Trabekelkreuzungen innerhalb der trabekulären Knochenfläche

mittlere Dicke aller Trabekel eines Sagittalschnittes, $(\mu \mathrm{m})$

\subsubsection{Validierung des Untersuchers der Mikroradiographien}

Um sicherzustellen, dass der Untersucher die Messungen jeweils auf die gleiche Weise durchführte, wurde seine individuelle Messgenauigkeit vor Beginn der eigentlichen Auswertung evaluiert. $\mathrm{Zu}$ diesem Zweck bestimmte er alle Messparameter an zwei Sagittalschnitten von drei beliebigen LWK an drei aufeinander folgenden Tagen. Die Schwankungsbreite durfte dabei für keinen der gemessenen Parameter 5\% überschreiten. 


\subsection{Veraschung}

\subsubsection{Volumen der Wirbelkörper}

Bevor der Anteil organischer und anorganischer Knochensubstanz durch Veraschung der Knochenproben bestimmt wurde, wurden die präparierten LWK II mit einer Schieblehre manuell vermessen. Aus Höhe und Durchmesser der Wirbelkörper wurde deren Volumen errechnet, um die Ergebnisse aus dieser Untersuchung und den biomechanischen Kompressionstest in Relation zum Volumen betrachten zu können $\left(\mathrm{V}=\pi \mathrm{hr}^{2}\right)$. Somit wurde der Einfluss des Volumens auf diese Untersuchungen rechnerisch eliminiert.

\subsubsection{Bestimmung des Anteils organischer und anorganischer Knochensubstanz}

Um den Anteil organischer und anorganischer Knochensubstanz im LWK II der Ratte zu bestimmen, wurde durch Veraschung der Knochenproben ein Glührückstand erzeugt. $\mathrm{Zu}$ diesem Zweck wurde zunächst ein feuerfester Porzellantiegel gewogen und sein Leergewicht als Tara bestimmt. Dann wurde jeweils ein LWK in den Tiegel gelegt und die Gesamtmasse erneut analytisch gewogen. Diese Gesamtmasse m abzüglich der Tara entspricht der Masse des LWK vor der Veraschung. Anschließend wurde der LWK in dem Porzellantiegel über 30 Minuten in einem Muffelofen einer Temperatur von $750^{\circ} \mathrm{C}$ ausgesetzt und danach zum Auskühlen in einen Exsikkator über Kieselgel gestellt, um das Entstehen von Kondensationsfeuchtigkeit zu verhindern. Nach Abkühlen bis auf Raumtemperatur wurde durch erneutes analytisches Wiegen die Gesamtmasse bestimmt und durch Subtraktion der Tara die Masse der Knochenprobe nach Veraschung errechnet.

Der prozentuale Anteil organischer Substanz an der Knochenmasse errechnet sich nach folgender Formel:

$$
\% \text { organische Substanz }=\left(\left(\mathrm{m}_{\text {vor Veraschung }}-\mathrm{m}_{\text {nach Veraschung }}\right) * 100\right) / \mathrm{m}_{\text {vor Veraschung }}
$$

Die Formel für die Berechnung der Anteile anorganischer Substanz lautet:

$$
\% \text { anorganische Substanz }=100-\% \text { organische Substanz }
$$

\subsubsection{Bestimmung des Calcium- und Phosphatgehalts der Knochensubstanz}

Für die Bestimmung des Calcium- bzw. Phosphatgehalts der Knochenproben wird zunächst ein Säureaufschluss des Glührückstandes mittels zehnprozentiger Salpetersäure durchgeführt. 
Für den Säureaufschluss wird der Glührückstand zunächst mit einem Mörser homogenisiert und $50 \mathrm{mg}$ der Gesamtmasse analytisch abgewogen. Diese Masse wird mit $200 \mathrm{ml}$ zehnprozentiger Salpetersäure versetzt und die Lösung anschließend, mit einem Rückflusskühler versehen, in einem Rundkolben eine halbe Stunde auf Siedetemperatur erhitzt. Es muss eine klare Lösung entstehen, welche dann in einen Messkolben überführt und auf $1000 \mathrm{ml}$ aufgefüllt wird.

Vor der Bestimmung wird die Lösung im Verhältnis 1:20 verdünnt, um eine Konzentration zu erhalten, welche im Vertrauensbereich des Messverfahrens liegt. Aufgrund eines technischen Fehlers besteht die SHAM-Gruppe mit den gesunden Kontrolltieren bei der Bestimmung des Calcium und Phosphatgehalts aus fünf statt 15 Tieren.

\subsubsection{Bestimmung des Phosphatgehalts}

Die Bestimmung des Phosphatgehalts erfolgt durch Photometrie des Phosphat-MolybdänblauKomplexes (DIN EN ISO 6878:2004).

Das Reaktionsgemisch (Phosphatreagenz) besteht aus $25 \mathrm{ml}$ Schwefelsäure, 7,5 ml Ammoniummolybdat-Lösung, $\quad 15 \mathrm{ml}$ Ascorbinsäure-Lösung und 2,5 $\mathrm{ml}$ Kaliumantimonoxidtartrat. Es werden $10 \mathrm{ml}$ der durch den Säureaufschluss entstandenen Flüssigkeit in einem Messkolben mit $2 \mathrm{ml}$ Phosphatreagenz versetzt. Nach zehn Minuten Reaktionszeit wird die Extinktion in einer Küvette der Schichtdicke $10 \mathrm{~mm}$ photometrisch bestimmt und mit der einer Blindprobe mit aqua destillata verglichen. Die Messwellenlänge beträgt $690 \mathrm{~nm}$. Durch Messung der Extinktion einer Verdünnungsreihe im Konzentrationsintervall 0,1 bis $1,5 \mathrm{mg} / \mathrm{l}$ einer Phosphat-Standardlösung wird eine Abgleichgerade erzeugt.

\subsubsection{Bestimmung des Calciumgehalts}

Der Calciumgehalt der Knochenproben wird mittels Atomabsorptionsspektroskopie (AAS) (DIN EN ISO 7980:2000) bestimmt. Nach Zugabe von Lanthanchlorid als Matrix-Modifier zur Maskierung des Phosphats werden $5 \mathrm{ml}$ der $\mathrm{zu}$ analysierenden Lösung in das Autosampler-Rack des AAS-Geräts (FIAS 4100, Perkin-Elmer, Rodgau, Deutschland) pipettiert. Die gelöste Probe wird kontinuierlich durch einen Zerstäuber in die Flamme des AAS, bestehend aus einem Acetylen-Luft-Gemisch, gebracht und darin atomisiert. Durch die Flamme wird eine monochromatische Strahlung geschickt, die von einer Hohlkathodenlampe emittiert wird. Die Kathode der Lampe besteht aus dem jeweils zu analysierenden Element bzw. muss für die Bestimmung des jeweiligen Elements geeignet sein. Die Extinktion der 
durch Calcium verursachten Färbung der Flamme wird an der Calcium-Emissionsbande von $422,8 \mathrm{~nm}$ bestimmt und mit einer Verdünnungsreihe kalibriert.

\subsection{Biomechanischer Kompressionstest}

\subsubsection{Durchführung des biomechanischen Kompressionstests}

Um die mechanische Stabilität der Wirbelkörper zu untersuchen, wurden die LWK IV der Versuchstiere in toto einem standardisierten axialen Kompressionstest unterzogen (Sehmisch et al. 2009b). Zu diesem Zweck wurden die LWK auf einer Aluminium-Basis locker fixiert, welche der Anatomie der LWK angepasst war und somit zwar das Verrutschen während der Krafteinwirkung verhinderte, dem Wirbelkörper jedoch keine zusätzliche Widerstandskraft verlieh. Diese Basis wurde fest in dem Kompressionsgerät (Typ 145660 Z020/TND Zwick/Roell, Ulm, Deutschland) verschraubt. Der Druck auf die Grundplatte des LWK IV wurde durch einen Stempel ausgeübt, dessen Fläche mit einer Schräge von $45^{\circ}$ ebenfalls der Anatomie des Wirbelkörpers gerecht wurde. Vor Durchführung des Kompressionsversuchs wurden alle Wirbelkörper gleichmäßig über drei Stunden bei Raumtemperatur aufgetaut.

Nach Positionierung des Wirbelkörpers wie beschrieben wurde der Kompressionstest mit der „testXpert“-Software gestartet. Der Stempel bewegte sich dann auf die Grundplatte des LWK $\mathrm{zu}$, bis er diese berührte und eine Vorkraft von $1 \mathrm{~N}$ erreicht war. Dann blieb dem Prüfer Gelegenheit, die Positionierung nochmals zu überprüfen und gegebenenfalls zu optimieren. Durch Bestätigung der korrekten Position wird der eigentliche Kompressionstest endgültig gestartet. Die Zwick-Testmaschine senkte dann mit einer Geschwindigkeit von $50 \mathrm{~mm} / \mathrm{min}$ den Stempel weiter herab und komprimierte den Wirbelkörper in axialer Richtung. Die Software speicherte automatisch die Kraft, die für jeden 0,1 mm Weg aufgewendet werden musste, der Messbereich des Kraftaufwandes reichte dabei von 2-500 N bei einer relativen Genauigkeit von 0,2-0,4 \%. Nachdem der Wirbelkörper entweder um 3 mm komprimiert worden oder die Kraftgrenze von $500 \mathrm{~N}$ erreicht war, endete der Test automatisch. 

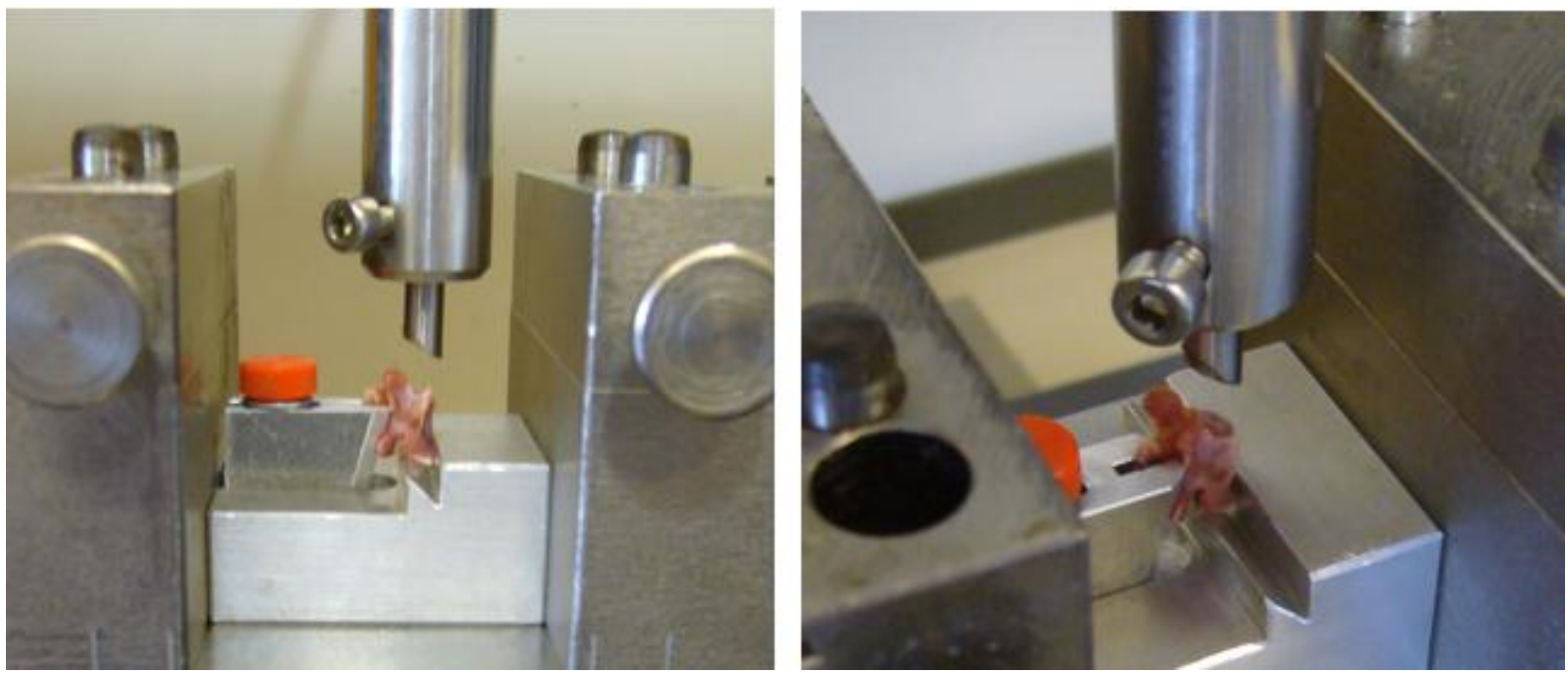

Abbildung 8: LWK in der Zwick-Testmaschine

\subsubsection{Messparameter des biomechanischen Kompressionstests}

\subsubsection{Maximalkraft}

Die Maximalkraft $\left(\mathrm{F}_{\max }\right)$ ist der höchste Kraftwert, der während des Kompressionsversuchs erreicht werden konnte, bevor es zu einem Einbruch der Grundplatte in den spongiösen Wirbelkörper kommt.

\subsubsection{Streckgrenze}

Im Kraft-Weg-Diagramm des Kompressionsversuchs bezeichnet die Streckgrenze den Punkt des Graphen, ab dem die Steigung nicht mehr linear ist, sie entspricht dem Übergang von der elastischen zur plastischen Verformung des Wirbelkörpers (siehe Abbildung 9: Kraft-WegDiagramm des biomechanischen Kompressionstests, der rote Pfeil markiert die Streckgrenze). Um die Streckgrenze zu bestimmen, wurden aus den Werten des linear ansteigenden Beginns des Graphen die Regressionsgerade und deren Standardabweichung berechnet. Der Punkt, an welchem der Graph den Bereich der doppelten Standardabweichung der Regressionsgerade verlässt, ist definiert als die Streckgrenze (Stuermer et al. 2006). 


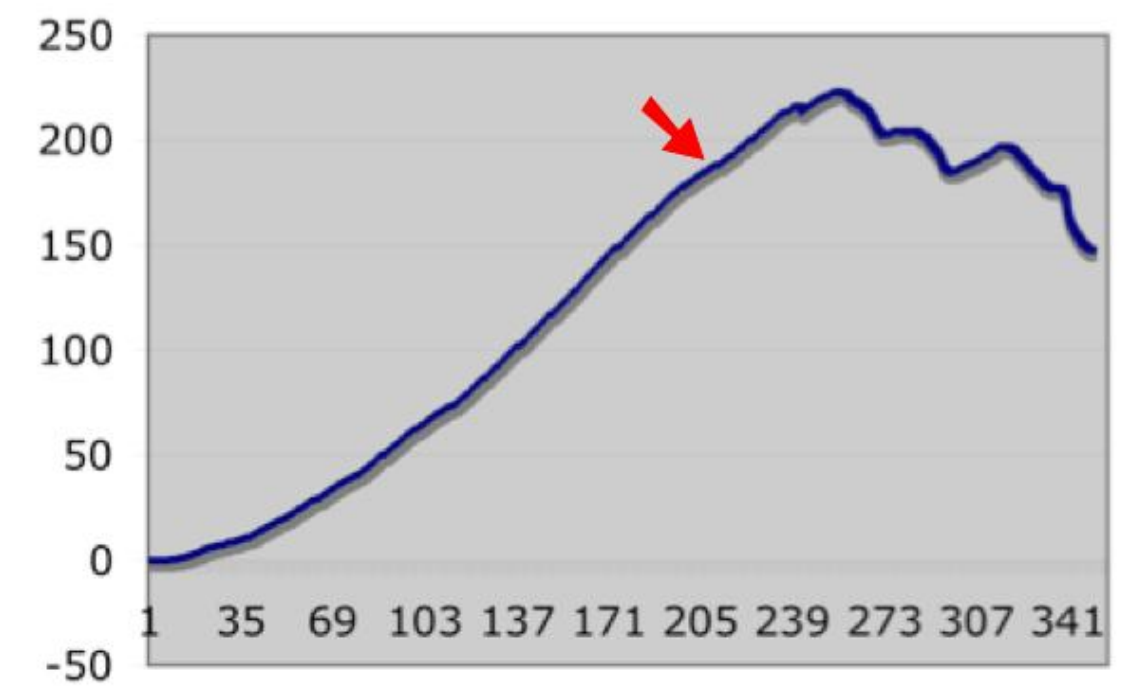

Abbildung 9: Kraft-Weg-Diagramm des biomechanischen Kompressionstests

\subsubsection{Steigung}

Dieser Parameter entspricht der linearen Steigung des Graphen im Kraft-Weg-Diagramm während der elastischen Verformung des Wirbelkörpers $\mathrm{zu}$ Beginn des Kompressionsversuchs. Sie entspricht der Elastizität des Wirbelkörpers.

\subsubsection{Validierung des Untersuchers des biomechanischen Kompressionstests}

Um sicherzustellen, dass der Untersucher keinen Einfluss auf den biomechanischen Kompressionstest hat, wurde dessen Reliabilität zuvor evaluiert. Zu diesem Zweck führte der Untersucher einen Kompressionstest an den LWK IV und V von zehn Ratten, welche in Größe und Gewicht den eigentlichen Versuchstieren glichen, durch. Es wurden diese beiden benachbarten Wirbelkörper gewählt, da der sonst übliche intraindividuelle Rechts-LinksVergleich bei der Wirbelsäule nicht möglich ist. Wie bei der eigentlichen Untersuchung wurden die drei Parameter Steigung, Maximalkraft und Streckgrenze bestimmt und deren intraindividuelle Abweichungen errechnet. Abweichungen von 15\% (+/- 3\%) zwischen LWK IV und LWK V eines Tieres wurden entsprechend eines Rechts-Links-Vergleiches als physiologisch betrachtet (Budsberg et al. 1993; Fisk und Baigent 1975). 


\subsection{Statistik}

Die statistischen Auswertungen sowie die graphischen Darstellungen der Ergebnisse wurden mit der Software GraphPad Prism (Version 4.00a, April 2003, GraphPad Software Inc., San Diego, USA) durchgeführt.

Die bei den Versuchen gewonnenen Daten wurden zunächst mittels einer one-way ANOVA auf signifikante Unterschiede zwischen den einzelnen Gruppen untersucht, im Anschluss diente ein Tukey-Kramer post-hoc Test zur genauen Identifizierung dieser. Als Signifikanzniveau wurde der $\mathrm{p}$-Wert $\alpha \leq 0,05$ gewählt.

Um Zusammenhänge zwischen den in der Mikroradiographie erfassten morphologischen Eigenschaften mit der, im biomechanischen Kompressionstest bestimmten, mechanischen Stabilität der Lendenwirbelkörper zu detektieren, wurde mit den gewonnenen Daten eine Pearson-Korrelation durchgeführt. Der Korrelationskoeffizient Pearson $r$ ist ein dimensionsloses Maß für den Grad eines linearen Zusammenhangs. Er kann sowohl positiv, als auch negativ sein, maximal +1 und minimal -1 . Bei Werten $\geq 0,4$ oder $\leq-0,4$ ist von einem starken Zusammenhang auszugehen.

Das Quadrat des Korrelationskoeffizienten, das Bestimmtheitsmaß $\mathrm{r}^{2}$, beschreibt den prozentualen Anteil der angenommenen Beeinflussung einer Variablen durch die Andere. 


\section{Ergebnisse}

\subsection{Gewicht der Tiere und Knochenvolumen}

\subsubsection{Gewicht und Futteraufnahme der Tiere im Verlauf}

Im Folgenden werden das Gewicht der Tiere sowie deren durchschnittliche tägliche Futteraufnahme graphisch und tabellarisch dargestellt. Die Tabellen beinhalten jeweils das durchschnittliche Gewicht der Tiere in einer Gruppe \pm Standardabweichung. Das Gewicht der Tiere wurde jeweils zu Beginn einer Versuchswoche erfasst, wohingegen das verbrauchte Futter am Ende einer Woche berechnet wurde. Nach der achten Woche fand die Osteotomie der Tibiae statt.

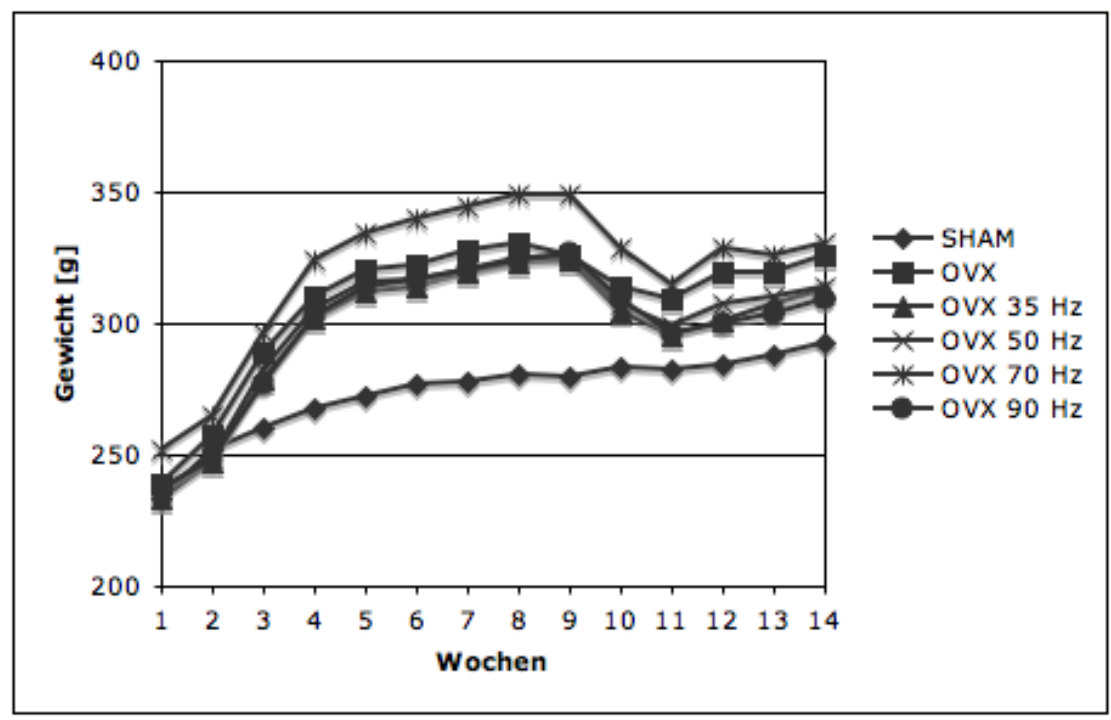

Abbildung 10: Gewicht der Tiere im Verlauf 
Tabelle 4: Gewicht der Tiere im Verlauf

\begin{tabular}{|c|c|c|c|c|c|c|}
\hline Woche & SHAM & OVX & $\begin{array}{l}\text { OVX } \\
35 \mathrm{~Hz}\end{array}$ & $\begin{array}{c}\text { OVX } \\
50 ~ H z\end{array}$ & $\begin{array}{c}\text { OVX } \\
70 \mathrm{~Hz}\end{array}$ & $\begin{array}{c}\text { OVX } \\
90 \mathrm{~Hz}\end{array}$ \\
\hline 1 & $\begin{array}{r}232,667 \\
\pm 17,09\end{array}$ & $\begin{array}{r}239,133 \\
\pm 12,64\end{array}$ & $\begin{array}{r}232,733 \\
\pm 15,83\end{array}$ & $\begin{array}{c}235,500 \\
\pm 7,86\end{array}$ & $\begin{array}{r}252,143 \\
\pm 13,35\end{array}$ & $\begin{array}{r}236,533 \\
\pm 7,78\end{array}$ \\
\hline 2 & $\begin{array}{r}252,333 \\
\pm 16,38\end{array}$ & $\begin{array}{r}256,733 \\
\pm 14,08\end{array}$ & $\begin{array}{l}247,333 \\
\pm 20,51\end{array}$ & $\begin{array}{l}248,643 \\
\pm 10,40\end{array}$ & $\begin{array}{r}265,286 \\
\pm 12,79\end{array}$ & $\begin{array}{r}248,333 \\
\pm 9,04\end{array}$ \\
\hline 3 & $\begin{array}{r}260,466 \\
\pm 16,86\end{array}$ & $\begin{array}{r}289,067 \\
\pm 13,10\end{array}$ & $\begin{array}{r}278,933 \\
\pm 18,23\end{array}$ & $\begin{array}{l}281,786 \\
\pm 12,01\end{array}$ & $\begin{array}{r}296,357 \\
\pm 13,70\end{array}$ & $\begin{array}{r}276,600 \\
\pm 11,26\end{array}$ \\
\hline 4 & $\begin{array}{r}268,400 \\
\pm 15,06\end{array}$ & $\begin{array}{r}310,467 \\
\pm 13,49\end{array}$ & $\begin{array}{l}302,000 \\
\pm 20,37\end{array}$ & $\begin{array}{l}306,143 \\
\pm 11,45\end{array}$ & $\begin{array}{r}324,071 \\
\pm 16,72\end{array}$ & $\begin{array}{r}302,800 \\
\pm 12,69\end{array}$ \\
\hline 5 & $\begin{array}{r}272,266 \\
\pm 16,32\end{array}$ & $\begin{array}{r}319,733 \\
\pm 12,94\end{array}$ & $\begin{array}{l}312,333 \\
\pm 23,26\end{array}$ & $\begin{array}{l}315,714 \\
\pm 11,53\end{array}$ & $\begin{array}{r}334,214 \\
\pm 18,14\end{array}$ & $\begin{array}{l}313,867 \\
\pm 12,02\end{array}$ \\
\hline 6 & $\begin{array}{r}277,466 \\
\pm 13,51\end{array}$ & $\begin{array}{r}322,400 \\
\pm 14,55\end{array}$ & $\begin{array}{l}314,333 \\
\pm 23,32\end{array}$ & $\begin{array}{l}317,429 \\
\pm 11,91\end{array}$ & $\begin{array}{l}340,071 \\
\pm 18,65\end{array}$ & $\begin{array}{l}316,600 \\
\pm 13,13\end{array}$ \\
\hline 7 & $\begin{array}{r}278,333 \\
\pm 14,33\end{array}$ & $\begin{array}{r}328,267 \\
\pm 15,06\end{array}$ & $\begin{array}{l}319,467 \\
\pm 24,06\end{array}$ & $\begin{array}{l}319,929 \\
\pm 11,96\end{array}$ & $\begin{array}{l}344,286 \\
\pm 20,66\end{array}$ & $\begin{array}{r}320,333 \\
\pm 13,99\end{array}$ \\
\hline 8 & $\begin{array}{r}281,067 \\
\pm 13,67\end{array}$ & $\begin{array}{r}330,600 \\
\pm 13,99\end{array}$ & $\begin{array}{l}323,467 \\
\pm 25,16\end{array}$ & $\begin{array}{r}324,571 \\
\pm 12,86\end{array}$ & $\begin{array}{l}349,214 \\
\pm 20,99\end{array}$ & $\begin{array}{l}324,267 \\
\pm 15,12\end{array}$ \\
\hline 9 & $\begin{array}{r}280,400 \\
\pm 17,02\end{array}$ & $\begin{array}{r}325,867 \\
\pm 28,65\end{array}$ & $\begin{array}{l}324,333 \\
\pm 23,38\end{array}$ & $\begin{array}{r}324,929 \\
\pm 11,16\end{array}$ & $\begin{array}{l}349,286 \\
\pm 21,01\end{array}$ & $\begin{array}{r}326,800 \\
\pm 15,19\end{array}$ \\
\hline 10 & $\begin{array}{r}282,733 \\
\pm 17,56\end{array}$ & $\begin{array}{r}313,533 \\
\pm 16,27\end{array}$ & $\begin{array}{l}305,071 \\
\pm 27,25\end{array}$ & $\begin{array}{c}306,857 \\
\pm 12,22\end{array}$ & $\begin{array}{r}329,357 \\
\pm 19,76\end{array}$ & $\begin{array}{l}309,000 \\
\pm 12,21\end{array}$ \\
\hline 11 & $\begin{array}{r}282,400 \\
\pm 15,99\end{array}$ & $\begin{array}{r}308,733 \\
\pm 14,90\end{array}$ & $\begin{array}{r}294,929 \\
\pm 25,54\end{array}$ & $\begin{array}{l}298,786 \\
\pm 15,70\end{array}$ & $\begin{array}{l}314,571 \\
\pm 18,90\end{array}$ & $\begin{array}{l}296,200 \\
\pm 14,14\end{array}$ \\
\hline 12 & $\begin{array}{r}283,600 \\
\pm 16,78\end{array}$ & $\begin{array}{r}318,600 \\
\pm 17,36\end{array}$ & $\begin{array}{l}301,286 \\
\pm 26,62\end{array}$ & $\begin{array}{l}306,571 \\
\pm 15,57\end{array}$ & $\begin{array}{l}328,857 \\
\pm 22,34\end{array}$ & $\begin{array}{l}300,133 \\
\pm 15,10\end{array}$ \\
\hline 13 & $\begin{array}{r}288,200 \\
\pm 17,43\end{array}$ & $\begin{array}{r}319,467 \\
\pm 15,93\end{array}$ & $\begin{array}{l}307,214 \\
\pm 25,58\end{array}$ & $\begin{array}{l}310,143 \\
\pm 15,90\end{array}$ & $\begin{array}{l}325,500 \\
\pm 21,17\end{array}$ & $\begin{array}{l}304,133 \\
\pm 15,70\end{array}$ \\
\hline 14 & $\begin{array}{r}293,000 \\
\pm 18,13\end{array}$ & $\begin{array}{r}325,533 \\
\pm 18,83\end{array}$ & $\begin{array}{l}312,500 \\
\pm 26,01\end{array}$ & $\begin{array}{c}314,214 \\
\pm 14,78\end{array}$ & $\begin{array}{l}331,071 \\
\pm 20,45\end{array}$ & $\begin{array}{l}309,067 \\
\pm 16,25\end{array}$ \\
\hline
\end{tabular}




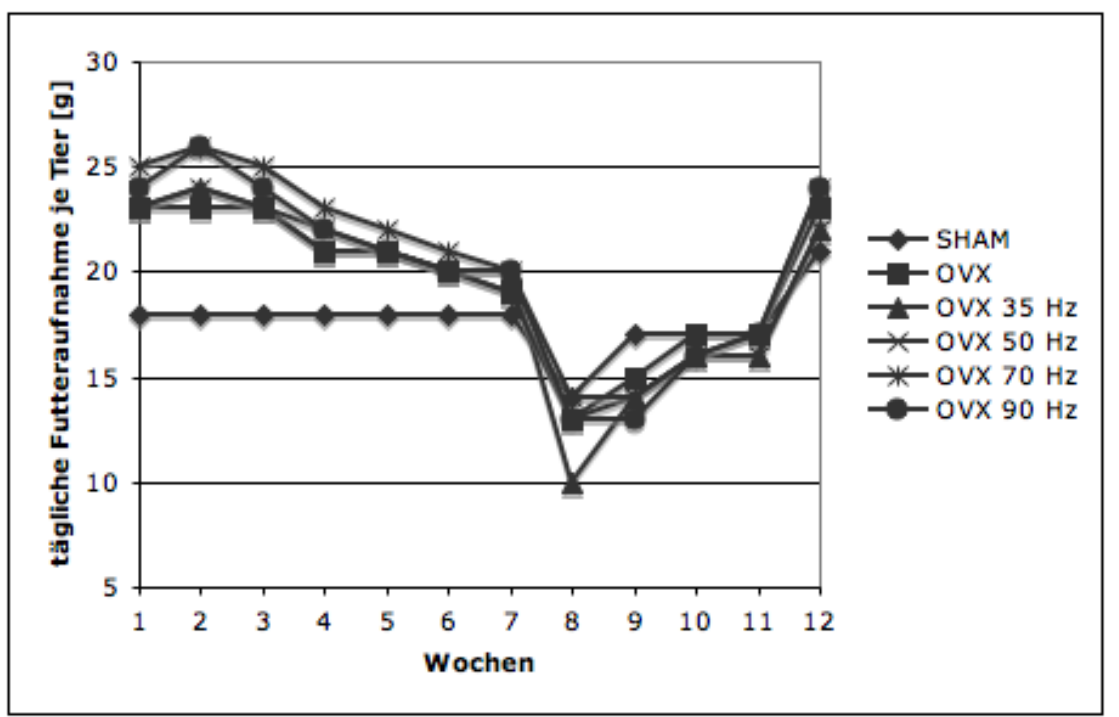

Abbildung 11: Futteraufnahme der Tiere im Verlauf 
Tabelle 5: Tägliche Futteraufnahme der Tiere im Verlauf

\begin{tabular}{|c|c|c|c|c|c|c|}
\hline Woche & SHAM & OVX & $\begin{array}{c}\text { OVX } \\
35 \mathrm{~Hz}\end{array}$ & $\begin{array}{c}\text { OVX } \\
50 ~ H z\end{array}$ & $\begin{array}{c}\text { OVX } \\
70 \mathrm{~Hz}\end{array}$ & $\begin{array}{c}\text { OVX } \\
90 \mathrm{~Hz}\end{array}$ \\
\hline 1 & $\begin{array}{l}18,333 \\
\pm 1,21\end{array}$ & $\begin{array}{r}22,667 \\
\pm 1,37 \\
\end{array}$ & $\begin{array}{l}22,581 \\
\pm 0,68 \\
\end{array}$ & $\begin{array}{r}23,302 \\
\pm 1,36 \\
\end{array}$ & $\begin{array}{l}24,621 \\
\pm 0,78\end{array}$ & $\begin{array}{r}24,343 \\
\pm 0,57\end{array}$ \\
\hline 2 & $\begin{array}{l}18,257 \\
\pm 0,52 \\
\end{array}$ & $\begin{array}{r}23,333 \\
\pm 0,92 \\
\end{array}$ & $\begin{array}{l}23,571 \\
\pm 0,76 \\
\end{array}$ & $\begin{array}{l}24,052 \\
\pm 0,74 \\
\end{array}$ & $\begin{array}{r}25,743 \\
\pm 0,73 \\
\end{array}$ & $\begin{array}{r}25,810 \\
\pm 0,39 \\
\end{array}$ \\
\hline 3 & $\begin{array}{l}18,457 \\
\pm 1,07\end{array}$ & $\begin{array}{l}22,571 \\
\pm 0,37\end{array}$ & $\begin{array}{r}22,543 \\
\pm 1,16\end{array}$ & $\begin{array}{r}23,276 \\
\pm 0,44\end{array}$ & $\begin{array}{l}24,779 \\
\pm 0,74\end{array}$ & $\begin{array}{l}24,114 \\
\pm 0,35\end{array}$ \\
\hline 4 & $\begin{array}{l}17,581 \\
\pm 0,58\end{array}$ & $\begin{array}{l}21,000 \\
\pm 0,83\end{array}$ & $\begin{array}{l}20,590 \\
\pm 1,16\end{array}$ & $\begin{array}{l}21,538 \\
\pm 0,25\end{array}$ & $\begin{array}{l}23,240 \\
\pm 0,58\end{array}$ & $\begin{array}{l}21,981 \\
\pm 0,57\end{array}$ \\
\hline 5 & $\begin{array}{l}17,905 \\
\pm 0,07\end{array}$ & $\begin{array}{r}20,962 \\
\pm 0,56\end{array}$ & $\begin{array}{l}20,552 \\
\pm 0,82\end{array}$ & $\begin{array}{l}20,740 \\
\pm 0,28\end{array}$ & $\begin{array}{l}22,400 \\
\pm 0,79\end{array}$ & $\begin{array}{r}21,200 \\
\pm 0,16\end{array}$ \\
\hline 6 & $\begin{array}{c}17,524 \\
\pm 0,93\end{array}$ & $\begin{array}{l}19,781 \\
\pm 0,77 \\
\end{array}$ & $\begin{array}{l}19,514 \\
\pm 0,72 \\
\end{array}$ & $\begin{array}{l}19,655 \\
\pm 0,27 \\
\end{array}$ & $\begin{array}{l}21,371 \\
\pm 0,89\end{array}$ & $\begin{array}{r}20,248 \\
\pm 0,28\end{array}$ \\
\hline 7 & $\begin{array}{l}17,790 \\
\pm 0,85\end{array}$ & $\begin{array}{l}19,229 \\
\pm 1,27\end{array}$ & $\begin{array}{l}20,119 \\
\pm 2,58\end{array}$ & $\begin{array}{l}18,729 \\
\pm 0,16\end{array}$ & $\begin{array}{l}20,162 \\
\pm 0,76\end{array}$ & $\begin{array}{l}19,724 \\
\pm 0,53\end{array}$ \\
\hline 8 & $\begin{array}{l}14,190 \\
\pm 1,58\end{array}$ & $\begin{array}{l}12,581 \\
\pm 1,41\end{array}$ & $\begin{array}{l}10,386 \\
\pm 4,09\end{array}$ & $\begin{array}{l}12,760 \\
\pm 0,79\end{array}$ & $\begin{array}{l}13,695 \\
\pm 0,74\end{array}$ & $\begin{array}{l}13,400 \\
\pm 1,37\end{array}$ \\
\hline 9 & $\begin{array}{l}17,286 \\
\pm 0,85\end{array}$ & $\begin{array}{l}14,895 \\
\pm 0,31\end{array}$ & $\begin{array}{l}13,536 \\
\pm 0,73\end{array}$ & $\begin{array}{l}14,483 \\
\pm 0,94\end{array}$ & $\begin{array}{l}14,193 \\
\pm 0,28\end{array}$ & $\begin{array}{l}13,467 \\
\pm 0,17\end{array}$ \\
\hline 10 & $\begin{array}{l}17,067 \\
\pm 0,61\end{array}$ & $\begin{array}{l}16,810 \\
\pm 0,18\end{array}$ & $\begin{array}{l}15,852 \\
\pm 0,56\end{array}$ & $\begin{array}{l}16,140 \\
\pm 0,59\end{array}$ & $\begin{array}{l}16,205 \\
\pm 0,55\end{array}$ & $\begin{array}{l}15,505 \\
\pm 0,68\end{array}$ \\
\hline 11 & $\begin{array}{r}17,048 \\
\pm 0,929 \\
\end{array}$ & $\begin{array}{l}16,886 \\
\pm 0,35 \\
\end{array}$ & $\begin{array}{l}16,238 \\
\pm 0,84 \\
\end{array}$ & $\begin{array}{l}16,419 \\
\pm 0,48 \\
\end{array}$ & $\begin{array}{l}17,081 \\
\pm 0,84\end{array}$ & $\begin{array}{l}16,724 \\
\pm 0,63\end{array}$ \\
\hline 12 & $\begin{array}{l}21,429 \\
\pm 3,20\end{array}$ & $\begin{array}{l}22,619 \\
\pm 4,32\end{array}$ & $\begin{array}{l}21,990 \\
\pm 3,17\end{array}$ & $\begin{array}{l}21,819 \\
\pm 4,48\end{array}$ & $\begin{array}{l}24,086 \\
\pm 3,44\end{array}$ & $\begin{array}{l}24,124 \\
\pm 3,48\end{array}$ \\
\hline
\end{tabular}




\subsubsection{Gewicht des Uterus}

Tabelle 6: Uterusgewicht

\begin{tabular}{|c|c|c|c|c|c|c|}
\hline & SHAM & OVX & $\begin{array}{c}\text { OVX } \\
\mathbf{3 5 ~ H z}\end{array}$ & $\begin{array}{c}\text { OVX } \\
\mathbf{5 0 ~ H z}\end{array}$ & $\begin{array}{c}\text { OVX } \\
\mathbf{7 0 ~ H z}\end{array}$ & $\begin{array}{c}\text { OVX } \\
\mathbf{9 0} \mathbf{~ H z}\end{array}$ \\
\hline $\begin{array}{c}\text { Uterusgewicht } \\
{[\mathrm{mg}]}\end{array}$ & 604,000 & 115,333 & 105,000 & 103,571 & 101,427 & 100,000 \\
\hline
\end{tabular}

Das durchschnittliche Uterusgewicht der SHAM-Tiere war am Tag der Tötung signifikant erhöht im Vergleich zu dem der ovariektomierten Tiere.

\subsubsection{Volumen der Wirbelkörper}

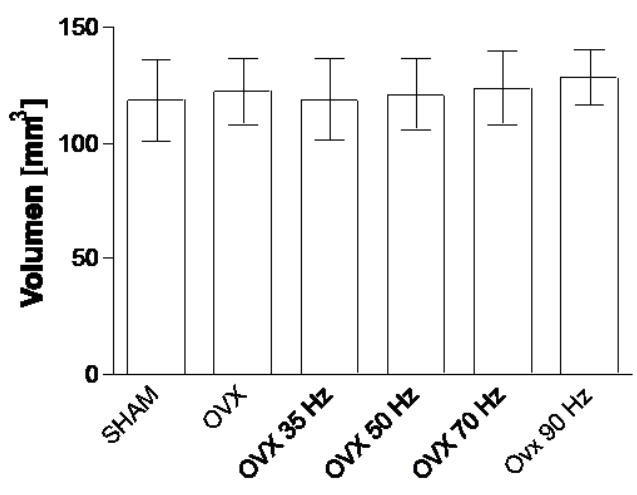

Abbildung 12: Wirbelkörpervolumen

Bezüglich des Wirbelkörpervolumens finden sich keine signifikanten Unterschiede zwischen den untersuchten Gruppen.

\subsection{Ergebnisse der Mikroradiographie}

Im Folgenden werden die Ergebnisse der einzelnen Messparameter der Mikroradiographien (s. 2.2.4) dargestellt. Dabei werden sowohl die absoluten, als auch die mit dem Wirbelkörpervolumen korrelierten Ergebnisse beschrieben. Es erfolgt zunächst die 
Darstellung der Ergebnisse in Säulendiagrammen, später die tabellarische Zusammenfassung der Mittelwerte und Standardabweichungen für alle untersuchten Parameter. Folgende Symbole dienen der Verdeutlichung von signifikanten Unterschieden in den Säulendiagrammen:

Signifikant gegenüber SHAM: *

Signifikant gegenüber OVX: \#

Signifikant gegenüber OVX $70 \mathrm{~Hz}$ : o

Signifikant gegenüber OVX $90 \mathrm{~Hz}$ ^ $^{\wedge}$

Für die mittels one-way ANOVA und Tukey-Kramer post-hoc Test ermittelten Unterschiede wurde ein $p \leq 0,05$ als Signifikanzniveau bestimmt.

\subsubsection{Kortikalisdicke ventral}

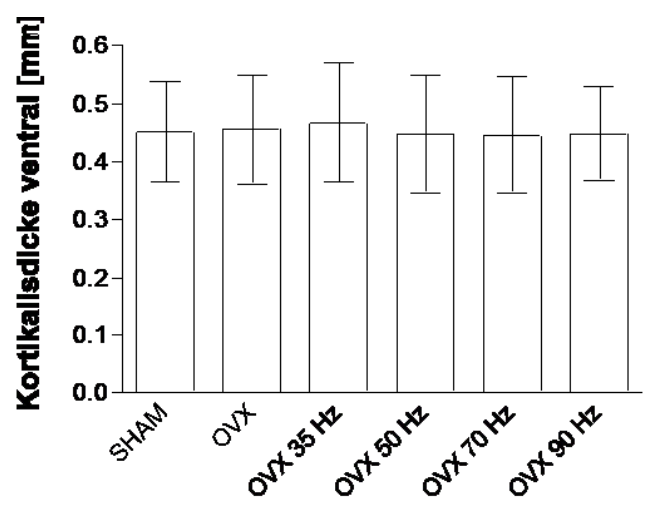

Abbildung 13: Kortikalisdicke ventral

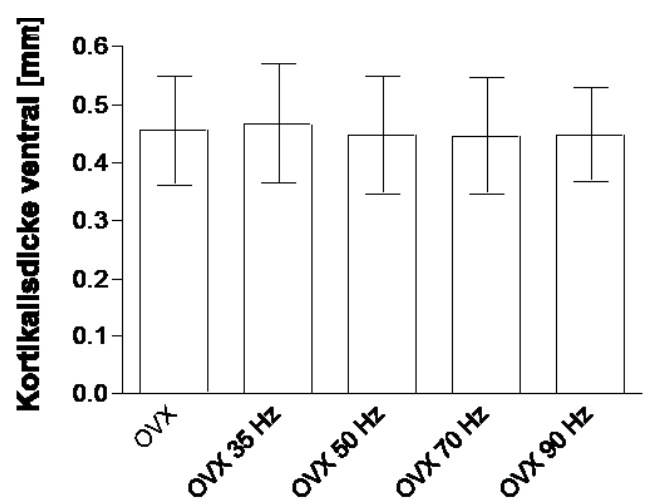

Abbildung 14: Kortikalisdicke ventral, ohne SHAM-Tiere 


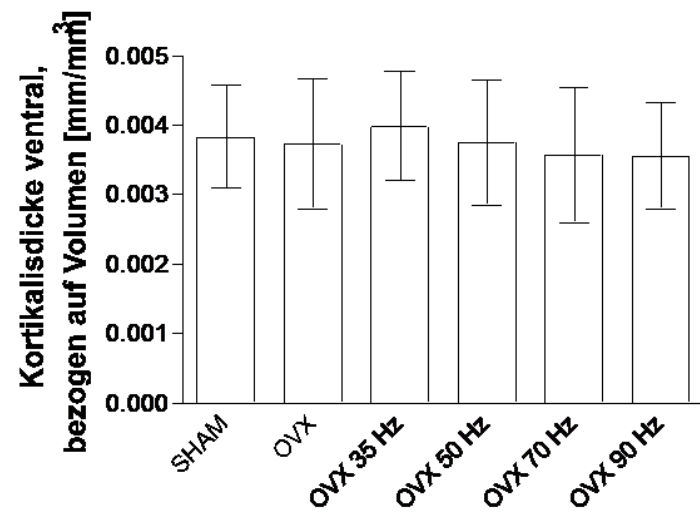

Abbildung 15: Kortikalisdicke ventral, bezogen auf das Wirbelkörpervolumen

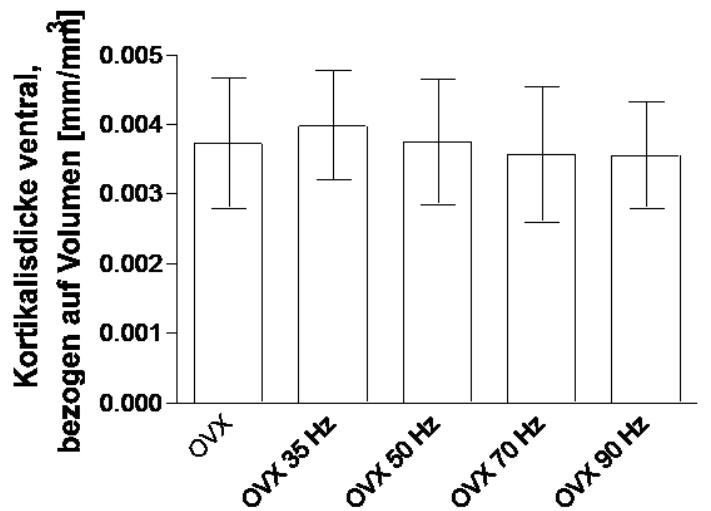

Abbildung 16: Kortikalisdicke ventral, ohne SHAM-Tiere,

bezogen auf das Wirbelkörpervolumen

Für die ventrale Kortikalisdicke fanden sich zwischen den untersuchten Gruppen keine signifikanten Unterschiede. Nach Bezug der Kortikalisdicke auf das Volumen der Wirbelkörper zeigt sich die Tendenz zu einer dickeren ventralen Kortikalis in den Gruppen SHAM und OVX $35 \mathrm{~Hz}$, die jedoch nicht signifikant ist (siehe Abbildungen 13-16). 


\subsubsection{Kortikalisdicke dorsal}

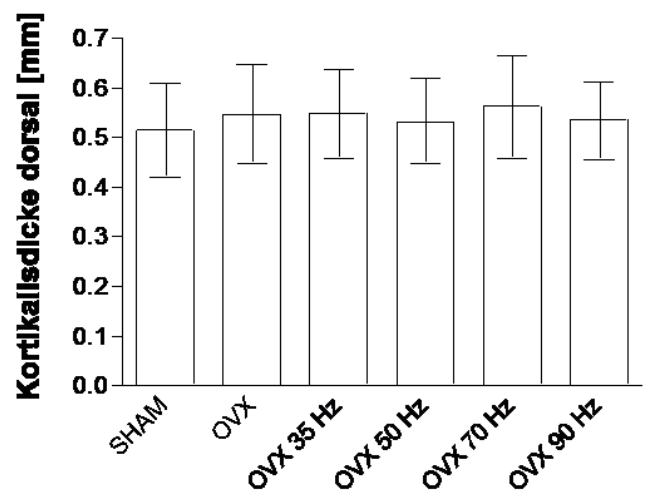

Abbildung 17: Kortikalisdicke dorsal

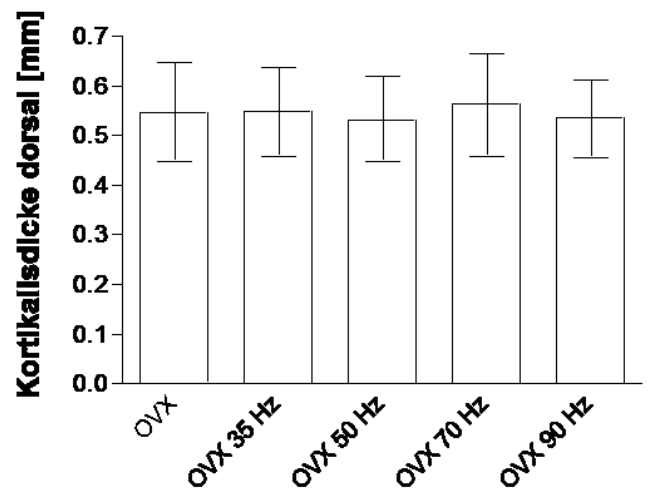

Abbildung 18: Kortikalisdicke dorsal, ohne SHAM-Tiere

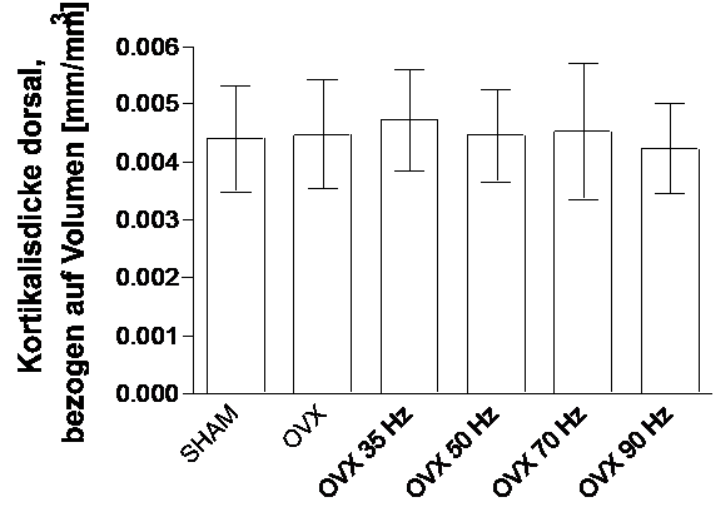

Abbildung 19: Kortikalisdicke dorsal, bezogen auf das Wirbelkörpervolumen 


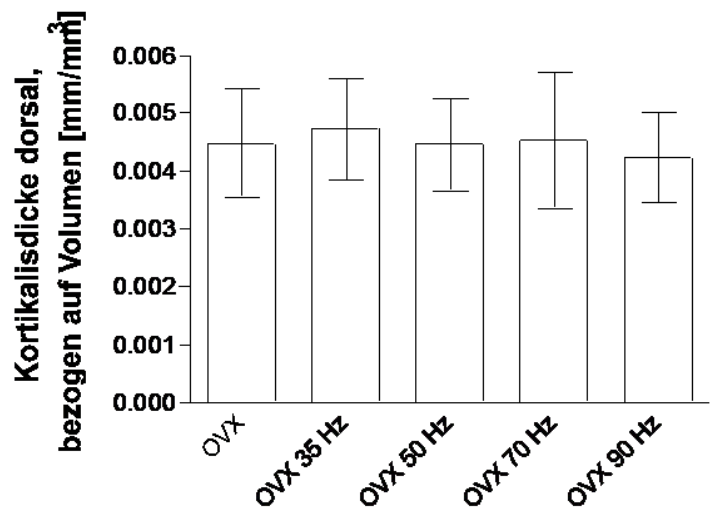

Abbildung 20: Kortikalisdicke dorsal, ohne SHAM-Tiere, bezogen auf das Wirbelkörpervolumen

Wie bei der ventralen Kortikalisdicke unterscheidet sich auch die dorsale Dicke der Kortikalis zwischen den Gruppen nicht signifikant. Ohne Bezug auf das Volumen der Wirbelkörper findet sich die dickste dorsale Kortikalis bei den mit $70 \mathrm{~Hz}$ vibrierten Tieren. Bezieht man die Dicke der Kortikalis auf das Volumen, so verschiebt sich diese Tendenz hin zu der mit $35 \mathrm{~Hz}$ vibrierten Gruppe (siehe Abbildungen 17-20).

\subsubsection{Kortikalisfläche}

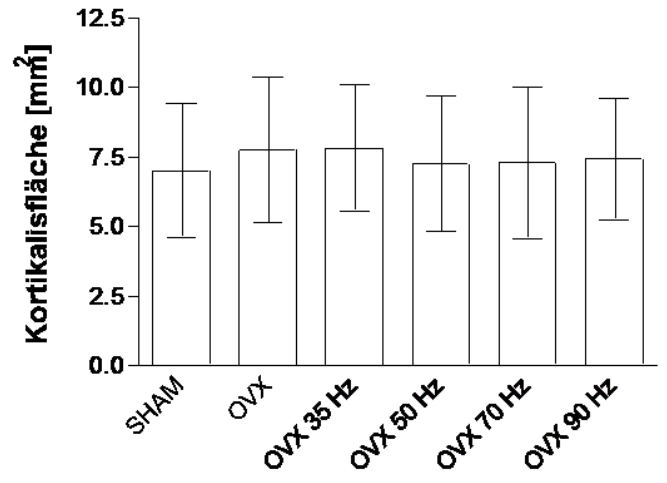

Abbildung 21: Kortikalisfläche 


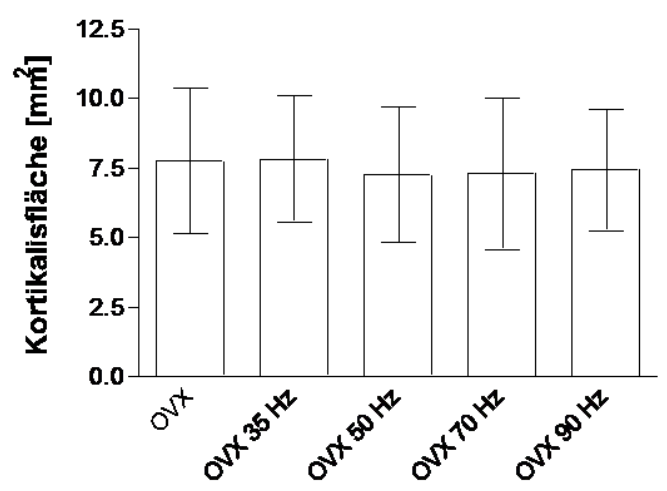

Abbildung 22: Kortikalisfläche, ohne SHAM-Tiere

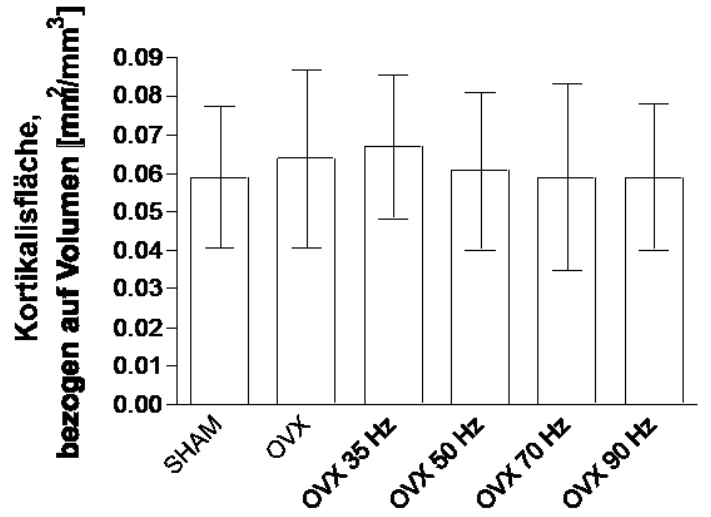

Abbildung 23: Kortikalisfläche, bezogen auf das Wirbelkörpervolumen

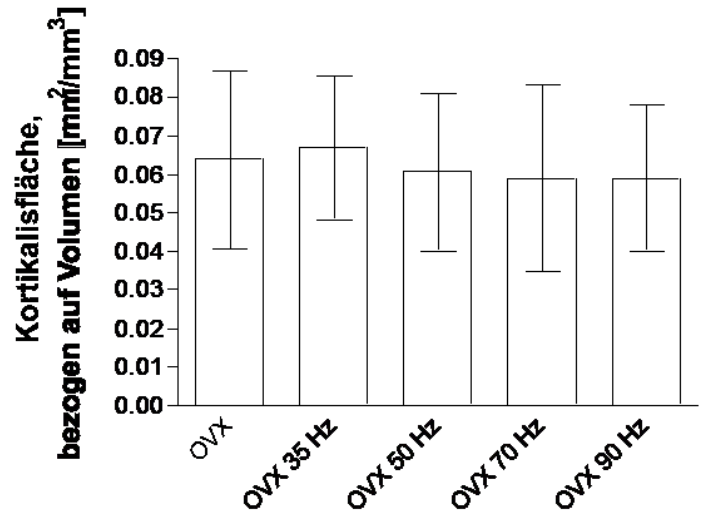

Abbildung 24: Kortikalisfläche, ohne SHAM-Tiere, bezogen auf das Wirbelkörpervolumen

Es finden sich keine signifikanten Unterschiede für den Messparameter der kortikalen Knochenfläche zwischen den einzelnen Gruppen. Sowohl mit, als auch ohne rechnerischen Bezug auf das Wirbelkörpervolumen fällt auf, dass die Kortikalisfläche in den Gruppen OVX 
und OVX $35 \mathrm{~Hz}$ höher ist, als in den gesunden bzw. mit höheren Frequenzen vibrierten Tieren (siehe Abbildungen 21-24).

\subsubsection{Anzahl der Trabekelkreuzungen}

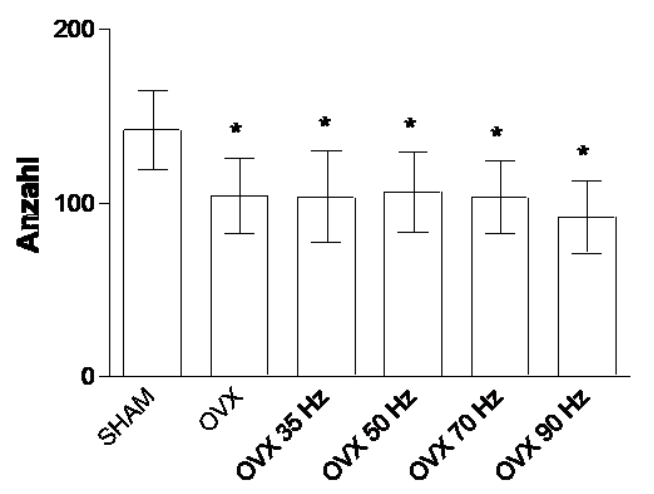

Abbildung 25: Trabekelkreuzungen absolut

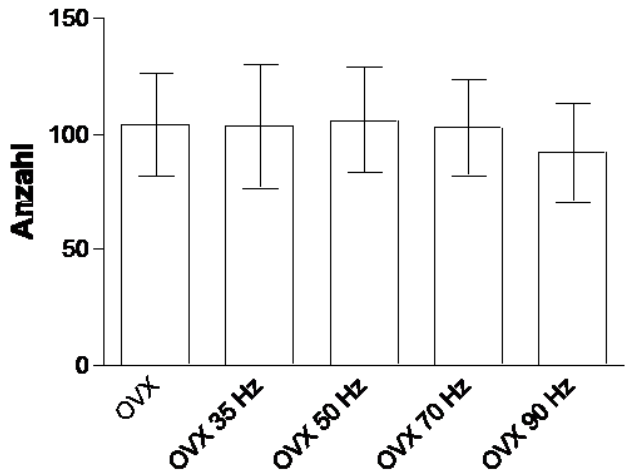

Abbildung 26: Trabekelkreuzungen absolut, ohne SHAM-Tiere 


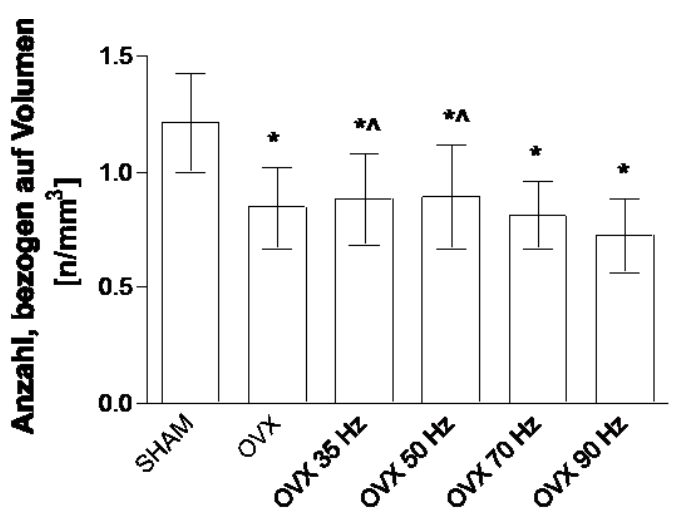

Abbildung 27: Trabekelkreuzungen absolut, bezogen auf das Wirbelkörpervolumen

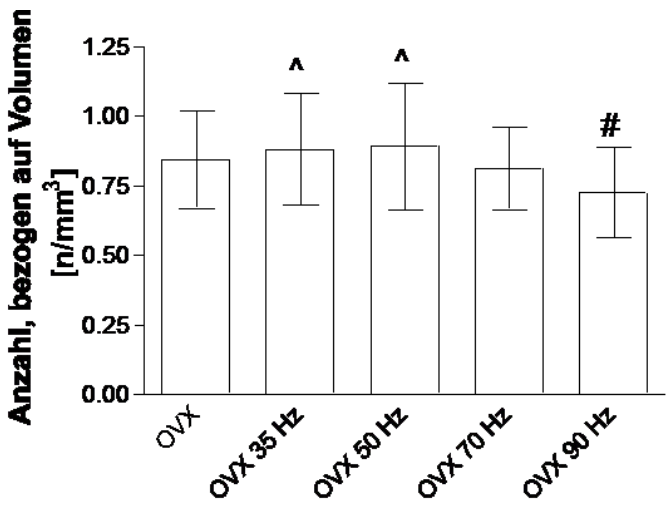

Abbildung 28: Trabekelkreuzungen absolut, ohne SHAM-Tiere, bezogen auf das Wirbelkörpervolumen

Betrachtet man die absolute Anzahl der Trabekelkreuzungen, ohne diese auf das Volumen der Wirbelkörper $\mathrm{zu}$ beziehen, so unterscheiden sich die gesunden SHAM-Tiere mit einer signifikant höheren Anzahl von den übrigen Gruppen (siehe Abbildungen 25 und 26). Setzt man die Zahl der Trabekelkreuzungen in Bezug zum Volumen der Wirbelkörper, so finden sich weitere signifikante Unterschiede. So sind die Zahlen bei den mit 35 und $50 \mathrm{~Hz}$ vibrierten Tieren signifikant erhöht im Vergleich zu der mit $90 \mathrm{~Hz}$ vibrierten Gruppe, wenn auch nicht so hoch wie bei den gesunden Kontrolltieren (siehe Abbildung 27). Lässt man diese Kontrolltiere außen vor, so sinkt der p-Wert für den Unterschied zwischen der OVXund der $90 \mathrm{~Hz}$-Gruppe ebenfalls unter 0,05, und die zuvor bereits erkennbare Tendenz ist signifikant (siehe Abbildung 28). 


\subsubsection{Dichte der Trabekelkreuzungen}

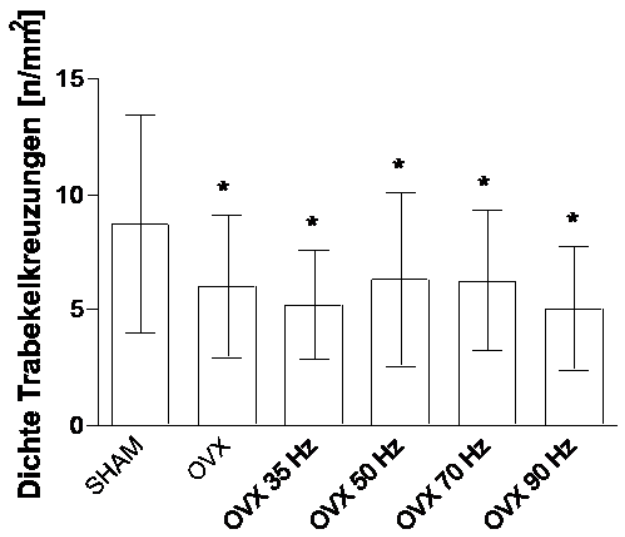

Abbildung 29: Dichte der Trabekelkreuzungen

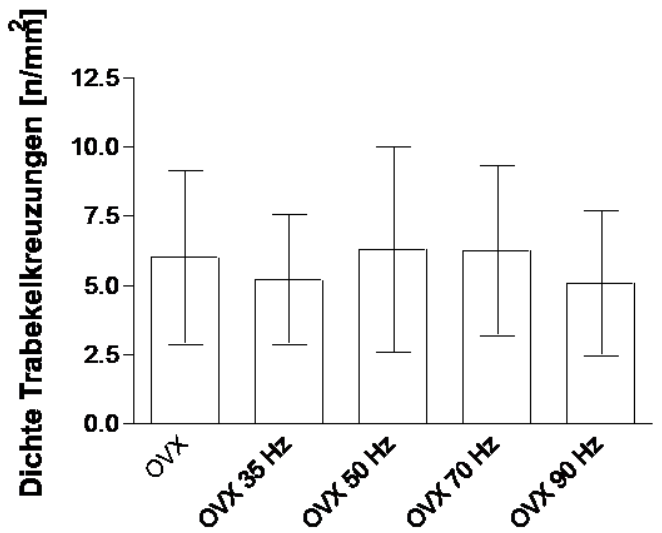

Abbildung 30: Dichte der Trabekelkreuzungen, ohne SHAM-Tiere

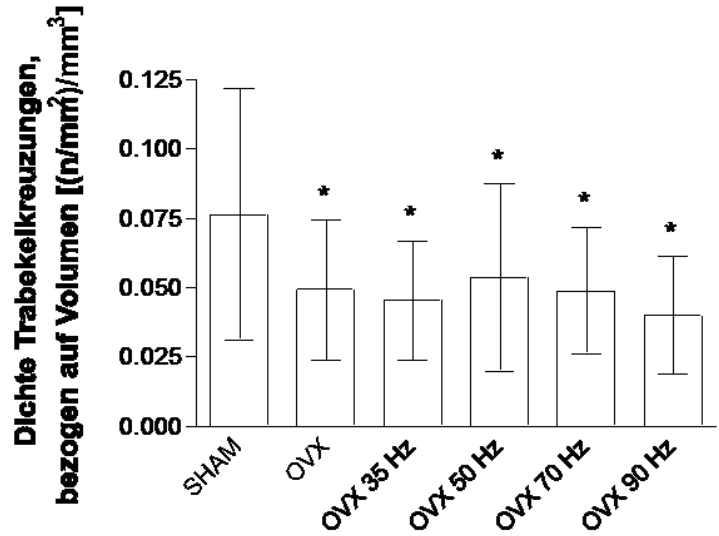

Abbildung 31: Dichte der Trabekelkreuzungen, bezogen auf das Wirbelkörpervolumen 


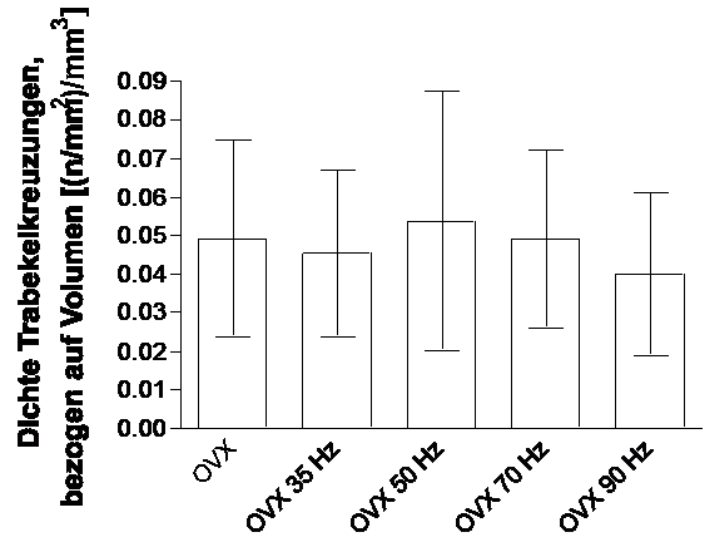

Abbildung 32: Dichte der Trabekelkreuzungen, ohne SHAM-Tiere, bezogen auf das Wirbelkörpervolumen

Unabhängig vom Bezug auf das Volumen der Wirbelkörper unterscheiden sich in der Dichte der Trabekelkreuzungen jeweils nur die gesunden SHAM-Tiere signifikant von den übrigen Gruppen. Wenn auch nicht signifikant, fällt auf, dass die Gruppen OVX $35 \mathrm{~Hz}$ und OVX 90 $\mathrm{Hz}$ deutlich weniger Trabekelkreuzungen pro Fläche aufweisen. $\mathrm{Zu}$ beachten ist die bei diesem Messparameter vergleichsweise hohe Standardabweichung (siehe Abbildungen 29$32)$.

\subsubsection{Durchschnittliche Trabekeldicke}

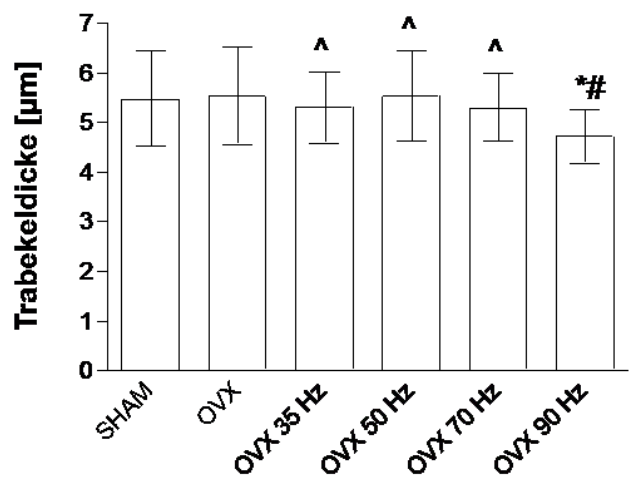

Abbildung 33: Trabekeldicke 


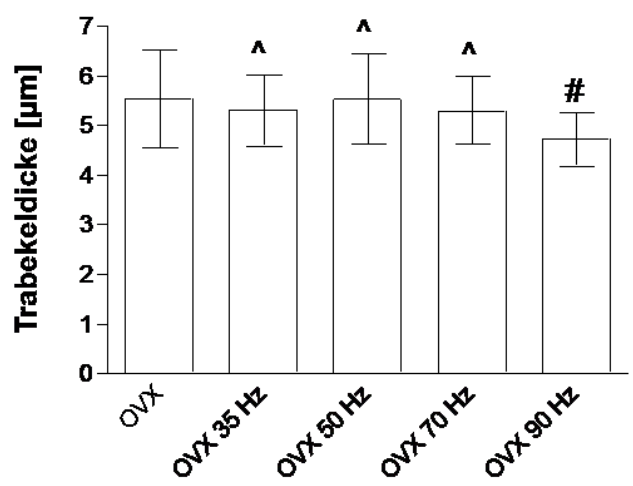

Abbildung 34: Trabekeldicke, ohne SHAM-Tiere

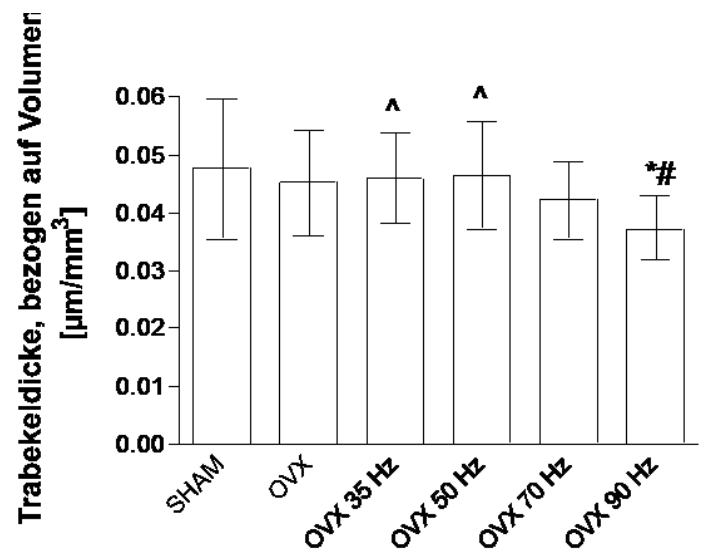

Abbildung 35: Trabekeldicke, bezogen auf das Wirbelkörpervolumen

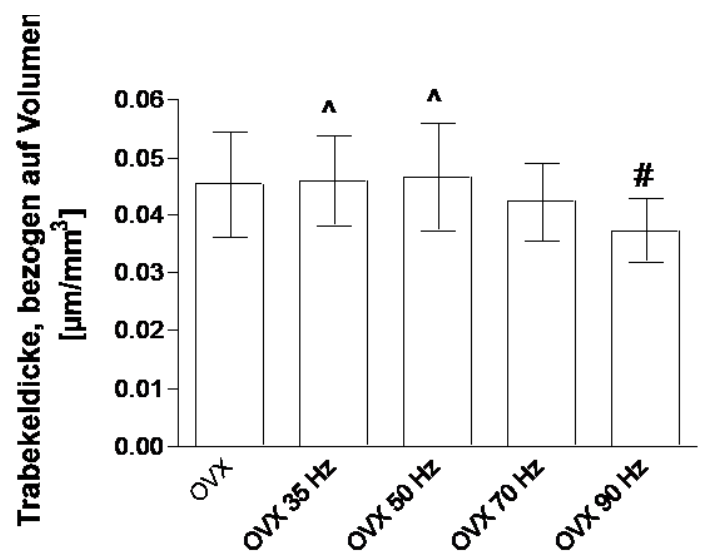

Abbildung 36: Trabekeldicke, ohne SHAM-Tiere, bezogen auf das Wirbelkörpervolumen

Ohne Bezug auf das Volumen der Wirbelkörper haben die mit $90 \mathrm{~Hz}$ vibrierten Tiere signifikant dünnere Trabekel, als alle anderen Gruppen. Setzt man die durchschnittliche Dicke 
der Trabekel in Relation zum Wirbelkörpervolumen, so bleibt die Tendenz bestehen, lediglich der Unterschied zur Gruppe OVX $70 \mathrm{~Hz}$ ist nicht mehr signifikant (siehe Abbildungen 33-36).

\subsubsection{Zusammenfassung der Ergebnisse der Mikroradiographie}

Die folgenden Tabellen fassen die Ergebnisse der Mikroradiographie zusammen. Angegeben sind jeweils Mittelwert \pm Standardabweichung für jeden Messparameter und jede Gruppe.

Ct.Wi. v. = Kortikalisdicke ventral, Ct.Wi. d. $=$ Kortikalisdicke dorsal, Ct.Ar. = Kortikalisfläche, Tb.N. = Trabekelkreuzungen absolut, Tb.N./mm ${ }^{2}=$ Dichte der Trabekelkreuzungen, Tb.Wi. $=$ Trabekeldicke.

Tabelle 7: Ergebnisse der Mikroradiographie: Kortikalisparameter

\begin{tabular}{|c|c|c|c|}
\hline & $\begin{array}{c}\text { Ct.Wi. v. } \\
{[\mathbf{m m}]}\end{array}$ & $\begin{array}{c}\text { Ct.Wi. d. } \\
{[\mathbf{m m}]}\end{array}$ & $\begin{array}{c}\text { Ct.Ar. } \\
{\left[\mathbf{m m}^{2}\right]}\end{array}$ \\
\hline SHAM & $0,45 \pm 0,09$ & $0,52 \pm 0,10$ & $7,03 \pm 2,40$ \\
\hline OVX & $0,46 \pm 0,09$ & $0,55 \pm 0,10$ & $7,78 \pm 2,63$ \\
\hline OVX 35 Hz & $0,47 \pm 0,10$ & $0,55 \pm 0,09$ & $7,85 \pm 2,30$ \\
\hline OVX 50 Hz & $0,45 \pm 0,10$ & $0,53 \pm 0,09$ & $7,28 \pm 2,44$ \\
\hline OVX 70 Hz & $0,45 \pm 0,10$ & $0,56 \pm 0,10$ & $7,30 \pm 2,73$ \\
\hline OVX 90 Hz & $0,45 \pm 0,08$ & $0,53 \pm 0,08$ & $7,43 \pm 2,19$ \\
\hline
\end{tabular}

Tabelle 8: Ergebnisse der Mikroradiographie: Kortikalisparameter, bezogen auf das Wirbelkörpervolumen

\begin{tabular}{|c|c|c|c|}
\hline & $\begin{array}{c}\text { Ct.Wi. v. } \\
{\left[\mathbf{m m} / \mathbf{m m}^{\mathbf{3}}\right]}\end{array}$ & $\begin{array}{c}\text { Ct.Wi. d. } \\
{\left[\mathbf{m m} / \mathbf{m m}^{\mathbf{3}}\right]}\end{array}$ & $\begin{array}{c}\text { Ct.Ar. } \\
{\left[\mathbf{m m}^{\mathbf{2}} / \mathbf{m m}^{\mathbf{3}}\right]}\end{array}$ \\
\hline SHAM & $0,0038 \pm 0,00074$ & $0,0044 \pm 0,00091$ & $0,0591 \pm 0,01848$ \\
\hline OVX & $0,0037 \pm 0,00093$ & $0,0045 \pm 0,00096$ & $0,0638 \pm 0,02329$ \\
\hline OVX 35 Hz & $0,0040 \pm 0,00079$ & $0,0047 \pm 0,00088$ & $0,0671 \pm 0,01864$ \\
\hline OVX 50 Hz & $0,0037 \pm 0,00090$ & $0,0045 \pm 0,00080$ & $0,0607 \pm 0,02062$ \\
\hline OVX 70 Hz & $0,0036 \pm 0,00097$ & $0,0045 \pm 0,00117$ & $0,0589 \pm 0,02425$ \\
\hline OVX 90 Hz & $0,0036 \pm 0,00076$ & $0,0042 \pm 0,00077$ & $0,0589 \pm 0,01885$ \\
\hline
\end{tabular}


Tabelle 9: Ergebnisse der Mikroradiographie: Trabekelparameter

\begin{tabular}{|c|c|c|c|}
\hline & Tb.N. & $\begin{array}{c}\text { Tb.N./mm } \\
{\left[\mathrm{n} / \mathbf{m m}^{2}\right]}\end{array}$ & $\begin{array}{c}\text { Tb.Wi. } \\
{[\mu \mathrm{m}]}\end{array}$ \\
\hline SHAM & $142,0 \pm 22,76$ & $8,72 \pm 4,70$ & $5,48 \pm 0,96$ \\
\hline OVX & $104,2 \pm 22,14$ & $6,01 \pm 3,10$ & $5,53 \pm 0,97$ \\
\hline OVX $35 \mathrm{~Hz}$ & $103,5 \pm 26,53$ & $5,22 \pm 2,36$ & $5,31 \pm 0,73$ \\
\hline OVX $50 \mathrm{~Hz}$ & $106,1 \pm 22,97$ & $6,31 \pm 3,73$ & $5,54 \pm 0,91$ \\
\hline OVX $70 \mathrm{~Hz}$ & $102,8 \pm 21,02$ & $6,26 \pm 3,06$ & $5,30 \pm 0,68$ \\
\hline OVX $90 \mathrm{~Hz}$ & $92,08 \pm 21,11$ & $5,07 \pm 2,65$ & $4,72 \pm 0,54$ \\
\hline
\end{tabular}

Tabelle 10: Ergebnisse der Mikroradiographie: Trabekelparameter, bezogen auf das Wirbelkörpervolumen

\begin{tabular}{|c|c|c|c|}
\hline & $\begin{array}{c}\text { Tb.N. } \\
{\left[\mathbf{n} / \mathbf{m m}^{3}\right]}\end{array}$ & $\begin{array}{c}\text { Tb.N./mm } \\
{\left[\left(\mathbf{n} / \mathbf{m m}^{2)} / \mathbf{m m}^{3}\right]\right.}\end{array}$ & $\begin{array}{c}\text { Tb.Wi. } \\
{\left[\mu \mathrm{m} / \mathbf{m m}^{3}\right]}\end{array}$ \\
\hline SHAM & $1,21 \pm 0,21$ & $0,077 \pm 0,045$ & $0,048 \pm 0,0122$ \\
\hline OVX & $0,85 \pm 0,17$ & $0,049 \pm 0,025$ & $0,045 \pm 0,0092$ \\
\hline OVX $35 \mathrm{~Hz}$ & $0,88 \pm 0,20$ & $0,045 \pm 0,022$ & $0,046 \pm 0,0078$ \\
\hline OVX $50 \mathrm{~Hz}$ & $0,89 \pm 0,23$ & $0,054 \pm 0,034$ & $0,047 \pm 0,0092$ \\
\hline OVX $70 \mathrm{~Hz}$ & $0,81 \pm 0,15$ & $0,049 \pm 0,230$ & $0,042 \pm 0,0068$ \\
\hline OVX 90 Hz & $0,73 \pm 0,16$ & $0,040 \pm 0,021$ & $0,037 \pm 0,0055$ \\
\hline
\end{tabular}




\subsection{Ergebnisse der Veraschung}

\subsubsection{Knochenmineraldichte}

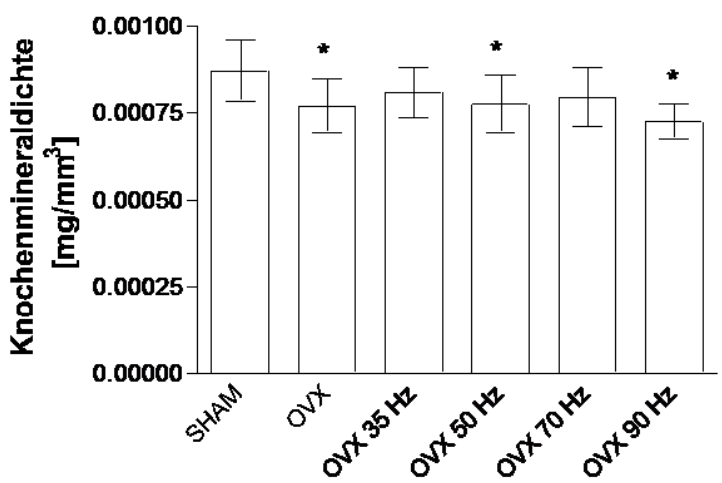

Abbildung 37: Knochenmineraldichte

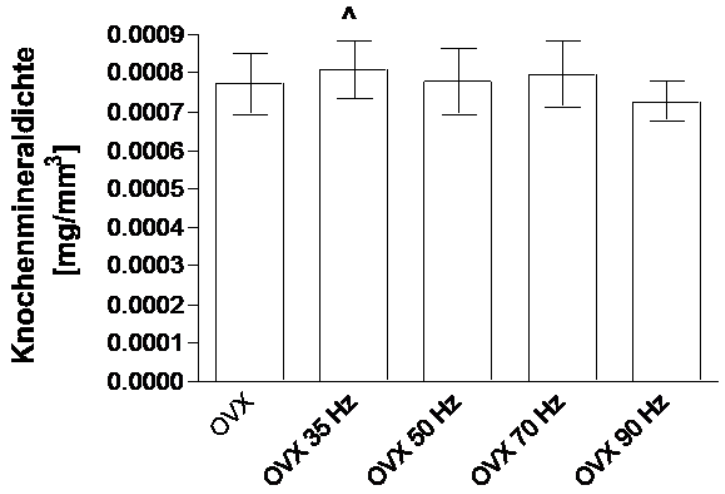

Abbildung 38: Knochenmineraldichte, ohne SHAM-Tiere

Vergleicht man alle untersuchten Gruppen miteinander, so findet sich bei den SHAM-Tieren eine signifikant höhere Knochenmineraldichte, als bei den mit 50 bzw. $90 \mathrm{~Hz}$ vibrierten und den nicht vibrierten Tieren. Auch die Knochenmineraldichte der Gruppen OVX 35 Hz und OVX $70 \mathrm{~Hz}$ ist geringer, als die der gesunden SHAM-Tiere, dieser Unterschied ist jedoch nicht signifikant (siehe Abbildung 37). Betrachtet man nur die ovariektomierten Tiere, so findet sich die geringste Knochenmineraldichte bei der Gruppe OVX $90 \mathrm{~Hz}$, die sich damit signifikant von der Gruppe OVX $35 \mathrm{~Hz}$ unterscheidet (siehe Abbildung 38). 


\subsubsection{Phosphatgehalt}

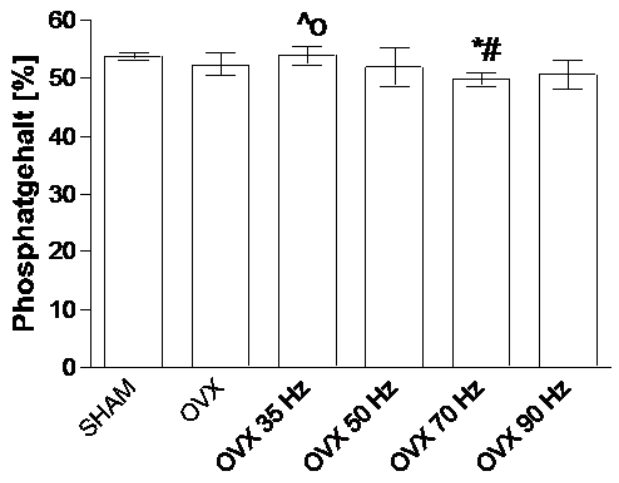

Abbildung 39: Phosphatgehalt

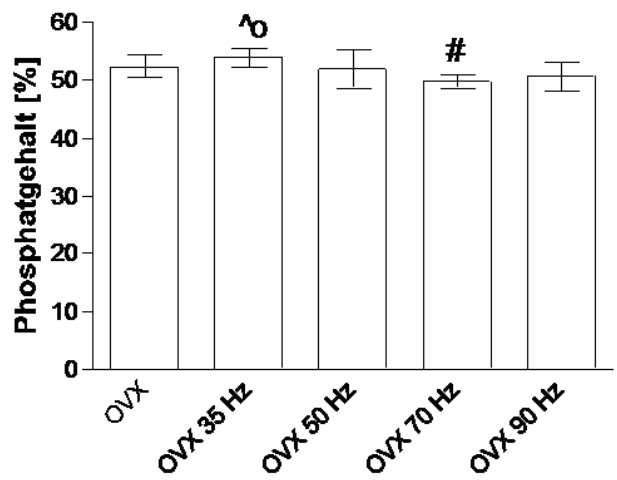

Abbildung 40: Phosphatgehalt, ohne SHAM-Tiere

Der prozentuale Phosphatgehalt der untersuchten Lendenwirbelkörper ist am höchsten bei den mit $35 \mathrm{~Hz}$ vibrierten Tieren, die sich signifikant von den Gruppen OVX $70 \mathrm{~Hz}$ und OVX 90 $\mathrm{Hz}$ abheben. Den niedrigsten Anteil an Phosphat weisen die mit $70 \mathrm{~Hz}$ vibrierten Tiere auf, die sich auch von SHAM und OVX signifikant unterscheiden (siehe Abbildungen 39 und 40). 


\subsubsection{Calciumgehalt}

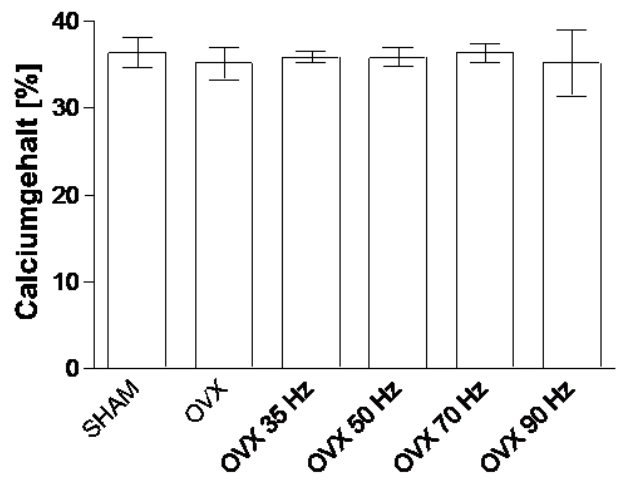

Abbildung 41: Calciumgehalt

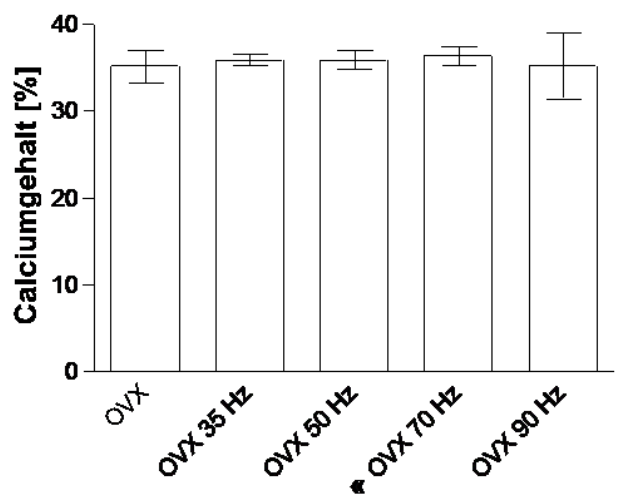

Abbildung 42: Calciumgehalt, ohne SHAM-Tiere

Es finden sich keine signifikanten Unterschiede bezüglich des Calciumgehalts zwischen den untersuchten Gruppen (siehe Abbildungen 41 und 42).

\subsubsection{Verhältnis von Calcium zu Phosphat}

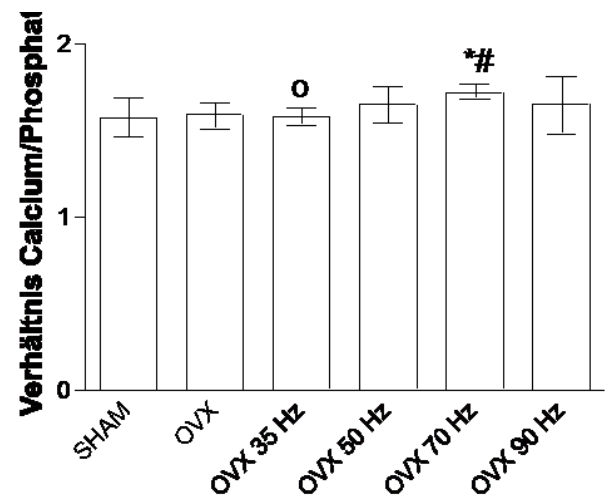

Abbildung 43: Verhältnis Calcium/Phosphat 


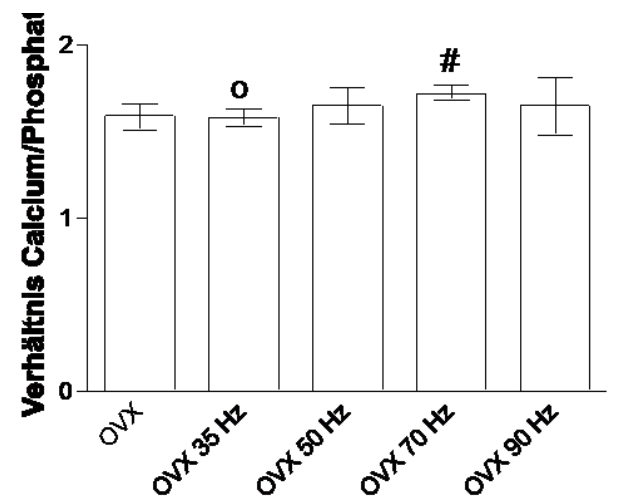

Abbildung 44: Verhältnis Calcium/Phosphat, ohne SHAM-Tiere

Das Verhältnis von Calcium zu Phosphat ist am höchsten bei der Gruppe OVX 70 Hz. Der Unterschied ist signifikant im Vergleich mit den Gruppen SHAM, OVX und OVX $35 \mathrm{~Hz}$ (siehe Abbildungen 43 und 44).

\subsubsection{Zusammenfassung der Ergebnisse der Veraschung}

Die Ergebnisse der Veraschung werden in der folgenden Tabelle zusammengefasst. Angegeben ist jeweils der Mittelwert \pm Standardabweichung für die untersuchten Gruppen und die bestimmten Parameter.

Tabelle 11: Zusammenfassung der Ergebnisse der Veraschung

\begin{tabular}{|c|c|c|c|c|}
\hline & $\mathbf{B M D}\left[\mathbf{m g} / \mathbf{m m}^{\mathbf{3}}\right]$ & $\mathbf{P O}_{\mathbf{4}}{ }^{\mathbf{3 -}}[\mathbf{\%}]$ & $\mathbf{C a}^{\mathbf{2 +}}[\mathbf{\%}]$ & $\mathbf{C a}^{\mathbf{2 +}} / \mathbf{P O}_{\mathbf{4}}{ }^{\mathbf{}}$ \\
\hline SHAM & $0,00087 \pm 0,00009$ & $53,74 \pm 0,56$ & $36,38 \pm 1,84$ & $1,58 \pm 0,11$ \\
\hline OVX & $0,00077 \pm 0,00008$ & $52,38 \pm 1,88$ & $35,16 \pm 1,97$ & $1,59 \pm 0,08$ \\
\hline OVX 35 Hz & $0,00081 \pm 0,00007$ & $53,93 \pm 1,63$ & $35,88 \pm 0,70$ & $1,58 \pm 0,49$ \\
\hline OVX 50 Hz & $0,00078 \pm 0,00008$ & $52,01 \pm 3,39$ & $35,91 \pm 1,15$ & $1,65 \pm 0,10$ \\
\hline OVX 70 Hz & $0,00080 \pm 0,00009$ & $49,91 \pm 1,27$ & $36,35 \pm 1,13$ & $1,73 \pm 0,04$ \\
\hline OVX 90 Hz & $0,00073 \pm 0,00005$ & $50,61 \pm 2,65$ & $35,19 \pm 3,83$ & $1,65 \pm 0,16$ \\
\hline
\end{tabular}




\subsection{Ergebnisse des biomechanischen Kompressionstests}

Analog zur Darstellung der Ergebnisse der Mikroradiographie werden hier die aus dem biomechanischen Kompressionstest gewonnenen Daten dargestellt. Es erfolgt zunächst in Säulendiagrammen die Darlegung der Ergebnisse für die einzelnen Messparameter (siehe 2.4.2), sowohl mit, als auch ohne Bezug auf das Volumen der Wirbelkörper, und im Anschluss die tabellarische Zusammenfassung der Mittelwerte \pm Standardabweichung.

\subsubsection{Steigung}

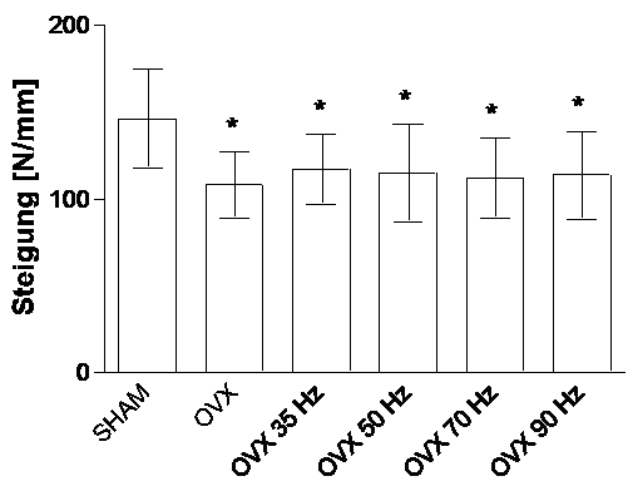

Abbildung 45: Steigung

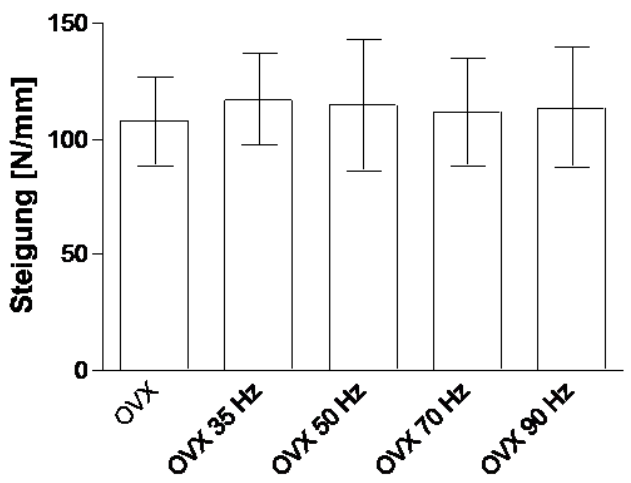

Abbildung 46: Steigung, ohne SHAM-Tiere 


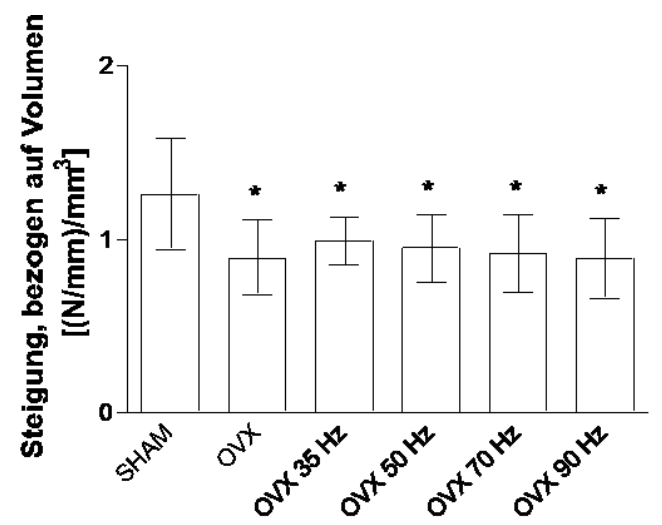

Abbildung 47: Steigung, bezogen auf das Wirbelkörpervolumen

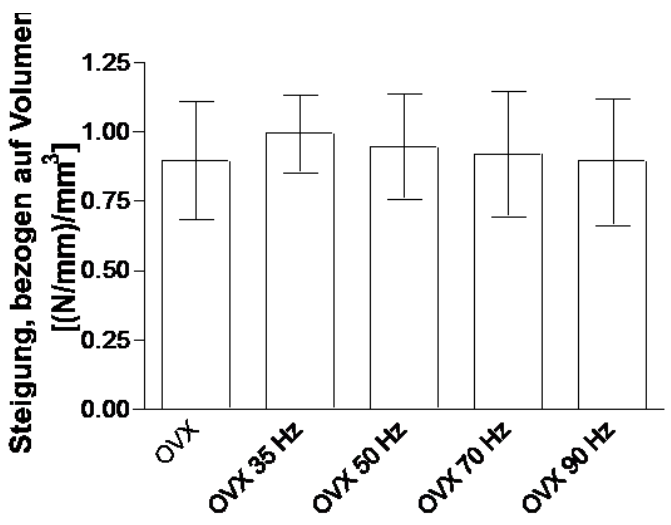

Abbildung 48: Steigung, ohne SHAM-Tiere, bezogen auf das Wirbelkörpervolumen

Unabhängig vom Bezug auf das Volumen der Wirbelkörper unterscheiden sich jeweils nur die gesunden SHAM-Tiere mit einer signifikant höheren Steigung von den übrigen Gruppen. Von den vibrierten Tieren erreicht die Gruppe OVX $35 \mathrm{~Hz}$ die höchsten Werte (siehe Abbildungen 45-48). 


\subsubsection{Streckgrenze}

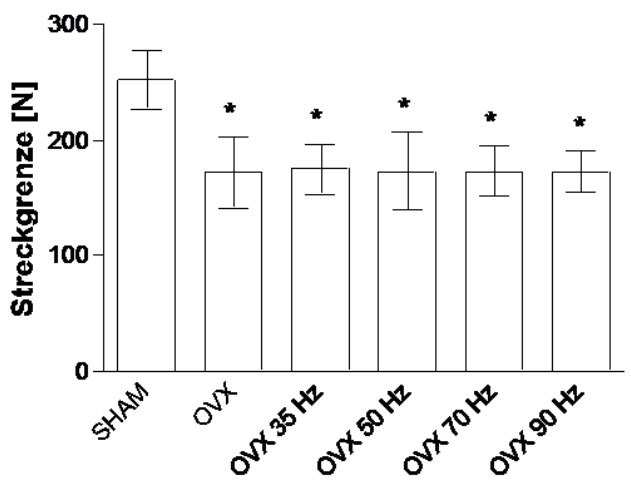

Abbildung 49: Streckgrenze

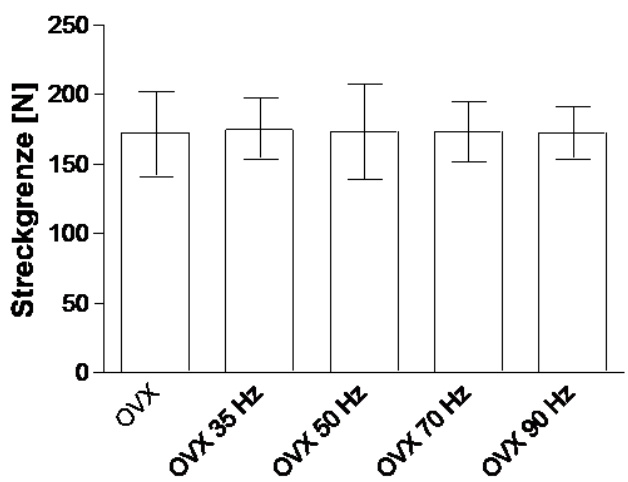

Abbildung 50: Streckgrenze, ohne SHAM-Tiere

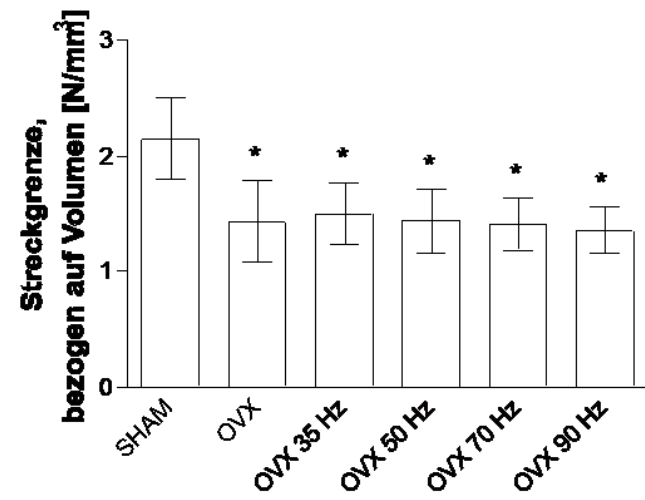

Abbildung 51: Streckgrenze, bezogen auf das Wirbelkörpervolumen 


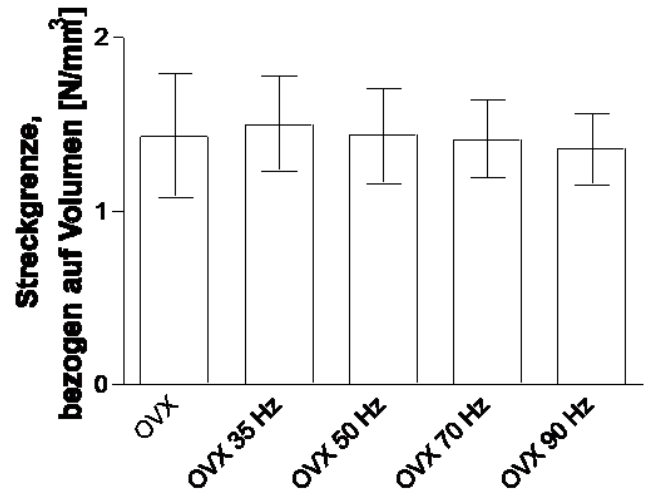

Abbildung 52: Streckgrenze, ohne SHAM-Tiere, bezogen auf das Wirbelkörpervolumen

Wie bei der Steigung unterscheiden sich auch bei der Streckgrenze nur die SHAM-Tieren signifikant von den übrigen Gruppen (siehe Abbildungen 49-52).

\subsubsection{Maximalkraft}

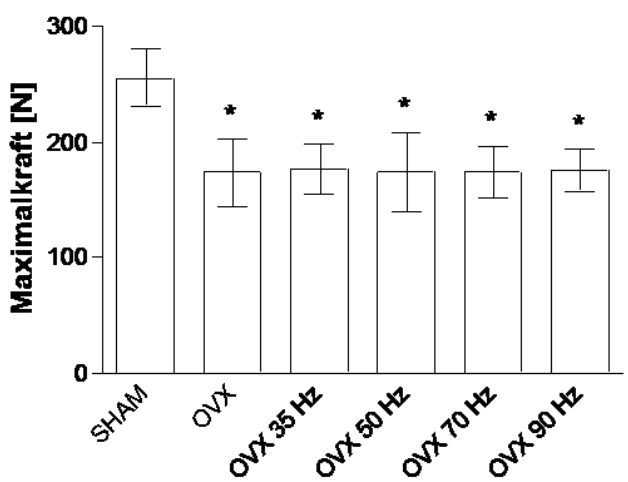

Abbildung 53: Maximalkraft

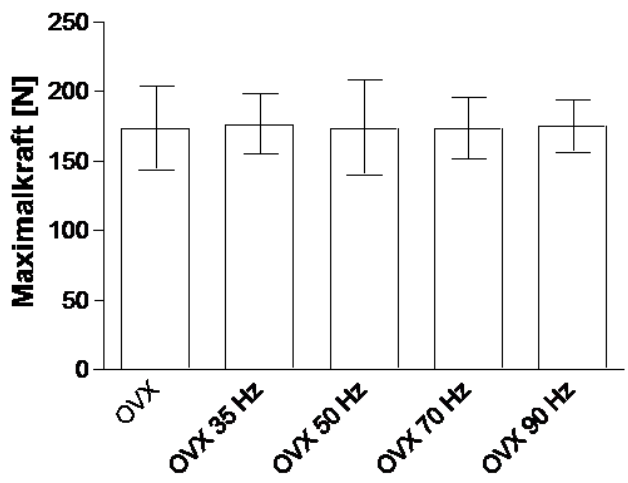

Abbildung 54: Maximalkraft, ohne SHAM-Tiere 


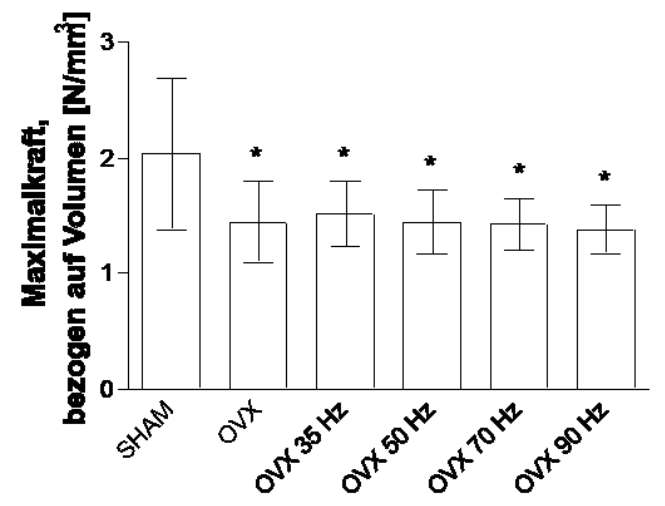

Abbildung 55: Maximalkraft, bezogen auf das Wirbelkörpervolumen

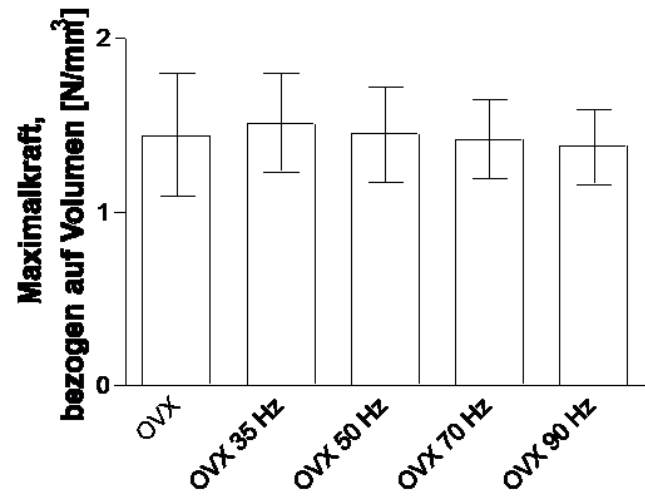

Abbildung 56: Maximalkraft, ohne SHAM-Tiere, bezogen auf das Wirbelkörpervolumen

Entsprechend den beiden anderen Messparametern des biomechanischen Kompressionstests finden sich auch bei der Maximalkraft keine signifikanten Unterschiede zwischen den ovariektomierten Gruppen. Lediglich bei den SHAM-Tieren ist die Maximalkraft signifikant erhöht gegenüber allen übrigen Tieren (siehe Abbildungen 53-56).

\subsubsection{Zusammenfassung der Ergebnisse des biomechanischen Kompressionstests}

Im Folgenden werden die Ergebnisse des biomechanischen Kompressionstests, zunächst ohne, dann mit Bezug auf das Wirbelkörpervolumen, tabellarisch zusammengefasst. Aufgeführt sind jeweils der Mittelwert \pm Standardabweichung für jeden erfassten Parameter sowie für jede Gruppe. 
Tabelle 12: Ergebnisse des biomechanischen Kompressionstests

\begin{tabular}{|c|c|c|c|}
\hline & Steigung [N/mm] & Streckgrenze [N] & Maximalkraft [N] \\
\hline SHAM & $146,6 \pm 28,94$ & $252,1 \pm 25,77$ & $255,9 \pm 24,21$ \\
\hline OVX & $107,9 \pm 18,87$ & $172,2 \pm 30,26$ & $173,6 \pm 29,82$ \\
\hline OVX 35 Hz & $117,3 \pm 19,84$ & $175,5 \pm 21,83$ & $176,9 \pm 21,92$ \\
\hline OVX 50 Hz & $114,9 \pm 28,18$ & $173,5 \pm 34,26$ & $174,5 \pm 34,29$ \\
\hline OVX 70 Hz & $112,1 \pm 23,17$ & $173,4 \pm 22,35$ & $174,4 \pm 22,38$ \\
\hline OVX 90 Hz & $113,7 \pm 25,69$ & $172,7 \pm 18,71$ & $175,2 \pm 18,17$ \\
\hline
\end{tabular}

Tabelle 13: Ergebnisse des biomechanischen Kompressionstests, bezogen auf das Wirbelkörpervolumen

\begin{tabular}{|c|c|c|c|}
\hline & $\begin{array}{c}\text { Steigung } \\
{\left[(\mathbf{N} / \mathbf{m m}) / \mathbf{m m}^{\mathbf{3}}\right]}\end{array}$ & $\begin{array}{c}\text { Streckgrenze } \\
{\left[\mathbf{N} / \mathbf{m m}^{\mathbf{3}}\right]}\end{array}$ & $\begin{array}{c}\text { Maximalkraft } \\
{\left[\mathbf{N} / \mathbf{m m}^{\mathbf{3}}\right]}\end{array}$ \\
\hline SHAM & $1,27 \pm 0,32$ & $2,15 \pm 0,35$ & $2,04 \pm 0,66$ \\
\hline OVX & $0,90 \pm 0,21$ & $1,43 \pm 0,35$ & $1,45 \pm 0,35$ \\
\hline OVX 35 Hz & $0,99 \pm 0,14$ & $1,50 \pm 0,28$ & $1,52 \pm 0,28$ \\
\hline OVX 50 Hz & $0,95 \pm 0,19$ & $1,44 \pm 0,28$ & $1,45 \pm 0,28$ \\
\hline OVX 70 Hz & $0,92 \pm 0,22$ & $1,42 \pm 0,23$ & $1,42 \pm 0,23$ \\
\hline OVX 90 Hz & $0,89 \pm 0,23$ & $1,36 \pm 0,21$ & $1,38 \pm 0,21$ \\
\hline
\end{tabular}

\subsection{Korrelation der Ergebnisse}

\subsubsection{Korrelation der Ergebnisse des Kompressionsversuchs mit denen der}

\section{Mikroradiographie}

Um den prädiktiven Wert der morphologischen Parameter für die mechanische Stabilität der Lendenwirbelkörper $\mathrm{zu}$ erfassen, werden im Folgenden die aus der Auswertung der Mikroradiographien gewonnenen Ergebnisse mit denen des biomechanischen Kompressionstests korreliert. 
Tabelle 14 fasst die Werte des Pearson $\mathrm{r}$ für die Korrelation der Ergebnisse des Kompressionsversuchs mit denen der Mikroradiographie zusammen. Die signifikanten Werte sind fett gedruckt.

Tabelle 14: Korrelation (Pearson r) des Kompressionsversuchs mit der Mikroradiographie

\begin{tabular}{|c|c|c|c|}
\hline & Steigung & Streckgrenze & Maximalkraft \\
\hline Kortikalisdicke ventral & $-0,0386$ & $-0,0876$ & $-0,0907$ \\
\hline Kortikalisdicke dorsal & $-0,0408$ & $-0,2281$ & $-0,2226$ \\
\hline Kortikalisfläche & $-0,1468$ & $-0,1581$ & $-0,1562$ \\
\hline Anzahl Trabekelkreuzungen & $\mathbf{0 , 2 6 2 3}$ & $\mathbf{0 , 4 7 1 0}$ & $\mathbf{0 , 4 6 4 9}$ \\
\hline Dichte Trabekelkreuzungen & $\mathbf{0 , 3 5 5 4}$ & $\mathbf{0 , 4 2 6 8}$ & $\mathbf{0 , 4 1 7 5}$ \\
\hline Trabekeldicke & 0,0052 & $-0,0007$ & $-0,0076$ \\
\hline
\end{tabular}

Tabelle 15: Korrelation $\left(\mathbf{R}^{2}\right)$ des Kompressionsversuchs mit der Mikroradiographie

\begin{tabular}{|c|c|c|c|}
\hline & Steigung & Streckgrenze & Maximalkraft \\
\hline Kortikalisdicke ventral & 0,0015 & 0,0077 & 0,0082 \\
\hline Kortikalisdicke dorsal & 0,0017 & 0,0520 & 0,0496 \\
\hline Kortikalisfläche & 0,0215 & 0,0249 & 0,0244 \\
\hline Anzahl Trabekelkreuzungen & $\mathbf{0 , 0 6 9 3}$ & $\mathbf{0 , 2 2 1 9}$ & $\mathbf{0 , 2 1 6 1}$ \\
\hline Dichte Trabekelkreuzungen & $\mathbf{0 , 1 2 6 3}$ & $\mathbf{0 , 1 8 2 2}$ & $\mathbf{0 , 1 7 4 3}$ \\
\hline Trabekeldicke & 0,00003 & 0,0000005 & 0,00006 \\
\hline
\end{tabular}

Aus den gewonnenen Daten geht eindeutig hervor, dass nur die Dichte der Trabekelkreuzungen sowie deren Gesamtzahl die biomechanische Stabilität des Lendenwirbelkörpers beeinflusst.

\subsubsection{Korrelation der morphologischen Parameter}

Bei der Untersuchung der Abhängigkeit der mechanischen Stabilität von der Knochenmorphologie fiel die konstant negative Korrelation der Kortikalisparameter auf, wenn diese auch nicht signifikant war. Um einen potentiellen Zusammenhang zwischen 
Kortikalis- und Trabekelparametern zu erfassen, werden diese im Folgenden zunächst für alle Tiere, im Anschluss für die einzelnen Gruppen, miteinander korreliert. Die signifikanten Werte sind fett gedruckt.

Tabelle 16: Korrelation (Pearson r) von Kortikalis- und Trabekelparametern

\begin{tabular}{|c|c|c|c|}
\hline & Tr.N./mm & Tr.N. & Tr.Wi. \\
\hline Ct.Wi. d. & $\mathbf{- 0 , 6 3 7}$ & $-0,109$ & 0,082 \\
\hline Ct.Ar. & $\mathbf{- 0 , 7 5 4}$ & 0,057 & 0,157 \\
\hline
\end{tabular}

Tabelle 17: Korrelation $\left(\mathbf{R}^{2}\right)$ von Kortikalis- und Trabekelparametern

\begin{tabular}{|c|c|c|c|}
\hline & Tr.N./mm & Tr.N. & Tr.Wi. \\
\hline Ct.Wi. d. & $\mathbf{0 , 4 0 6}$ & 0,012 & 0,007 \\
\hline Ct.Ar. & $\mathbf{0 , 5 6 9}$ & 0,003 & 0,025 \\
\hline
\end{tabular}

Die Trabekeldichte korreliert stark negativ mit der dorsalen Kortikalisdicke und der Kortikalisfläche.

Tabelle 18: Korrelation (Pearson r) von Kortikalis- und Trabekelparametern, nur SHAM

\begin{tabular}{|c|c|c|c|}
\hline SHAM & Tr.N./mm & Tr.N. & Tr.Wi. \\
\hline Ct.Wi. d. & $\mathbf{- 0 , 7 3 5}$ & 0,450 & $-0,289$ \\
\hline Ct.Ar. & $\mathbf{- 0 , 7 9 1}$ & 0,207 & $-0,181$ \\
\hline
\end{tabular}

Tabelle 19: Korrelation (Pearson r) von Kortikalis- und Trabekelparametern, nur OVX

\begin{tabular}{|c|c|c|c|}
\hline OVX & Tr.N./mm & Tr.N. & Tr.Wi. \\
\hline Ct.Wi. d. & $\mathbf{- 0 , 7 3 5}$ & $-0,043$ & 0,246 \\
\hline Ct.Ar. & $\mathbf{- 0 , 8 5 7}$ & 0,207 & 0,426 \\
\hline
\end{tabular}

Tabelle 20: Korrelation (Pearson r) von Kortikalis- und Trabekelparametern, nur OVX $35 \mathrm{~Hz}$

\begin{tabular}{|c|c|c|c|}
\hline OVX 35 Hz & Tr.N./mm & Tr.N. & Tr.Wi. \\
\hline Ct.Wi. d. & $-0,284$ & $\mathbf{0 , 6 0 1}$ & $\mathbf{0 , 6 9 7}$ \\
\hline Ct.Ar. & $\mathbf{- 0 , 6 5 1}$ & 0,574 & 0,517 \\
\hline
\end{tabular}


Tabelle 21: Korrelation (Pearson r) von Kortikalis- und Trabekelparametern, nur OVX 50 Hz

\begin{tabular}{|c|c|c|c|}
\hline OVX 50 Hz & Tr.N./mm & Tr.N. & Tr.Wi. \\
\hline Ct.Wi. d. & $\mathbf{- 0 , 8 8 0}$ & $-0,600$ & $-0,401$ \\
\hline Ct.Ar. & $\mathbf{- 0 , 7 2 1}$ & $-0,119$ & 0,218 \\
\hline
\end{tabular}

Tabelle 22: Korrelation (Pearson r) von Kortikalis- und Trabekelparametern, nur OVX 70 Hz

\begin{tabular}{|c|c|c|c|}
\hline OVX 70 Hz & Tr.N./mm & Tr.N. & Tr.Wi. \\
\hline Ct.Wi. d. & $\mathbf{- 0 , 8 8 5}$ & $-0,364$ & $-0,151$ \\
\hline Ct.Ar. & $\mathbf{- 0 , 9 3 6}$ & $-0,115$ & $-0,063$ \\
\hline
\end{tabular}

Tabelle 23: Korrelation (Pearson r) von Kortikalis- und Trabekelparametern, nur OVX 90 Hz

\begin{tabular}{|c|c|c|c|}
\hline OVX 90 Hz & Tr.N./mm & Tr.N. & Tr.Wi. \\
\hline Ct.Wi. d. & $\mathbf{- 0 , 6 5 5}$ & 0,016 & $-0,088$ \\
\hline Ct.Ar. & $\mathbf{- 0 , 7 9 3}$ & 0,100 & $-0,004$ \\
\hline
\end{tabular}

Bei der Betrachtung der einzelnen Gruppen korreliert weiterhin die Trabekeldichte stark negativ mit der dorsalen Dicke der Kortikalis und der Kortikalisfläche. Einzige Ausnahme bildet die Gruppe OVX $35 \mathrm{~Hz}$, innerhalb derer die dorsale Kortikalisdicke nicht signifikant mit der Trabekeldichte korreliert, dafür jedoch mit der absoluten Anzahl der Trabekelkreuzungen und der Trabekeldicke. 


\section{Diskussion}

\subsection{Die ovariektomierte Ratte als Osteoporosemodell}

Die beschriebenen Untersuchungen wurden an ovariektomierten Ratten durchgeführt. Diese sind ein etabliertes Tiermodell für die durch postmenopausalen Knochenverlust bedingte Osteoporose. Der durch die Ovariektomie induzierte Verlust von Knochensubstanz der Ratte gleicht dem der postmenopausalen Frauen in wesentlichen Gesichtspunkten. So führt die Ovariektomie bei Ratten innerhalb von acht bis zehn Wochen zu einer signifikanten Reduktion der Knochenmineraldichte in der Lendenwirbelsäule, wobei in erster Linie die spongiösen Anteile der Wirbelkörper betroffen sind, indem das trabekuläre Netzwerk ausgedünnt wird (Miller und Wronski 1993; Omi und Ezawa 1995). Bereits drei Tage nach der Ovariektomie steigt die Zahl der Osteoklasten im trabekulären Knochen deutlich an, innerhalb von 42 Tagen findet sich eine signifikant reduzierte Trabekeldicke (Yamaura et al. 1996). Mit dem Verlust der Knochenmasse sinkt gleichzeitig auch die mechanische Stabilität des Knochens (Mosekilde et al. 1993).

Ein weiterer wesentlicher Aspekt ist das Ansprechen auf therapeutische Maßnahmen. Der durch die Ovariektomie induzierte Verlust von Knochensubstanz bei der Ratte lässt sich durch die selben Pharmaka beeinflussen, wie die postmenopausale Osteoporose der Frau (Kalu 1991).

Obwohl die Ovariektomie-induzierte Osteoporose der Ratte der postmenopausalen Osteoporose in vielen Punkten gleicht, ist nicht bekannt, dass bei Ratten osteoporotische Frakturen, zum Beispiel der Lendenwirbelkörper, auftreten. So fand sich in einer Untersuchung über den Zeitraum von 540 Tagen bei zwölf ovariektomierten Ratten, trotz deutlich reduzierter trabekulärer Knochensubstanz, keine gesteigerte Inzidenz spontaner Frakturen im Vergleich zur SHAM-operierten Kontrollgruppe (Miller und Wronski 1993).

Es wurden in der Vergangenheit verschiedene Tiermodelle für die Osteoporose verwendet, darunter ovariektomierte Hunde, Schafe, Schweine und Affen. Aufgrund der großen Ähnlichkeiten des östrogendefizienten Knochenmetabolismus von Ratten und Menschen 
sowie der guten Verfügbarkeit der Ratte ist dieses Modell jedoch das etablierteste (Barlet et al. 1994).

\subsection{Analyse der Ergebnisse der Mikroradiographie}

Die mikroradiographische Auswertung erlaubt Rückschlüsse über den Einfluss der WBV auf die Morphologie der Lendenwirbelkörper. Die Eigenschaften des trabekulären Netzwerks sowie der kortikalen Hülle wurden in vorangegangenen Studien bereits vielfach untersucht, die Mikroradiographie ist hierfür eine etablierte Methode, die jedoch nur zweidimensionale Bilder liefert und somit nicht in der Lage ist, die ganze Komplexität der Knochenmorphologie abzubilden. Neuere Studien (Christiansen und Silva 2006; Lynch et al. 2010) verwenden teilweise anstelle der Mikroradiographie die Mikrocomputertomographie, wobei den Untersuchern keine vergleichenden Daten über Qualitätsunterschiede zwischen den beiden Verfahren vorliegen.

Ein Versuch mit Schafen, deren Hinterbeine über den Zeitraum eines Jahres an fünf Tagen pro Woche mit einer Frequenz von $30 \mathrm{~Hz} 20$ Minuten lang vibriert wurden, zeigte den osteoanabolen Effekt der Vibration. In der Histomorphometrie fanden sich bei den Femora der vibrierten Tiere eine Zunahme des trabekulären Knochenvolumens um $32 \%$ und der Trabekelanzahl um 45\% im Vergleich zu den nicht-vibrierten Kontrollschafen (Rubin et al. 2002a). Diese Ergebnisse wurden in einer Studie mit ovariektomierten und SHAM-operierten Ratten bestätigt. Die Tiere wurden für 28 Tage der WBV mit 45 oder $90 \mathrm{~Hz}$ unterzogen, zehn Minuten täglich. In der Histomorphometrie der Tibiae zeigte sich ein signifikant erhöhtes trabekuläres Knochenvolumen bei den mit $90 \mathrm{~Hz}$ vibrierten Tieren im Vergleich zu den anderen Gruppen (Judex et al. 2007). Auch bei Mäusen hatte die WBV einen positiven Einfluss auf das Knochengewebe. Nachdem die Tiere über fünf Wochen täglich 15 Minuten mit $45 \mathrm{~Hz}$ vibriert worden waren, zeigte sich in der Mikrocomputertomographie des LWK V eine signifikante Zunahme des Knochenvolumens und der Trabekeldicke (Christiansen und Silva 2006). Ein weiterer Versuch untersuchte den Effekt der WBV auf den osteoporotischen Lendenwirbelkörper der Ratte. $\mathrm{Zu}$ diesem Zweck wurden ovariektomierte und SHAMoperierte Tiere über einen Zeitraum von 35 Tagen zweimal täglich mit einer Frequenz von 90 $\mathrm{Hz}$ vertikal vibriert und im Anschluss mit nicht-vibrierten Kontrollgruppen verglichen. In der Mikroradiographie zeigte sich bei den WBV-Tieren ein Anstieg der Trabekelzahl und deren Dicke im Vergleich zu den Kontrollgruppen (Sehmisch et al. 2009a). 
Trotz kleiner Unterschiede bei genauerer Betrachtung, beschreiben alle bisherigen Studien einen osteoanabolen Einfluss der WBV, besonders auf die trabekulären Bereiche des Knochens.

Diese Tendenz kann die hier vorliegende Untersuchung nur teilweise bestätigen. Die mit Abstand höchsten Werte für die absolute Anzahl der Trabekelkreuzungen fanden sich bei den SHAM-Tieren. Betrachtete man jedoch die Zahl der Trabekelkreuzungen in Relation zum Volumen der untersuchten Wirbelkörper, so zeigte sich, dass die Gruppen OVX $35 \mathrm{~Hz}$ und OVX $50 \mathrm{~Hz}$ signifikant mehr Trabekelkreuzungen pro $\mathrm{mm}^{3}$ aufwiesen, als die mit $90 \mathrm{~Hz}$ vibrierten Tiere, und, wenn auch nicht signifikant, so doch tendenziell mehr als die Gruppe OVX. Die Zahl der Trabekelkreuzungen bei der Gruppe OVX 90 Hz sank nach Bezug auf das Wirbelkörpervolumen und Ausschluss der SHAM-Tiere sogar signifikant unter den Wert der ovariektomierten und nicht-vibrierten Tiere, so dass die Möglichkeit in Betracht gezogen werden muss, dass die WBV mit $90 \mathrm{~Hz}$ einen eher negativen Effekt auf das trabekuläre Netzwerk des Wirbelkörpers hat. Dieser Verdacht wird weiter erhärtet bei Betrachtung der Parameter Trabekeldicke und Dichte der Trabekelkreuzungen, bei beiden zeigt die Gruppe OVX $90 \mathrm{~Hz}$ die niedrigsten Werte, die durchschnittliche Trabekeldicke der mit $90 \mathrm{~Hz}$ vibrierten Tiere ist signifikant geringer als die aller anderen Gruppen. Die übrigen Gruppen unterscheiden sich bezüglich der Trabekeldicke nicht signifikant voneinander.

Auf die Kortikalis hatte die WBV im vorliegenden Versuch keinen wesentlichen Einfluss. Analog zu den meisten der bisherigen Veröffentlichungen fanden sich keine signifikanten Unterschiede zwischen den sechs Gruppen für die Parameter ventrale Kortikalisdicke, dorsale Kortikalisdicke und Kortikalisfläche. Möglicherweise hätte das häufigere Vibrieren, zum Beispiel zweimal täglich, einen Effekt auf die Kortikalis. Dies legen Ergebnisse der eigenen Arbeitsgruppe nahe, bei der die zweimal tägliche Vibration mit $90 \mathrm{~Hz}$ für 15 Minuten auch zu einer Zunahme des kortikalen Knochenanteils geführt hatte (Sehmisch et al. 2009a).

\subsection{Analyse der Ergebnisse der Veraschung}

Die Veraschung der Knochen zeigte die Wirkung der WBV auf die Knochenmineraldichte. Laut WHO-Definition liegt eine Osteoporose vor, wenn die Knochendichte 2,5 Standardabweichungen unter den Mittelwert der Knochendichte skelettgesunder Erwachsener zwischen dem zwanzigsten und vierzigsten Lebensjahr (T-Score), bzw. den Mittelwert 
Skelettgesunder der gleichen Altersgruppe (Z-Score), fällt. Frühere Studien belegten den Einfluss der WBV auf die Knochendichte. So konnte gezeigt werden, dass der Verlust von Knochensubstanz in ovariektomierten Ratten durch die WBV mit $50 \mathrm{~Hz}$ für 30 Minuten an fünf Tagen der Woche über einen Zeitraum von drei Monaten den Verlust von Knochenmasse reduziert. Die Knochenmineraldichte in den Femora und Tibiae der vibrierten Tiere war sowohl in der SHAM-, als auch in der OVX-Gruppe signifikant höher, als bei den nichtvibrierten Tieren (Flieger et al. 1998). Eine ähnliche Untersuchung an Schafen lieferte vergleichbare Ergebnisse. Die Hinterbeine der Tiere wurden für ein Jahr an fünf Tagen der Woche für 20 Minuten mit einer Frequenz von $30 \mathrm{~Hz}$ vibriert. Das führte zu einer Zunahme des Knochenmineralgehalts der Femora um 10,6\% im Vergleich zur Kontrollgruppe (Rubin et al. 2002b). Das Prinzip wurde weiter in einer klinischen Studie an 70 postmenopausalen Frauen getestet. Diese wurden in zwei Gruppen eingeteilt, von denen eine keine WBV erfuhr, während die Probandinnen der anderen Gruppe über den Zeitraum von einem Jahr täglich 10 Minuten auf einer mit $30 \mathrm{~Hz}$ vibrierenden Plattform standen. Die Knochendichte wurde mittels DXA zu Beginn sowie nach sechs und zwölf Monaten gemessen. Während die Kontrollgruppe innerhalb dieses Jahres einen Verlust der Knochendichte im proximalen Femur von 2,13\% verzeichnen musste, stieg die BMD der vibrierten Gruppe um 0,04\%, was einem relativen Gewinn von 2,17\% entspricht. Die Ergebnisse waren mit einem p=0,06 knapp nicht signifikant (Rubin et al. 2004). Eine Meta-Analyse über die Wirkung der WBV auf die Knochenmineraldichte bestätigte diese Ergebnisse. Diese beschreibt die Zunahme der Knochenmineraldichte im Bereich des proximalen Femurs, jedoch nicht in der Wirbelsäule oder der Tibia postmenopausaler Frauen. Bei Kindern und jungen Erwachsenen zwischen vier und 20 Jahren hatte die WBV auch eine Zunahme des trabekulären Knochenvolumens in Wirbelsäule und Tibia zur Folge. Kein Effekt zeigte sich dagegen bei jungen Erwachsenen zwischen 19 und 38 Jahren (Slatkovska et al. 2010), was möglicherweise damit zu begründen ist, dass diese Altersgruppe auch unbehandelt die maximale Knochenmineraldichte aufweist. Eine der vorliegenden Untersuchung ähnliche Studie betrachtete den Einfluss der WBV auf den osteoporotischen Lendenwirbelkörper der Ratte. Nachdem die Tiere ovariektomiert oder SHAM-operiert worden waren, wurde jeweils die Hälfte der beiden Gruppen über 35 Tage zweimal täglich mit einer Frequenz von $90 \mathrm{~Hz}$ vertikal vibriert. Die Knochenmineraldichte wurde mittels Veraschung bestimmt. Es zeigte sich bei den vibrierten Tieren eine signifikant höhere Knochenmineraldichte, als in den nicht-vibrierten Ratten. Dabei lagen die Werte für die ovariektomierten Ratten jedoch immer unter denen der SHAM-Tiere (Sehmisch et al. 2009a). 
Bei der Bestimmung der Knochenmineraldichte der hier untersuchten Tiere wiesen die SHAM-Tiere die höchsten Werte auf, auf gleichem Signifikanzniveau waren die vibrierten Gruppen OVX $35 \mathrm{~Hz}$ und OVX $70 \mathrm{~Hz}$. Die geringste Knochenmineraldichte fand sich in der Gruppe OVX 90 Hz, deren Werte sogar die der nicht-vibrierten Gruppe OVX unterschritten. Diese Erkenntnis nährt die unter 4.2 geäußerte Vermutung, dass die WBV mit einer Frequenz von $90 \mathrm{~Hz}$ eher negativen Einfluss auf den Knochen hat und steht im Gegensatz zu den oben beschriebenen Ergebnissen der Arbeit von Sehmisch et al. 2009a, wobei die Tiere bei dieser Untersuchung zweimal täglich vibriert worden waren. Die WBV mit 35 und $70 \mathrm{~Hz}$ dagegen scheint einen sehr positiven Effekt auf die Knochenmineraldichte zu haben, nachdem die mit diesen Frequenzen vibrierten Tiere sich von den gesunden SHAM-Tieren nicht signifikant unterschieden. Trotz der verschiedenen Messmethoden für die Bestimmung der Knochenmineraldichte und damit eingeschränkter Vergleichbarkeit der verschiedenen Studien besteht Konsens darüber, dass die WBV einen positiven Effekt auf die Knochenmineraldichte hat. Dies konnte in der hier vorliegenden Studie für verschiedene Frequenzen bestätigt werden.

Zur genaueren Analyse der Knochen wurden außerdem der Calcium- und Phosphatgehalt der Lendenwirbelkörper bestimmt. Dieser neue Ansatz ist in bisherigen Studien nicht beschrieben, so dass die gewonnenen Ergebnisse nicht mit denen anderer Untersuchungen verglichen werden können. Auffällig war der relativ hohe prozentuale Phosphatgehalt in der Gruppe OVX $35 \mathrm{~Hz}$, die Gruppe, die auch bei den anderen Messungen tendenziell die besten Werte erzielte. Der Calciumgehalt dagegen unterschied sich nicht signifikant innerhalb der Gruppen, so dass davon auszugehen ist, dass das vermehrt enthaltene Phosphat nicht als Hydroxylapatit, sondern in Form von Di- oder Triphosphat in den Knochen eingebaut worden ist. Welchen Einfluss dies auf die biomechanische Festigkeit oder die Knochenmikrostruktur hat, bleibt abzuwarten. Entsprechend den Daten der vorliegenden Studie scheint die Di- oder Triphosphateinlagerung in einer verbesserten Festigkeit zu resultieren. Dieses Ergebnis deckt sich mit bisher nicht veröffentlichten Daten der Arbeitsgruppe. Nach Therapie mit Alendronsäure, dem Mittel der Wahl zur Behandlung der Osteoporose, zeigte sich an intakten Knochen eine verbesserte biomechanische Festigkeit und höhere mineralische Dichte. Die chemische Elementanalyse zeigte auch hier eine verstärkte Phosphatanreicherung im Knochen, was zu negativen Effekten in der computertomographischen Knochendichteanalyse führte. 


\subsection{Analyse der Ergebnisse des biomechanischen Kompressionstests}

Mit dem biomechanischen Kompressionstest wurde der Effekt der WBV auf die mechanische Stabilität der Lendenwirbelkörper untersucht. Sinterungsfrakturen der Lendenwirbelsäule aufgrund reduzierter mechanischer Stabilität sind ein klassisches Phänomen bei der postmenopausalen Osteoporose (Gardner et al. 2006). Ein Tierversuch, welcher die Lendenwirbelkörper von drei verschiedenen Mäusestämmen verglich, konnte zeigen, dass eine höhere Knochenmineraldichte nicht gleichbedeutend mit einer höheren mechanischen Belastbarkeit ist (Akhter et al. 2004). Um die biomechanische Stabilität eines Knochens zu messen genügt es also nicht, dessen Knochenmineraldichte $\mathrm{zu}$ bestimmen, sondern er muss einem mechanischen Kompressionstest unterzogen werden, was in Humanstudien jedoch nicht möglich ist. Diese Messung der biomechanischen Knochenstabilität ist in vorangegangenen Studien bereits vielfach durchgeführt worden, wobei häufig nicht Wirbelkörper, sondern andere Knochen wie Tibiae und Femora untersucht wurden (Flieger et al. 1998; Hao et al. 2007; Leung et al. 2009; Stuermer et al. 2006).

Andere Untersucher verwendeten zwar Wirbelkörper, komprimierten diese jedoch nicht in toto, sondern nur Teile davon. Mit dem Ziel einer reproduzierbaren Untersuchung entfernten sie vor der Messung entweder die Grund- und Deckplatten bzw. die gesamte Kortikalis, oder sie verwendeten nur Knochenzylinder (Breitman et al. 2005; Dai et al. 2004; Ikeda et al. 2001).

Es ist davon auszugehen, dass die mechanische Stabilität eines Wirbelkörpers nur dann beurteilt werden kann, wenn der intakte Wirbelkörper einem Kompressionstest unterzogen wird, da das komplexe Zusammenspiel von trabekulärem Netzwerk, kortikaler Hülle sowie den Quer- und Dornfortsätzen als Ganzes erfasst werden muss. Zu diesem Zweck entwickelten Sehmisch et al. einen biomechanische Kompressionstest, bei dem die Stabilität des intakten Lendenwirbelkörpers gemessen werden kann (Sehmisch et al. 2009b). Dieser wurde auch in der hier beschriebenen Studie angewendet.

Da die biomechanische Stabilität eines Körpers mit dessen Volumen steigt (Ruyssen-Witrand et al. 2007), wurde dieser Einfluss rechnerisch eliminiert, indem die für Steigung, Streckgrenze und Maximalkraft gemessenen Werte bei der statistischen Auswertung in Relation zum Wirbelkörpervolumen betrachtet wurden. Für alle drei erfassten Parameter fanden sich nur signifikante Unterschiede zwischen den SHAM-Tieren und allen anderen Gruppen, unabhängig ob mit oder ohne Bezug auf das Volumen. Die ovariektomierten Tiere 
unterschieden sich nicht signifikant untereinander, wobei sich bei der Gruppe OVX $35 \mathrm{~Hz}$ konstant die höchsten Werte nach den SHAM-Tieren fanden.

Flieger et al. verglichen die mechanische Stabilität der Femora ovariektomierter und gesunder Ratten, welche über einen Zeitraum von zwölf Wochen an je fünf Tagen für 30 Minuten mit einer Frequenz von $50 \mathrm{~Hz}$ der WBV unterzogen worden waren. Dabei fanden sich eine, wenn auch nicht signifikant, erhöhte Stabilität bei den WBV-Tieren (Flieger et al. 1998). Ebenso fand sich eine höhere mechanische Belastbarkeit für Femora und Tibiae vibrierter Ratten in Vergleich zur nicht-vibrierten Kontrollgruppe in einem weiteren Tierversuch. Die ovariektomierten oder SHAM-operierten Tiere waren über den Zeitraum von 90 Tagen mit 17 oder $45 \mathrm{~Hz}$ täglich 30 Minuten vibriert worden. Die Maximalkraft für die mechanische Belastung der Tibiae war bei den mit $17 \mathrm{~Hz}$ vibrierten Tieren $12 \%$, bei den mit $45 \mathrm{~Hz}$ vibrierten Tieren $8 \%$ höher als bei den ovariektomierten und nicht-vibrierten Tieren. Die maximale Belastbarkeit der Femora erhöhte sich durch die WBV um 15\% (17 Hz) bzw. 19\% (45 Hz) (Oxlund et al. 2003).

In einer anderen Studie, welche den Einfluss der WBV auf den osteoporotischen Lendenwirbelkörper der Ratte untersuchte, waren die Tiere über einen Zeitraum von 35 Tagen zweimal täglich mit einer Frequenz von $90 \mathrm{~Hz}$ vertikal vibriert worden. Dies führte zu einer signifikant verbesserten mechanischen Stabilität im Vergleich zur nicht-vibrierten Kontrollgruppe, die ovariektomierten Tiere erreichten ähnliche Werte wie die nichtosteoporotischen SHAM-Tiere (Sehmisch et al. 2009a).

Diese Ergebnisse konnten in der vorliegenden Untersuchung nicht reproduziert werden, zwei wesentliche Aspekte sind als Ursache dafür in Betracht zu ziehen. Aufgrund der noch relativ neuen Herangehensweise, den biomechanischen Kompressionstest am intakten Wirbelkörper durchzuführen, ist die Vergleichbarkeit mit anderen Studien, welche nur Teile des LWK einem Kompressionstest unterzogen haben, nur bedingt gegeben. Dieses Verfahren wurde zuvor nur von Sehmisch et al. 2009a durchgeführt, in deren Studie waren die Tiere zweimal täglich der WBV unterzogen worden. Die Vermutung liegt also nahe, dass es, unabhängig von der Frequenz, nicht ausreicht, die WBV nur einmal täglich für 15 Minuten durchzuführen, um eine signifikante Verbesserung der biomechanischen Knochenstabilität zu erreichen. Eine längere Versuchsdauer oder das mehrmals tägliche Durchführen der WBV könnte den Einfluss auf den osteoporotischen Knochen verstärken. Weiter gibt es bisher keine Veröffentlichungen, welche den Einfluss der WBV bei Tetrapoden auf die Wirbelsäule mit dem Einfluss auf die Extremitäten vergleicht. 


\subsection{Analyse der korrelierten Ergebnisse}

Die Korrelation der Ergebnisse der Mikroradiographie und des biomechanischen Kompressionstests erfolgte, um zu analysieren, inwiefern die Kenntnis eines dieser Parameter Rückschlüsse auf den Anderen erlaubt. Während die absolute Anzahl der Trabekelkreuzungen sowie deren Dichte stark positiv mit den biomechanischen Parametern Steigung, Streckgrenze und Maximalkraft korrelierten, schien die durchschnittliche Dicke der Trabekel die mechanischen Eigenschaften des Wirbelkörpers nicht zu beeinflussen. Bei der Analyse der Zusammenhänge biomechanischer und morphologischer Ergebnisse fiel die negative Korrelation der Kortikalisparameter mit der Steigung, der Streckgrenze und der Maximalkraft auf, wenn diese auch nicht signifikant war. Daraufhin wurden die morphologischen Parameter auf Abhängigkeiten untereinander untersucht. Dabei zeigte sich eine stark negative Korrelation zwischen der Dichte der Trabekelkreuzungen und der dorsalen Kortikalisdicke bzw. der Kortikalisfläche. Um dies genauer zu ergründen wurden die gleiche Korrelationen für alle untersuchten Gruppen einzeln berechnet, wobei das Ergebnis für die Gruppen SHAM, OVX, OVX $50 \mathrm{~Hz}$, OVX $70 \mathrm{~Hz}$ und OVX $90 \mathrm{~Hz}$ reproduzierbar war. Lediglich die Gruppe OVX $35 \mathrm{~Hz}$ zeigte gänzlich unterschiedliche Ergebnisse für die dorsal Kortikalisdicke, diese korrelierte hier zwar auch leicht mit der Dichte der Trabekelkreuzungen, stand aber gleichzeitig in stark positivem Zusammenhang mit der absoluten Zahl der Trabekelkreuzungen und der durchschnittlichen Trabekeldicke. Abhängigkeiten wie diese sind den Untersuchern aus der Literatur nicht bekannt. Man könnte vermuten, dass der negativen Korrelation von Kortikalisdicke und Trabekeldichte ein Kompensationsmechanismus zugrunde liegt, klarer dagegen die stark positive Korrelation von Trabekeldichte und deren absoluter Anzahl mit der mechanischen Stabilität der Wirbelkörper. Nachdem Julius Wolff bereits im 19. Jahrhundert den Einfluss mechanischer Zug- und Druckbelastung auf die Trabekelstruktur im proximalen Femur beschrieben hatte, ist dieser Zusammenhang Bestätigung eines altbekannten Fakts und für die Untersucher eine Affirmation des Testverfahrens. 


\subsection{Schlussfolgerungen}

Die vorliegende Untersuchung konnte belegen, dass die mechanische Stimulation mittels vertikaler WBV den osteoporotischen Lendenwirbelkörper der Ratte beeinflusst. So hatte die WBV mit $35 \mathrm{~Hz}$ tendenziell eine Verbesserung aller gemessenen Parameter im Vergleich zu den anderen osteoporotischen Gruppen zur Folge, wenn diese auch nicht immer signifikant war. Die Vibration mit einer Frequenz von $90 \mathrm{~Hz}$ hatte dagegen in der vorliegenden Untersuchung eher negative Effekte, sowohl auf die morphologischen Parameter, als auch auf Stabilität und Knochenmineraldichte. Diese Daten stehen im Gegensatz zu den Erkenntnissen von Sehmisch et al. 2009, in deren Studie fand sich ein deutlich positiver Einfluss der WBV mit $90 \mathrm{~Hz}$, wobei die Tiere bei diesem Versuch zweimal täglich vibriert worden waren. Die WBV mit $90 \mathrm{~Hz}$ scheint nur bei zweimal täglicher Anwendung den gewünschten Effekt zu erzielen und wirkt bei einmal täglicher Durchführung eher entgegengesetzt. Bei den Gruppen OVX $50 \mathrm{~Hz}$ und OVX $70 \mathrm{~Hz}$ zeigten sich keine klaren Tendenzen in eine Richtung. Weiterhin konnte eindeutig die Abhängigkeit der mechanischen Stabilität der Wirbelkörper von der Trabekelmorphologie belegt werden.

Im Hinblick auf vorangegangene Studien ist davon auszugehen, dass es nicht ausreicht, die WBV über einen Zeitraum von nur 30 Tagen einmal täglich für 15 Minuten durchzuführen, weitere Untersuchungen müssen sich damit befassen, wie häufig die WBV angewendet werden muss, um höher signifikante Effekte zu erzielen. Der Zusammenhang des Phosphatgehalts mit den mechanischen Eigenschaften des Knochens bedarf ebenfalls weiterer Betrachtung. 


\section{$5 \quad$ Zusammenfassung}

Um den Einfluss der vertikalen Ganzkörpervibration mit verschiedenen Frequenzen auf den osteoporotischen Lendenwirbelkörper der Ratte zu untersuchen, wurden zu Beginn des Versuches 75 Ratten ovariektomiert und 15 Ratten SHAM-operiert. Nach 65 Tagen, in denen die Versuchstiere eine Osteoporose entwickelten, wurde mit der mechanischen Stimulation durch vertikale Vibration begonnen. Dabei wurden die Tiere in sechs Gruppen aufgeteilt, zum einen die nicht-osteoporotischen Tiere (SHAM) und eine ovariektomierte Kontrollgruppe (OVX), welche nicht vibriert wurden, zum anderen vier Gruppen ovariektomierter Tiere, welche mit den Frequenzen 35, 50, 70 und $90 \mathrm{~Hz}$ vibriert wurden (OVX $35 \mathrm{~Hz}$, OVX $50 \mathrm{~Hz}$, OVX $70 \mathrm{~Hz}$ und OVX $90 \mathrm{~Hz}$ ). Über einen Zeitraum von 30 Tagen wurden die Tiere täglich 15 Minuten mit der ihnen zugeordneten Frequenz vibriert. Nach Dekapitation der Tiere wurden die Wirbelkörper präpariert und den einzelnen Untersuchungen zugeführt. Für das Erstellen der Mikroradiographien wurden die LWK I in Methylmethacrylat eingebettet, nach Aushärtung konnten $100 \mu \mathrm{m}( \pm 20 \mu \mathrm{m})$ dünne Sagittalschnitte angefertigt werden, welche geröntgt und fixiert wurden und im Anschluss für die mikroradiographische Auswertung zur Verfügung standen. Die LWK II wurden verascht und deren Knochenmineraldichte sowie der Calcium- und Phosphatgehalt bestimmt. Um die mechanische Belastbarkeit der Wirbelkörper $\mathrm{zu}$ erfassen, wurden die LWK IV in toto einem standardisierten biomechanischen Kompressionstest unterzogen.

Die Auswertung zeigte tendenziell einen positiven Einfluss der WBV auf den osteoporotischen Knochen, besonders die Gruppe OVX $35 \mathrm{~Hz}$ profitierte von der mechanischen Stimulation, wohingegen die Vibrationsfrequenz von $90 \mathrm{~Hz}$ eher negative Auswirkungen auf morphologische Parameter, Knochenmineraldichte und Stabilität der Wirbelkörper im Kompressionstest hatte. Es zeigte sich bei der Korrelation der Ergebnisse eine starke Abhängigkeit der mechanischen Knochenstabilität von der Menge der Trabekelkreuzungen. Erstmalig wurde in der vorliegenden Studie auch der Calcium- und Phosphatgehalt in diesem Zusammenhang bestimmt. Der Calciumgehalt der Wirbelkörper unterschied sich zwischen den Gruppen nicht, der Phosphatgehalt dagegen verhielt sich weitestgehend analog zu den anderen erfassten Parametern, war also vergleichsweise hoch bei OVX $35 \mathrm{~Hz}$ und niedrig bei OVX $90 \mathrm{~Hz}$. Weitere Versuche sind nötig, um den Zusammenhang zwischen einem hohen Phosphatgehalt und mechanischer Knochenstabilität 
genauer zu betrachten. Diese Studie zeigte, dass die vertikale WBV mit einer Frequenz von $35 \mathrm{~Hz}, 50 \mathrm{~Hz}$ oder $70 \mathrm{~Hz}$ die Knochenstruktur des osteoporotischen Lendenwirbelkörpers der Ratte im Experiment tendenziell positiv beeinflusst. $\mathrm{Ob}$ dieses Ergebnis durch täglich mehrmalige oder über einen längeren Zeitraum durchgeführte WBV weiter intensiviert werden kann, bleibt weiteren Untersuchungen überlassen. 


\section{Tabellenverzeichnis}

Tabelle 1: Ursachen der sekundären Osteoporose, modifiziert nach Classen et al. 2003 _........ 8

Tabelle 2: T-Werte als Therapieindikation in Abhängigkeit von Alter und Geschlecht,

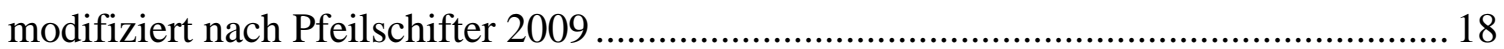

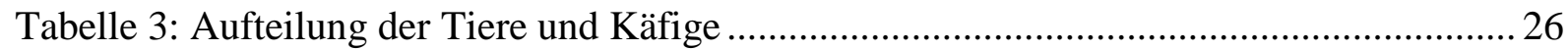

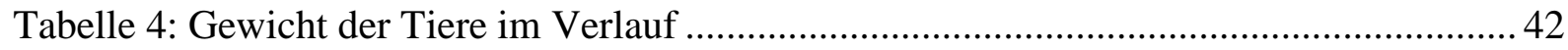

Tabelle 5: Tägliche Futteraufnahme der Tiere im Verlauf ................................................... 44

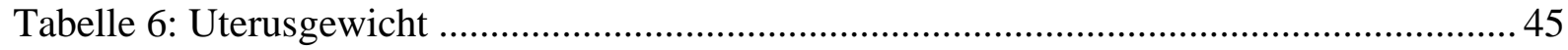

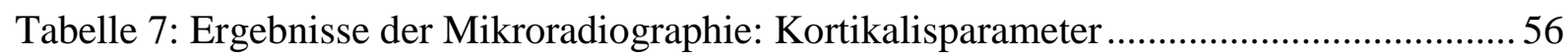

Tabelle 8: Ergebnisse der Mikroradiographie: Kortikalisparameter, bezogen auf das

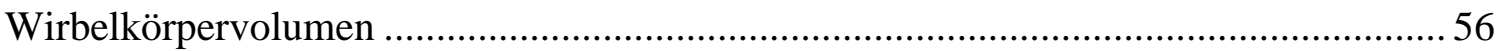

Tabelle 9: Ergebnisse der Mikroradiographie: Trabekelparameter......................................... 57

Tabelle 10: Ergebnisse der Mikroradiographie: Trabekelparameter, bezogen auf das

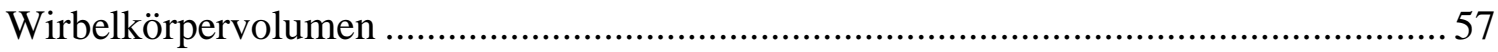

Tabelle 11: Zusammenfassung der Ergebnisse der Veraschung ............................................ 61

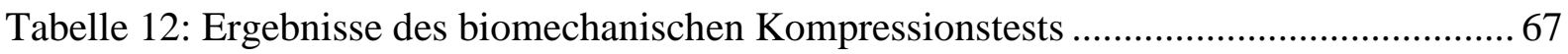

Tabelle 13: Ergebnisse des biomechanischen Kompressionstests, bezogen auf das

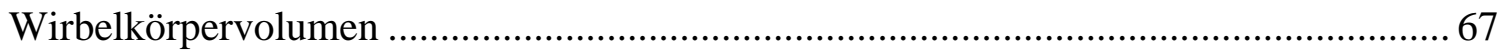

Tabelle 14: Korrelation (Pearson r) des Kompressionsversuchs mit der Mikroradiographie .. 68

Tabelle 15: Korrelation $\left(\mathrm{R}^{2}\right)$ des Kompressionsversuchs mit der Mikroradiographie.............. 68

Tabelle 16: Korrelation (Pearson r) von Kortikalis- und Trabekelparametern ........................ 69

Tabelle 17: Korrelation $\left(\mathrm{R}^{2}\right)$ von Kortikalis- und Trabekelparametern ...................................69

Tabelle 18: Korrelation (Pearson r) von Kortikalis- und Trabekelparametern, nur SHAM .... 69

Tabelle 19: Korrelation (Pearson r) von Kortikalis- und Trabekelparametern, nur OVX ....... 69

Tabelle 20: Korrelation (Pearson r) von Kortikalis- und Trabekelparametern, nur OVX $35 \mathrm{~Hz}$

Tabelle 21: Korrelation (Pearson r) von Kortikalis- und Trabekelparametern, nur OVX $50 \mathrm{~Hz}$ 70

Tabelle 22: Korrelation (Pearson r) von Kortikalis- und Trabekelparametern, nur OVX $70 \mathrm{~Hz}$ 70

Tabelle 23: Korrelation (Pearson r) von Kortikalis- und Trabekelparametern, nur OVX $90 \mathrm{~Hz}$ 70 


\section{$7 \quad$ Abbildungsverzeichnis}

Abbildung 1: Anatomie der Ratte, modifiziert nach Hebel und Stromberg 1986, S. 10 ........ 29

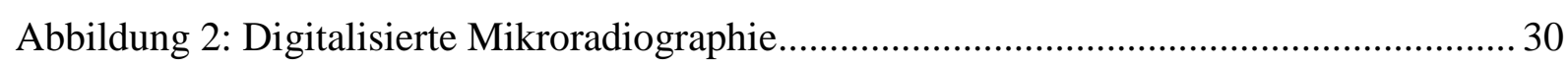

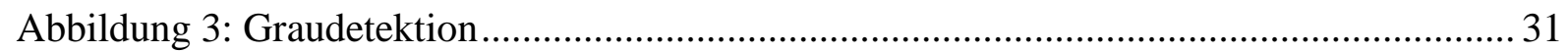

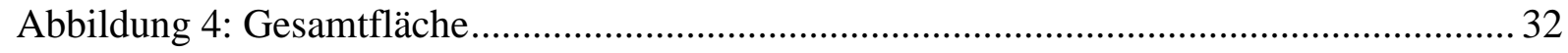

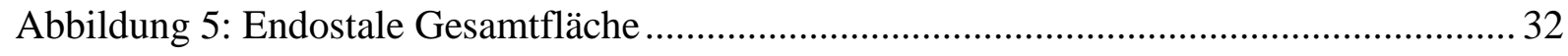

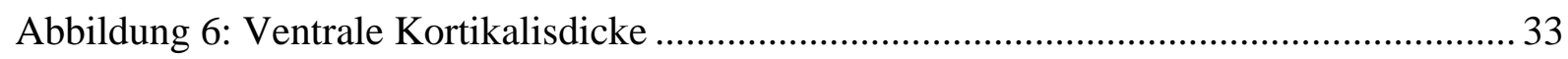

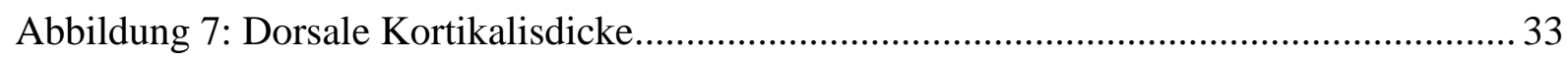

Abbildung 8: LWK in der Zwick-Testmaschine................................................................ 38

Abbildung 9: Kraft-Weg-Diagramm des biomechanischen Kompressionstests ...................... 39

Abbildung 10: Gewicht der Tiere im Verlauf ........................................................................ 41

Abbildung 11: Futteraufnahme der Tiere im Verlauf ......................................................... 43

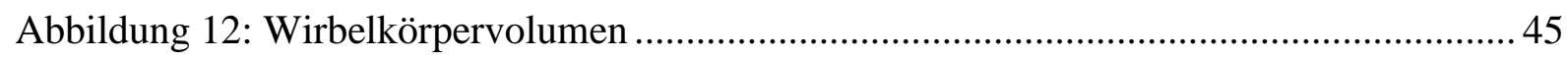

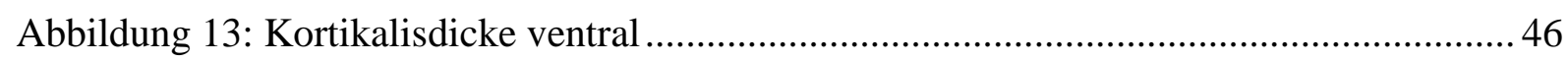

Abbildung 14: Kortikalisdicke ventral, ohne SHAM-Tiere ................................................. 46

Abbildung 15: Kortikalisdicke ventral, bezogen auf das Wirbelkörpervolumen..................... 47

Abbildung 16: Kortikalisdicke ventral, ohne SHAM-Tiere, ............................................ 47

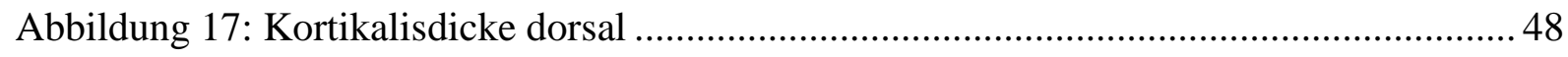

Abbildung 18: Kortikalisdicke dorsal, ohne SHAM-Tiere .............................................. 48

Abbildung 19: Kortikalisdicke dorsal, bezogen auf das Wirbelkörpervolumen ...................... 48

Abbildung 20: Kortikalisdicke dorsal, ohne SHAM-Tiere, .............................................. 49

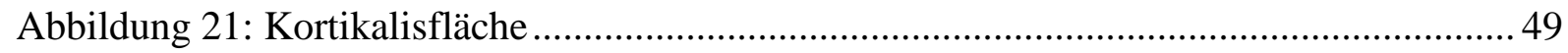

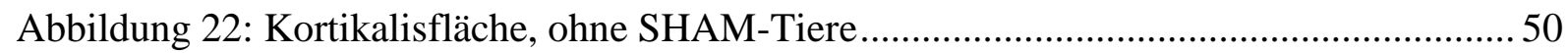

Abbildung 23: Kortikalisfläche, bezogen auf das Wirbelkörpervolumen................................ 50

Abbildung 24: Kortikalisfläche, ohne SHAM-Tiere, ........................................................ 50

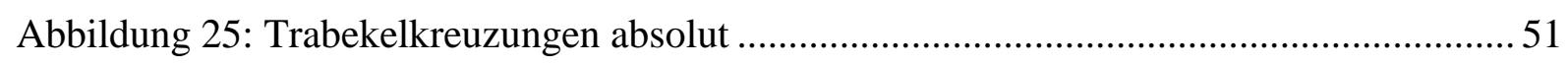

Abbildung 26: Trabekelkreuzungen absolut, ohne SHAM-Tiere ........................................... 51

Abbildung 27: Trabekelkreuzungen absolut, bezogen auf das Wirbelkörpervolumen .............52

Abbildung 28: Trabekelkreuzungen absolut, ohne SHAM-Tiere, ...................................... 52

Abbildung 29: Dichte der Trabekelkreuzungen ................................................................. 53

Abbildung 30: Dichte der Trabekelkreuzungen, ohne SHAM-Tiere ...................................... 53

Abbildung 31: Dichte der Trabekelkreuzungen, bezogen auf das Wirbelkörpervolumen........ 53

Abbildung 32: Dichte der Trabekelkreuzungen, ohne SHAM-Tiere, .................................... 54

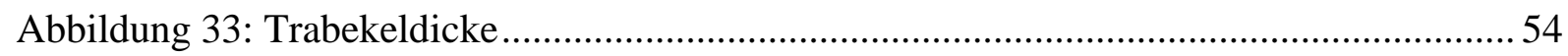

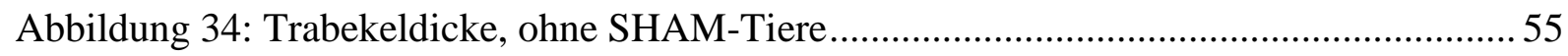


Abbildung 35: Trabekeldicke, bezogen auf das Wirbelkörpervolumen ................................ 55

Abbildung 36: Trabekeldicke, ohne SHAM-Tiere, ,............................................................ 55

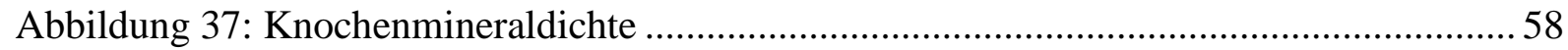

Abbildung 38: Knochenmineraldichte, ohne SHAM-Tiere ............................................... 58

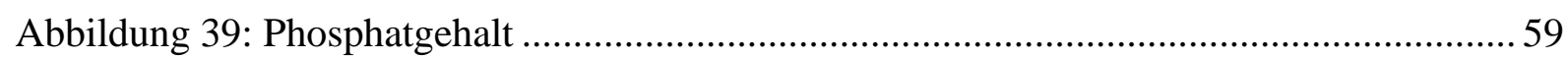

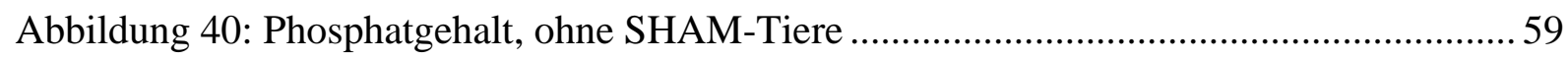

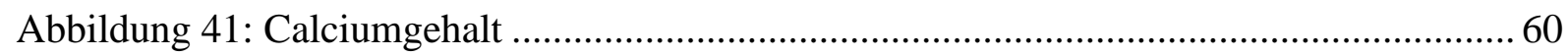

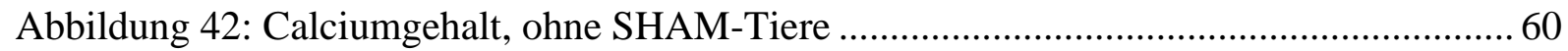

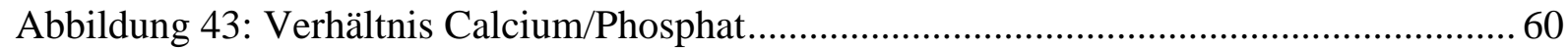

Abbildung 44: Verhältnis Calcium/Phosphat, ohne SHAM-Tiere........................................ 61

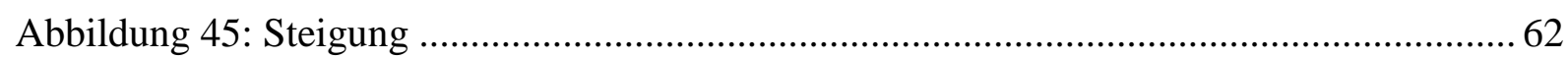

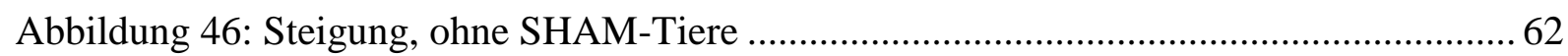

Abbildung 47: Steigung, bezogen auf das Wirbelkörpervolumen ......................................... 63

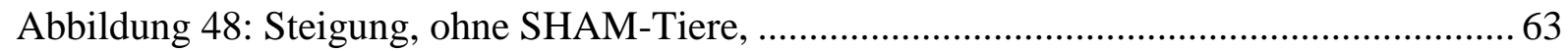

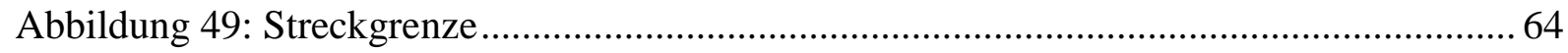

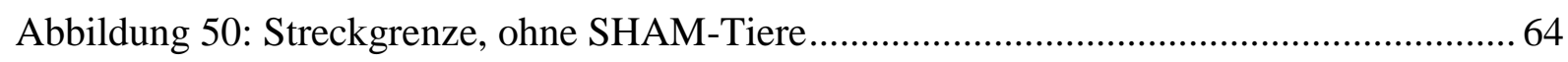

Abbildung 51: Streckgrenze, bezogen auf das Wirbelkörpervolumen .................................... 64

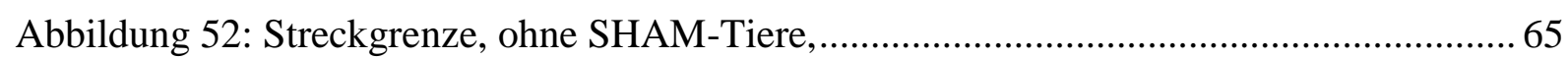

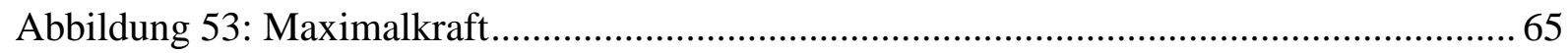

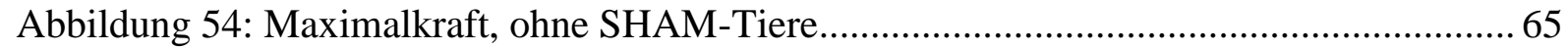

Abbildung 55: Maximalkraft, bezogen auf das Wirbelkörpervolumen ................................. 66

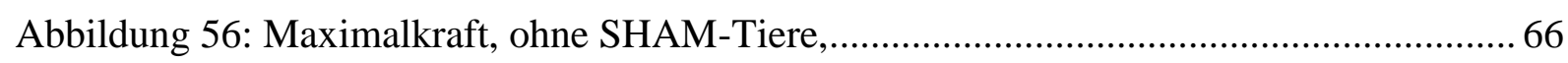




\section{Literaturverzeichnis}

1. Akhter MP, Otero JK, Iwaniec UT, Cullen DM, Haynatzki GR, Recker RR (2004): Differences in vertebral structure and strength of inbred female mouse strains. J Musculoskelet Neuronal Interact 4(1): 33-40.

2. Anderson GL, Limacher M, Assaf AR, Bassford T, Beresford SA, Black H, Bonds D, Brunner R, Brzyski R, Caan B, et al. (2004): Effects of conjugated equine estrogen in postmenopausal women with hysterectomy: the Women's Health Initiative randomized controlled trial. JAMA 291(14): 1701-1712.

3. Armbrecht G, Belavy DL, Gast U, Bongrazio M, Touby F, Beller G, Roth HJ, Perschel FH, Rittweger J, Felsenberg D (2009): Resistive vibration exercise attenuates bone and muscle atrophy in 56 days of bed rest: biochemical markers of bone metabolism. Osteoporos Int. 21(4): 597-607.

4. Barlet JP, Coxam V, Davicco MJ, Gaumet N (1994): Animal models of postmenopausal osteoporosis. Reprod Nutr Dev 34(3): 221-236.

5. Bartl R: Osteoporose: Prävention - Diagnostik - Therapie. 3. Auflage; Georg Thieme Verlag, Stuttgart 2008

6. Benninghoff A, Drenckhahn D: Anatomie. Makroskopische Anatomie, Histologie, Embryologie, Zellbiologie, Bd. 1. 17. Auflage; Urban \& Fischer, München 2008

7. Beral V (2003): Breast cancer and hormone-replacement therapy in the Million Women Study. Lancet 362(9382): 419-427.

8. Black DM, Thompson DE, Bauer DC, Ensrud K, Musliner T, Hochberg MC, Nevitt MC, Suryawanshi S, Cummings SR (2000): Fracture risk reduction with alendronate in women with osteoporosis: the Fracture Intervention Trial. FIT Research Group. J Clin Endocrinol Metab 85(11): 4118-4124.

9. Black DM, Schwartz AV, Ensrud KE, Cauley JA, Levis S, Quandt SA, Satterfield S, Wallace RB, Bauer DC, Palermo L, et al. (2006): Effects of continuing or stopping alendronate after 5 years of treatment: the Fracture Intervention Trial Long-term Extension (FLEX): a randomized trial. JAMA 296(24): 2927-2938.

10. Bonjour P, Clark P, Cooper C, Dawson-Hughes B, De Laet C, Delmas P, Johansson H, Johnell O, Kanis J, Melton J, et al. (2004): WHO scientific group on the assessment of osteoporosis at primary health care level.

11. Breitman PL, Fonseca D, Ward WE (2005): Combination of soy protein and high dietary calcium on bone biomechanics and bone mineral density in ovariectomized 
rats. Menopause 12(4): 428-435.

12. Budsberg SC, Jevens DJ, Brown J, Foutz TL, DeCamp CE, Reece L (1993): Evaluation of limb symmetry indices, using ground reaction forces in healthy dogs. Am J Vet Res 54(10): 1569-1574.

13. Burr DB (1997): Muscle strength, bone mass, and age-related bone loss. J Bone Miner Res 12(10): 1547-1551.

14. Canalis E, Giustina A, Bilezikian JP (2007): Mechanisms of anabolic therapies for osteoporosis. N Engl J Med 357(9): 905-916.

15. Christiansen BA, Silva MJ (2006): The effect of varying magnitudes of whole-body vibration on several skeletal sites in mice. Ann Biomed Eng 34(7): 1149-1156.

16. Christiansen C (1993): Consensus development conference: diagnosis, prophylaxis, and treatment of osteoporosis. Am J Med 94(6): 646-650.

17. Classen M, Diehl V, Kochsiek K: Innere Medizin. 5. Auflage; Urban \& Fischer, München 2004

18. Cummings SR, Melton LJ (2002): Epidemiology and outcomes of osteoporotic fractures. Lancet 359(9319): 1761-1767.

19. Dai RC, Liao EY, Yang C, Wu XP, Jiang Y (2004): Microcracks: an alternative index for evaluating bone biomechanical quality. J Bone Miner Metab 22(3): 215223.

20. Delank H-W, Gehlen W: Neurologie. 11. Auflage; Georg Thieme Verlag, Stuttgart 2006

21. Ettinger B, Black DM, Mitlak BH, Knickerbocker RK, Nickelsen T, Genant HK, Christiansen C, Delmas PD, Zanchetta JR, Stakkestad J, et al. (1999): Reduction of vertebral fracture risk in postmenopausal women with osteoporosis treated with raloxifene: results from a 3-year randomized clinical trial. Multiple Outcomes of Raloxifene Evaluation (MORE) Investigators. JAMA 282(7): 637-645.

22. Fassbender WJ, Steinhauer B, Stracke H, Schumm-Draeger PM, Usadel KH (2002): Validation of a new automated immunoassay for measurement of intact osteocalcin. Clin Lab 48(1-2): 31-38.

23. Fisk JW, Baigent ML (1975): Clinical and radiological assessment of leg length. $\mathrm{N}$ Z Med J 81(540): 477-480. 
24. Flieger J, Karachalios T, Khaldi L, Raptou P, Lyritis G (1998): Mechanical stimulation in the form of vibration prevents postmenopausal bone loss in ovariectomized rats. Calcif Tissue Int 63(6): 510-514.

25. Forwood MR (1996): Inducible cyclo-oxygenase (COX-2) mediates the induction of bone formation by mechanical loading in vivo. J Bone Miner Res 11(11): 16881693.

26. Fox SW, Chambers TJ, Chow JW (1996): Nitric oxide is an early mediator of the increase in bone formation by mechanical stimulation. Am J Physiol 270(6 Pt 1): E955-960.

27. Frost HM: The Utah Paradigm of Skeletal Physiology, Band 1. International Society of Musculoskeletal and Neuronal Interactions ISMNI, 1960.

28. Frost HM (2000): The Utah paradigm of skeletal physiology: an overview of its insights for bone, cartilage and collagenous tissue organs. J Bone Miner Metab 18(6): 305-316.

29. Gao Y, Wu X, Terauchi M, Li JY, Grassi F, Galley S, Yang X, Weitzmann MN, Pacifici R (2008): T cells potentiate PTH-induced cortical bone loss through CD40L signaling. Cell Metab $\underline{8(2)}$ : 132-145.

30. Gardner MJ, Demetrakopoulos D, Shindle MK, Griffith MH, Lane JM (2006): Osteoporosis and skeletal fractures. Hospital for Special Surgery J 2(1): 62-69.

31. Gomez B, Jr., Ardakani S, Ju J, Jenkins D, Cerelli MJ, Daniloff GY, Kung VT (1995): Monoclonal antibody assay for measuring bone-specific alkaline phosphatase activity in serum. Clin Chem 41(11): 1560-1566.

32. Goodship AE, Lawes TJ, Rubin CT (2009): Low-magnitude high-frequency mechanical signals accelerate and augment endochondral bone repair: preliminary evidence of efficacy. J Orthop Res 27(7): 922-930.

33. Hao YJ, Zhang G, Wang YS, Qin L, Hung WY, Leung K, Pei FX (2007): Changes of microstructure and mineralized tissue in the middle and late phase of osteoporotic fracture healing in rats. Bone 41(4): 631-638.

34. Harris ST, Watts NB, Genant HK, McKeever CD, Hangartner T, Keller M, Chesnut $\mathrm{CH}$, 3rd, Brown J, Eriksen EF, Hoseyni MS, et al. (1999): Effects of risedronate treatment on vertebral and nonvertebral fractures in women with postmenopausal osteoporosis: a randomized controlled trial. Vertebral Efficacy With Risedronate Therapy (VERT) Study Group. JAMA 282(14): 1344-1352.

35. Häussler B, Gothe H, Gol D, Glaeske G, Pientka L, Felsenberg D (2007): 
Epidemiology, treatment and costs of osteoporosis in Germany--the BoneEVA Study. Osteoporos Int 18(1): 77-84.

36. Hebel R, Stromberg MW: Anatomy and embryology of the laboratory rat. Biomed, Wörthsee 1986.

37. Ikeda S, Tsurukami H, Ito M, Sakai A, Sakata T, Nishida S, Takeda S, Shiraishi A Nakamura T (2001): Effect of trabecular bone contour on ultimate strength of lumbar vertebra after bilateral ovariectomy in rats. Bone 28(6): 625-633.

38. Judex S, Gupta S, Rubin C (2009): Regulation of mechanical signals in bone. Orthod Craniofac Res 12(2): 94-104.

39. Judex S, Lei X, Han D Rubin C (2007): Low-magnitude mechanical signals that stimulate bone formation in the ovariectomized rat are dependent on the applied frequency but not on the strain magnitude. J Biomech 40(6): 1333-1339.

40. Junqueira LC, Carneiro J: Histologie. 6. Auflage; Springer Verlag, Berlin 2004

41. Kalpakcioglu BB, Morshed S, Engelke K, Genant HK (2008): Advanced imaging of bone macrostructure and microstructure in bone fragility and fracture repair. J Bone Joint Surg Am 90 Suppl 1: 68-78.

42. Kalu DN (1991): The ovariectomized rat model of postmenopausal bone loss. Bone Miner 15(3): 175-191.

43. Klein-Nulend J, Burger EH, Semeins CM, Raisz LG, Pilbeam CC (1997): Pulsating fluid flow stimulates prostaglandin release and inducible prostaglandin $\mathrm{G} / \mathrm{H}$ synthase mRNA expression in primary mouse bone cells. J Bone Miner Res $\underline{12(1)}$ : 45-51.

44. Lauper M, Kuhn A, Gerber R, Luginbühl H, Radlinger L (2009): Pelvic floor stimulation: What are the good vibrations?. Neurourol Urodyn 28(5):405-410.

45. Lee K, Jessop H, Suswillo R, Zaman G, Lanyon L (2003): Endocrinology: bone adaptation requires oestrogen receptor-alpha. Nature 424(6947): 389.

46. Leung KS, Shi HF, Cheung WH, Qin L, Ng WK, Tam KF, Tang N (2009): Lowmagnitude high-frequency vibration accelerates callus formation, mineralization, and fracture healing in rats. J Orthop Res 27(4): 458-465.

47. Link TM Majumdar S (2003): Osteoporosis imaging. Radiol Clin North Am 41(4): 813-839. 
48. Lüllmann-Rauch R: Histologie. Verstehen - Lernen - Nachschlagen. 1. Auflage; Georg Thieme Verlag, Stuttgart 2003.

49. Lynch MA, Brodt MD, Silva MJ (2010): Skeletal effects of whole-body vibration in adult and aged mice. J Orthop Res 28(2): 241-247.

50. Melton LJ, 3rd, Thamer M, Ray NF, Chan JK, Chesnut CH, 3rd, Einhorn TA, Johnston CC, Raisz LG, Silverman SL, Siris ES (1997): Fractures attributable to osteoporosis: report from the National Osteoporosis Foundation. J Bone Miner Res 12(1): 16-23.

51. Meunier PJ, Roux C, Seeman E, Ortolani S, Badurski JE, Spector TD, Cannata J, Balogh A, Lemmel EM, Pors-Nielsen S, et al. (2004): The effects of strontium ranelate on the risk of vertebral fracture in women with postmenopausal osteoporosis. N Engl J Med 350(5): 459-468.

52. Miller SC, Wronski TJ (1993): Long-term osteopenic changes in cancellous bone structure in ovariectomized rats. Anat Rec 236(3): 433-441.

53. Mosekilde L, Danielsen CC, Knudsen UB (1993): The effect of aging and ovariectomy on the vertebral bone mass and biomechanical properties of mature rats. Bone 14(1): 1-6.

54. Muller R, Van Campenhout H, Van Damme B, Van Der Perre G, Dequeker J, Hildebrand T, Ruegsegger P (1998): Morphometric analysis of human bone biopsies: a quantitative structural comparison of histological sections and microcomputed tomography. Bone 23(1): 59-66.

55. Neer RM, Arnaud CD, Zanchetta JR, Prince R, Gaich GA, Reginster JY, Hodsman AB, Eriksen EF, Ish-Shalom S, Genant HK, et al. (2001): Effect of parathyroid hormone (1-34) on fractures and bone mineral density in postmenopausal women with osteoporosis. N Engl J Med 344(19): 1434-1441.

56. Omi N, Ezawa I (1995): The effect of ovariectomy on bone metabolism in rats. Bone 17(4 Suppl): 163S-168S.

57. Oxlund BS, Ortoft G, Andreassen TT, Oxlund H (2003): Low-intensity, highfrequency vibration appears to prevent the decrease in strength of the femur and tibia associated with ovariectomy of adult rats. Bone 32(1): 69-77.

58. Pacifici R (1998): Cytokines, estrogen, and postmenopausal osteoporosis--the second decade. Endocrinology 139(6): 2659-2661.

59. Pfeilschifter J: DVO-Leitlinie 2009 zur Prophylaxe, Diagnostik und Therapie der Osteoporose beim Erwachsenen. Dachverband Osteologie, Essen 2009. 
60. Pitsillides AA, Rawlinson SC, Suswillo RF, Bourrin S, Zaman G, Lanyon LE (1995): Mechanical strain-induced NO production by bone cells: a possible role in adaptive bone (re)modeling? FASEB J 9(15): 1614-1622.

61. Rahn DA (1976): The fluorochrome sequence labeling of the bone. Nova Acta Leopoldina 44: 249-255.

62. Reginster JY, Sarlet N, Lejeune E, Leonori L (2005): Strontium ranelate: a new treatment for postmenopausal osteoporosis with a dual mode of action. Curr Osteoporos Rep 3(1): 30-34.

63. Reginster JY, Felsenberg D, Boonen S, Diez-Perez A, Rizzoli R, Brandi ML, Spector TD, Brixen K, Goemaere S, Cormier C, et al. (2008): Effects of long-term strontium ranelate treatment on the risk of nonvertebral and vertebral fractures in postmenopausal osteoporosis: Results of a five-year, randomized, placebocontrolled trial. Arthritis Rheum 58(6): 1687-1695.

64. Riggs BL (2000): The mechanisms of estrogen regulation of bone resorption. J Clin Invest 106(10): 1203-1204.

65. Rittweger J, Beller G, Armbrecht G, Mulder E, Buehring B, Gast U, Dimeo F, Schubert H, de Haan A, Stegeman DF, et al. (2009): Prevention of bone loss during 56 days of strict bed rest by side-alternating resistive vibration exercise. Bone 46(1): 137-147.

66. Rodin A, Murby B, Smith MA, Caleffi M, Fentiman I, Chapman MG, Fogelman I (1990): Premenopausal bone loss in the lumbar spine and neck of femur: a study of 225 Caucasian women. Bone 11(1): 1-5.

67. Rossouw JE, Anderson GL, Prentice RL, LaCroix AZ, Kooperberg C, Stefanick ML, Jackson RD, Beresford SA, Howard BV, Johnson KC, et al. (2002): Risks and benefits of estrogen plus progestin in healthy postmenopausal women: principal results From the Women's Health Initiative randomized controlled trial. JAMA 288(3): 321-333.

68. Roux C, Seeman E, Eastell R, Adachi J, Jackson RD, Felsenberg D, Songcharoen S, Rizzoli R, Di Munno O, Horlait S, et al. (2004): Efficacy of risedronate on clinical vertebral fractures within six months. Curr Med Res Opin 20(4): 433-439.

69. Rubin C, Judex S, Qin YX (2006): Low-level mechanical signals and their potential as a non- pharmacological intervention for osteoporosis. Age Ageing 35 Suppl 2: ii32-ii36.

70. Rubin C, Turner AS, Mallinckrodt C, Jerome C, McLeod K, Bain S (2002a): 
Mechanical strain, induced noninvasively in the high-frequency domain, is anabolic to cancellous bone, but not cortical bone. Bone 30(3): 445-452.

71. Rubin C, Recker R, Cullen D, Ryaby J, McCabe J, McLeod K (2004): Prevention of postmenopausal bone loss by a low-magnitude, high-frequency mechanical stimuli: a clinical trial assessing compliance, efficacy, and safety. J Bone Miner Res 19(3): 343-351.

72. Rubin C, Turner AS, Muller R, Mittra E, McLeod K, Lin W, Qin YX (2002b): Quantity and quality of trabecular bone in the femur are enhanced by a strongly anabolic, noninvasive mechanical intervention. J Bone Miner Res 17(2): 349-357.

73. Rubinacci A, Marenzana M, Cavani F, Colasante F, Villa I, Willnecker J, Moro GL, Spreafico LP, Ferretti M, Guidobono F, et al. (2008): Ovariectomy sensitizes rat

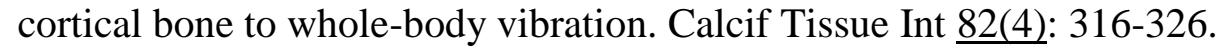

74. Ruyssen-Witrand A, Gossec L, Kolta S, Dougados M, Roux C (2007): Vertebral dimensions as risk factor of vertebral fracture in osteoporotic patients: a systematic literature review. Osteoporos Int 18(9): 1271-1278.

75. Sarkar S, Mitlak BH, Wong M, Stock JL, Black DM, Harper KD (2002): Relationships between bone mineral density and incident vertebral fracture risk with raloxifene therapy. J Bone Miner Res 17(1): 1-10.

76. Sehmisch S, Galal R, Kolios L, Tezval M, Dullin C, Zimmer S, Stuermer KM, Stuermer EK (2009a): Effects of low-magnitude, high-frequency mechanical stimulation in the rat osteopenia model. Osteoporos Int 20(12): 1999-2008.

77. Sehmisch S, Erren M, Rack T, Tezval M, Seidlova-Wuttke D, Richter J, Wuttke W, Stuermer KM Stuermer EK (2009b): Short-term effects of parathyroid hormone on rat lumbar vertebrae. Spine (Phila Pa 1976) 34(19): 2014-2021.

78. Sioka C, Fotopoulos A, Georgiou A, Xourgia X, Papadopoulos A, Kalef-Ezra JA (2009): Age at menarche, age at menopause and duration of fertility as risk factors for osteoporosis. Climacteric 13(1): 63-71.

79. Slatkovska L, Alibhai SM, Beyene J, Cheung AM (2010): Effect of whole-body vibration on BMD: a systematic review and meta-analysis. Osteoporos Int, epub ahead of print.

80. Smith EL, Gilligan C (1991): Physical activity effects on bone metabolism. Calcif Tissue Int 49 Suppl: S50-54.

81. Somjen D, Binderman I, Berger E, Harell A (1980): Bone remodelling induced by physical stress is prostaglandin E2 mediated. Biochim Biophys Acta 627(1): 91-100. 
82. Stuermer EK, Seidlova-Wuttke D, Sehmisch S, Rack T, Wille J, Frosch KH, Wuttke W, Stuermer KM (2006): Standardized bending and breaking test for the normal and osteoporotic metaphyseal tibias of the rat: effect of estradiol, testosterone, and raloxifene. J Bone Miner Res 21(1): 89-96.

83. Stuermer EK, Sehmisch S, Rack T, Wenda E, Seidlova-Wuttke D, Tezval M, Wuttke W, Frosch KH, Stuermer KM (2010): Estrogen and raloxifene improve metaphyseal fracture healing in the early phase of osteoporosis. A new fracturehealing model at the tibia in rat. Langenbecks Arch Surg 395(2): 163-172.

84. Tuna H, Birtane M, Ekuklu G, Cermik F, Tuna F, Kokino S (2008): Does quantitative tibial ultrasound predict low bone mineral density defined by dual energy X-ray absorptiometry? Yonsei Med J 49(3): 436-442.

85. Turner CH, Pavalko FM (1998): Mechanotransduction and functional response of the skeleton to physical stress: the mechanisms and mechanics of bone adaptation. $\mathbf{J}$ Orthop Sci 3(6): 346-355.

86. Turner CH, Warden SJ, Bellido T, Plotkin LI, Kumar N, Jasiuk I, Danzig J, Robling AG (2009): Mechanobiology of the skeleton. Sci Signal 2(68): pt3.

87. Verschueren SM, Roelants M, Delecluse C, Swinnen S, Vanderschueren D, Boonen S (2004): Effect of 6-month whole body vibration training on hip density, muscle strength, and postural control in postmenopausal women: a randomized controlled pilot study. J Bone Miner Res 19(3): 352-359.

88. Watts NB, Cooper C, Lindsay R, Eastell R, Manhart MD, Barton IP, van Staa TP, Adachi JD (2004): Relationship between changes in bone mineral density and vertebral fracture risk associated with risedronate: greater increases in bone mineral density do not relate to greater decreases in fracture risk. J Clin Densitom 7(3): 255261.

89. Wolff J: Das Gesetz der Transformation der Knochen. Hirschwald, Berlin 1852.

90. Xie L, Rubin C, Judex S (2008): Enhancement of the adolescent murine musculoskeletal system using low-level mechanical vibrations. J Appl Physiol 104(4): 1056-1062.

91. Xie L, Jacobson JM, Choi ES, Busa B, Donahue LR, Miller LM, Rubin CT, Judex S (2006): Low-level mechanical vibrations can influence bone resorption and bone formation in the growing skeleton. Bone 39(5): 1059-1066.

92. Yamaura M, Nakamura T, Tsurukami H, Hijioka A, Narusawa K, Ohnishi H, Ohta T, Hosoda K (1996): Local bone turnover in the metaphysis of the proximal tibia 
and the lumbar vertebra during the early periods after ovariectomy in rats. Calcif Tissue Int 58(1): 52-59. 


\section{Danksagung}

Zunächst gilt mein Dank Prof. Dr. med. Klaus Michael Stürmer als Abteilungsleiter für die Ermöglichung des Projekts sowie die sehr schöne und lehrreiche Zeit in seiner Abteilung.

Weiter möchte ich mich bei meiner Doktormutter PD Dr. med. Ewa Stürmer bedanken. Zum einen für die Motivation und den Zuspruch, während des PJ eine experimentelle Doktorarbeit zu beginnen, und für die freundliche Aufnahme in die Arbeitsgruppe, zum anderen für die schnelle Korrektur und das Vorantreiben meiner Arbeit.

Mein ganz besonderer Dank gilt Dr. med. Stephan Sehmisch für die herausragende Betreuung. Durch seine ständige Präsenz und Erreichbarkeit, seine nicht enden wollende Geduld sowie seine klaren und strukturierten Erläuterungen hat er wesentlich zum erfolgreichen Abschluss der Arbeit beigetragen.

Ich danke weiterhin den Mitarbeiterinnen und Mitarbeitern des Labors, Dr. rer. nat. Marina Komrakova, Ramona Castro-Machguth, Fritz Kauer und ganz besonders Annette Witt für ihre Hilfe, ihre Zuverlässigkeit und ihr immer offenes Ohr bei Problemen jeglicher Art.

Außerdem danke ich Dr. med. Thomas Rack für die schnelle Programmierung der Software zum Auswerten der Mikroradiographien und Dr. med. Ulrich Schmelz für die großzügige Bereitstellung seiner Räumlichkeiten und die Unterstützung bei den Laboranalysen.

Allen genannten Personen ist es zu verdanken, dass es mir möglich war, die Arbeit noch vor Ende des Studiums abzuschließen. Durch Ihre Unterstützung habe ich meine Begeisterung für wissenschaftliches Arbeiten entdeckt und sehr viel gelernt. Danke! 